Data de Depósito: 22/04/2008

Assinatura:

\title{
Avaliação de políticas de escalonamento para execução de simulações distribuídas
}

\author{
Osvaldo Adilson de Carvalho Junior \\ Orientadora: Profa. Dra. Regina Helena Carlucci Santana \\ Dissertação apresentada ao Instituto de Ciências \\ Matemáticas e de Computação - ICMC-USP, como parte \\ dos requisitos para obtenção do título de Mestre em \\ Ciências - Ciências de Computação e Matemática \\ Computacional.
}

USP - São Carlos

Abril de 2008 
Avaliação de políticas de escalonamento para execução de simulações distribuídas

Osvaldo Adilson de Carvalho Junior 


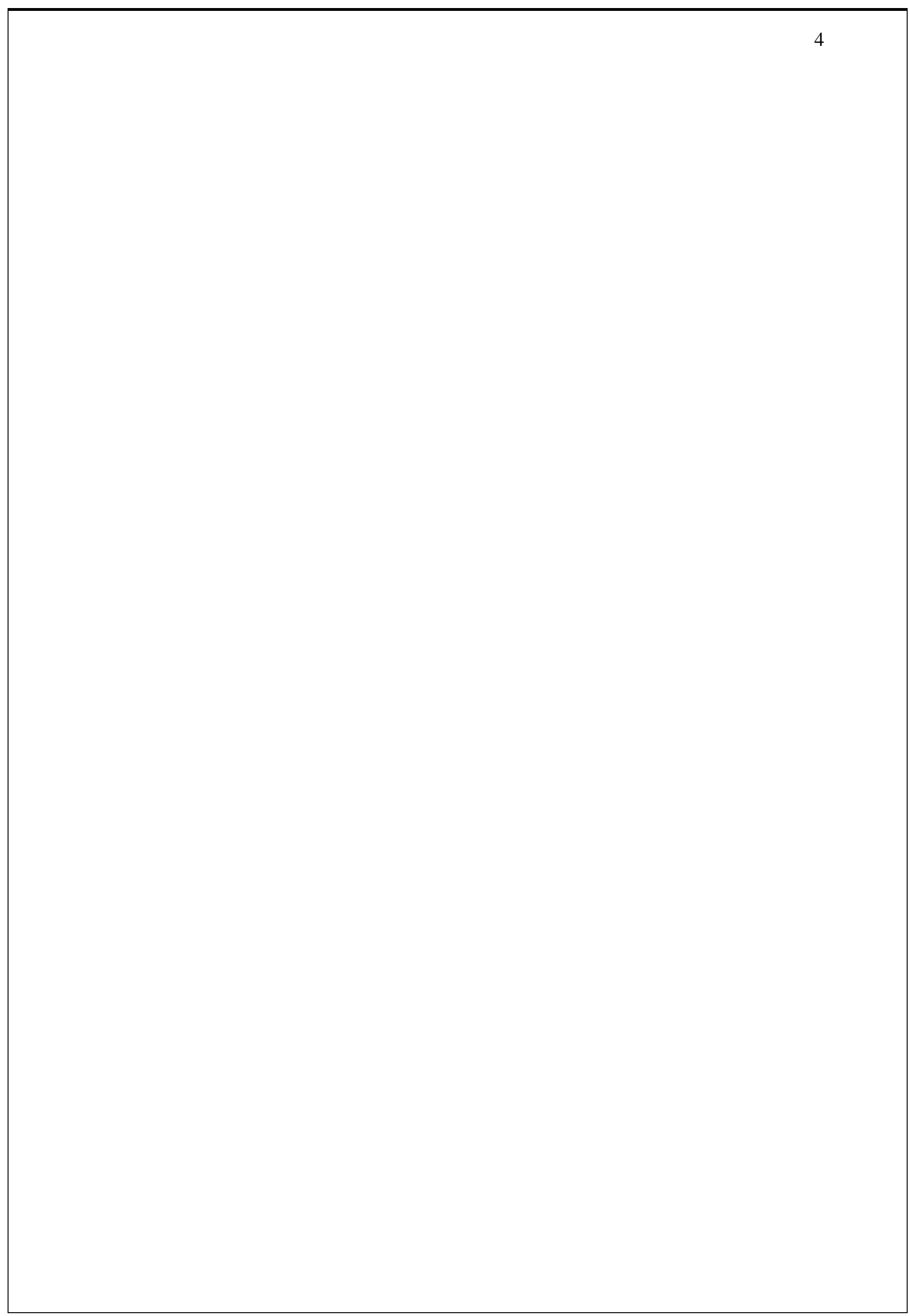




\section{Agradecimentos}

Primeiramente, à vida, por todas as boas oportunidades que eu tive, tenho e, certamente, terei.

À minha amada esposa Karin, pelo carinho e amor a mim dedicados, por me apoiar em todas as horas difíceis e agüentar meus dias de mau humor, por eu estar atolado de coisas para fazer, e ainda, minhas "crises" de perfeccionismo. Amo muito vocês.

Aos meus pais Oswaldo e Zezé, pelo apoio, ainda que distantes, sempre me ajudaram em tudo que precisei. Amo vocês.

À minha querida irmãzinha Damares, pelo seu carinho incondicional.

Aos meus tios Rui e Dirce, pois sem eles, seria tudo mais difícil, agradeço de coração por todas as palavras de ajuda e carinho.

Aos meus sogros Francisco e Neide pela amizade e apoio sempre dado.

À minha família, por sempre acreditar em mim e pela força que obtive a cada abraço e palavra de carinho.

À minha orientadora Professora Regina Santana, por toda sua dedicação e ajuda, sem seu apoio eu não conseguiria, obrigado por me agüentar todo este tempo em que mandei milhares de e-mails com textos perguntando: "Professora será se dá tempo?".

Ao meu "segundo orientador" professor Marcos Santana, pela ajuda e atenção. Juro, eu tentei, de todas as formas ser um bom "Neto" para ambos.

A todos os professores do LaSDPC (Laboratório de Sistemas Distribuídos e Programação Paralela), em especial Paulo, Sarita e Mônaco, por estarem sempre dispostos a ajudar e pela amizade construída no decorrer desses anos.

Aos meus amigos do LaSDPC pela ajuda e companheirismo, a união do nosso grupo é um exemplo a ser seguido.

Às atenciosas Ana Paula, Laura e Beth da SPG, por estarem sempre dispostas a ajudar. A simpatia é característica de todas.

A todos os funcionários do ICMC (Instituto de Ciências Matemáticas e Computação), fundamentais, cada um na sua competência, para o bom funcionamento da instituição.

Ao ICMC e a USP, pela estrutura oferecida às minhas pesquisas.

Ao CNPq, pelo apoio financeiro.

E finalmente à Pitty, nossa cachorrinha de $2 \mathrm{~kg}$, pela companhia e carinho dados todos os dias, inclusive, estando ao meu lado todo o tempo em que escrevi esta dissertação. 


\section{Resumo}

Um melhor escalonamento em simulação distribuída é fundamental para uma execução mais rápida e eficiente. O projeto desenvolvido tem como objetivo a avaliação de desempenho de políticas de escalonamento convencionais e específicas para Simulação Distribuída (SD), apresentando uma comparação do desempenho destas duas abordagens. Análises das pesquisas feitas na área mostram que não existe avaliação semelhante. Assim, este trabalho tem a importante contribuição de demonstrar as vantagens e desvantagens do uso de políticas tradicionais em relação às específicas em SD. Para execução das simulações foi utilizada a ferramenta Warped, que está descrita nesta dissertação. Foram desenvolvidas e implementadas novas técnicas de escalonamento que utilizam os resultados da simulação em execução, assim executam um melhor balanceamento de carga. Para o desenvolvimento deste projeto foi necessária uma revisão bibliográfica envolvendo conceitos de simulação distribuída com seus respectivos protocolos de sincronização, escalonamento de processos específicos para programas de SD e políticas tradicionais. Com este estudo soma-se como contribuição deste trabalho uma nova classificação das políticas específicas para SD que utilizam protocolo otimista. 


\section{Abstract}

A bestter scheduling in distributed simulation is fundamental to a fast and efficient execution. The developed project has as objective the evaluation of performance of conventional and specific politics of scheduling for Distributed Simulation (DS), presenting a comparison of the performance of these two boardings. Analyses of the research done in the area show that similar evaluation does not exists. Thus, this work has the important contribution to demonstrate to the advantages and disadvantages of the use of traditional politics in relation to the specific ones in DS. For execution of the simulations the Warped tool was used, that is described in this work. They had been developed and implemented new techniques of scheduling that use the results of the simulation in execution, thus they execute one better load balancing. For the development of this project a bibliographical revision was necessary involving concepts of simulation distributed with its respective protocols of synchronization, traditional scheduling of specific processes for DS programs and politics. With this study a new classification of the specific politics for DS is added as contribution of this work that use optimistical protocol. 


\section{Sumário}

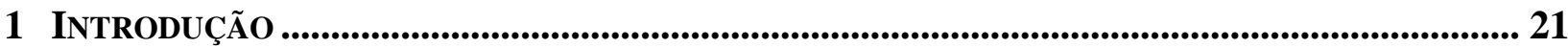

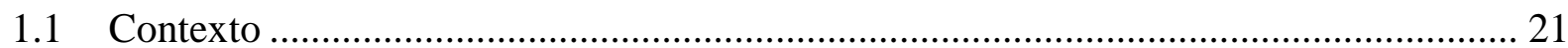

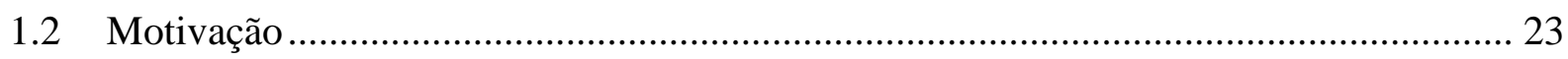

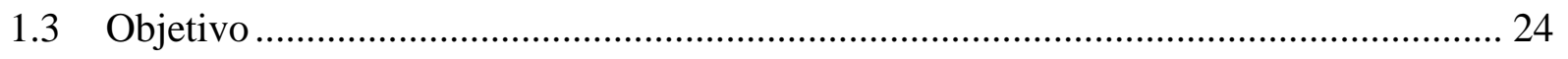

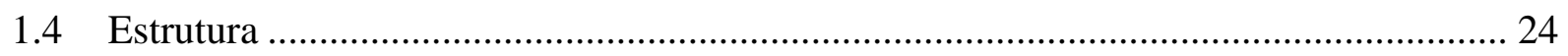

2 SiMULAÇÃo DiSTRIBUÍDA........................................................................................................... 27

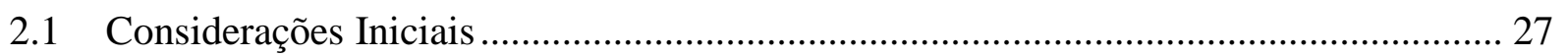

2.2 Limitações da Simulação Seqüencial ......................................................................... 28

2.3 Conceitos em simulação ...................................................................................... 28

2.4 Questões Relevantes em Simulação ………………………………………………...... 32

2.5 Protocolos de Sincronização para Simulação Distribuída................................................ 33

2.5.1 Protocolo de Sincronização Conservativo CMB ………………………………... 34

2.5.2 Protocolo de Sincronização Otimista Time Warp................................................... 35

2.6 Ferramentas para Simulação Distribuída ……………………………………………….... 39

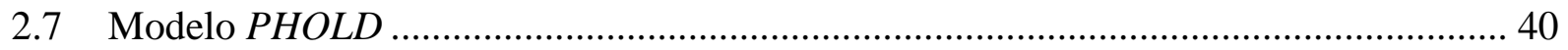

2.8 Considerações Finais ............................................................................................. 43

3 ESCALONAMENTo EM SimulaÇão DistribuíDA ....................................................................... 45

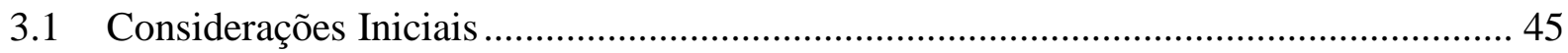

3.2 Classificação de Políticas Específicas para Protocolos Otimistas..................................... 46

3.2.1 Balanceamento em Tempo de Execução ............................................................ 47

3.2.2 Balanceamento em Tempo de Mapeamento …………………………………...... 50

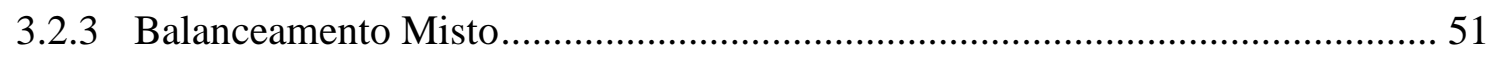

3.3 Comparação entre as Formas de Escalonamento Específicas ………………………….. 55

3.3.1 Dificuldades de Implementação..................................................................... 56

3.3.2 Sobrecarga Gerada pelo Algoritmo em Tempo de Execução e/ou Tempo de Mapeamento 57

3.3.3 Influência do Usuário da Simulação .................................................................. 58

3.3.4 Métrica(s) em que as Políticas se Baseiam .......................................................... 58 
3.3.5 Políticas que Consideram Carga Externa e/ou usam Migração 59

3.3.6 Classificação do Tipo de Balanceamento 60

3.4 Considerações Finais

\section{Avaliação de Desempenho do Uso de Políticas de Escalonamento}

TRADICIONAIS 63

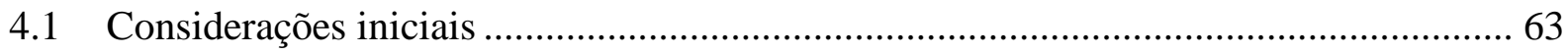

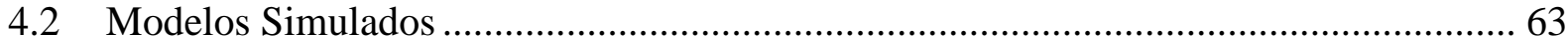

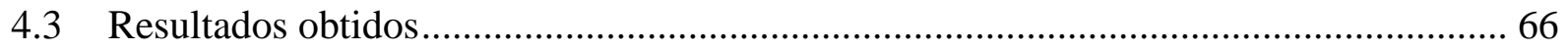

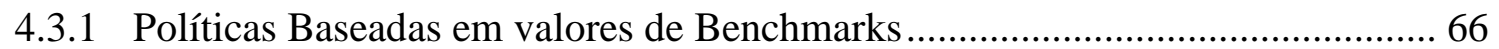

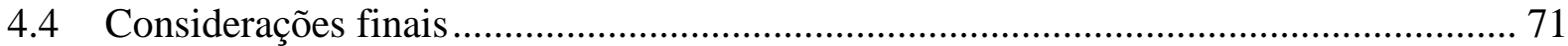

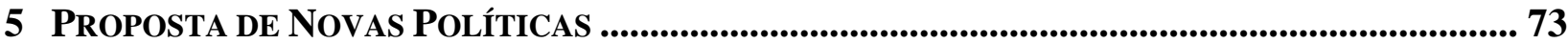

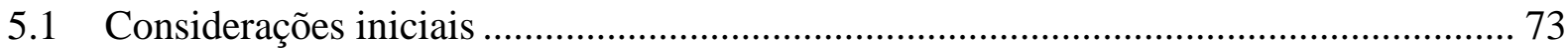

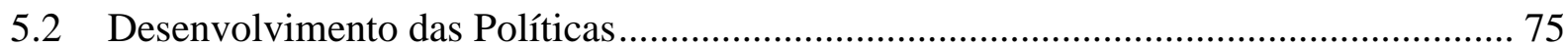

5.2.1 Metodologia para Avaliação das Políticas Propostas ........................................ 76

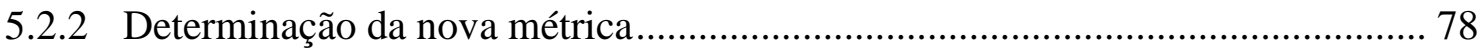

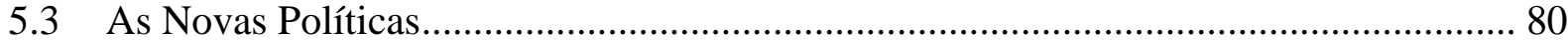

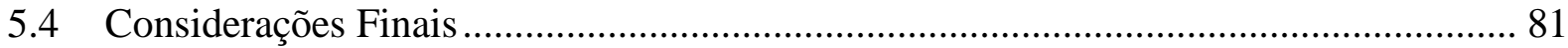

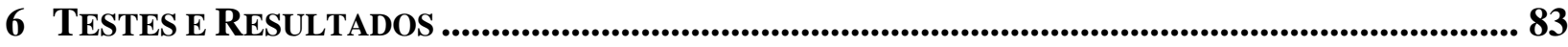

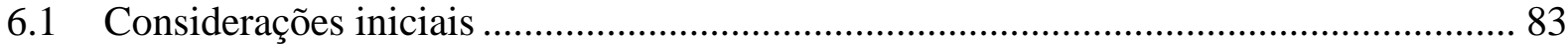

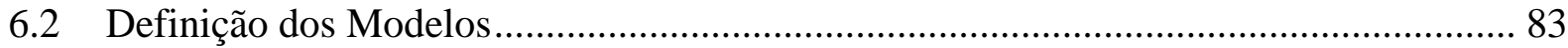

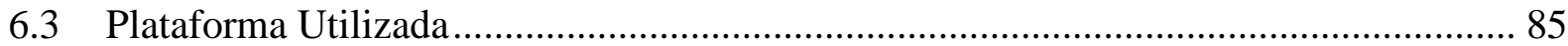

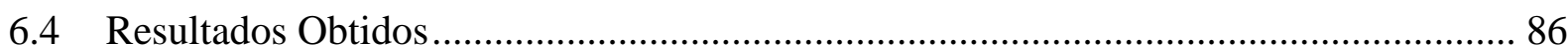

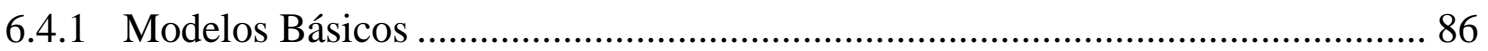

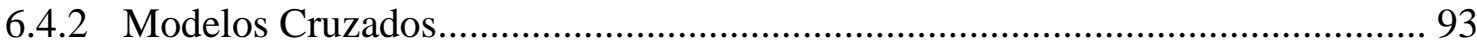

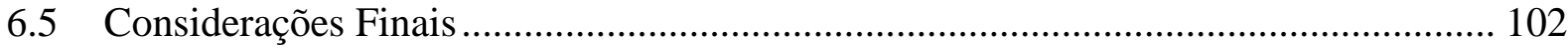

7 CONCLUSÃO

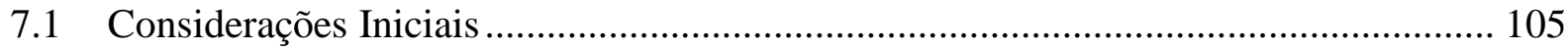

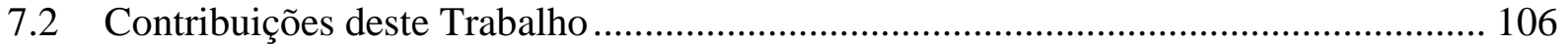

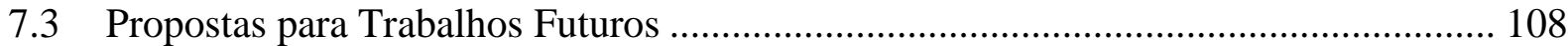




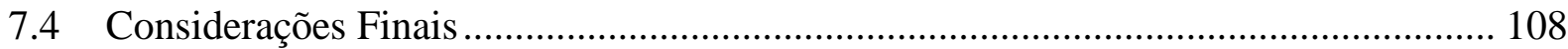

Referências Bibliográficas ............................................................................................... 109 


\section{Lista de Tabelas}

Tabela 2.7.1 Tabela de escolha do receptor da próxima mensagem.

Tabela 3.1 Comparação entre as formas de escalonamento específicas

Tabela 4.1 Modelos do Grupo Rede (retirada de Voorsluys, 2006)

Tabela 4.2 Modelos do Grupo Memória (retirada de Voorsluys, 2006)

Tabela 4.2 Modelos do Grupo CPU (retirada de Voorsluys, 2006)

Tabela 6.1 Modelos utilizados na execução das simulações.

Tabela 6.2 Esquema operacional dos experimentos (fatorial completo).

Tabela 6.3 Especificação dos computadores do cluster utilizado.

Tabela 6.4 Notas dos benchmarks dadas aos nós do cluster utilizado. 


\section{Lista de Figuras}

Figura 2.2.1 Relação entre Evento, Processo e Atividade (retirado de Voorsluys, 2006).......31

Figura 2.5.1 Representação da chegada de uma mensagem com timestamp menor que o do

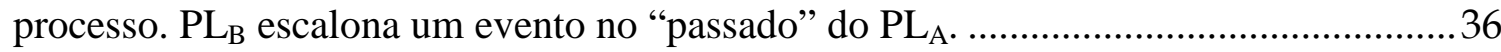

Figuras 2.5.2 Etapas envolvidas quando uma mensagem atrasada é recebida........................37

Figura 2.7.1 Organização dos objetos. ( Voorsluys, 2006) .................................................... 41

Figura 3.1 Migração de processos pela política de utilização efetiva. .................................... 48

Figura 3.2 Balanceamento feito através de uma heurística de mapeamento...........................51

Figura 3.3 Balanceamento feito pelo algoritmo de Carga BGE............................................54

Figura 3.4 Balanceamento feito pelo algoritmo de Carga BGE.............................................55

Figura 4.2 Comparativo do tempo total de execução dos modelos do grupo rede...................67

Figura 4.3 Comparativo da quantidade de rollbacks durante a execução dos modelos do grupo

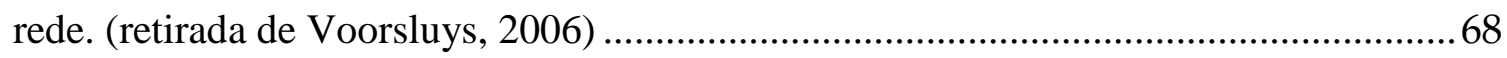

Figura 4.4 Comparativo do tempo total da execução dos modelos do grupo memória. ..........69

Figura 4.5 Comparativo da quantidade de rollbacks ocorridas na execução dos modelos do grupo memória. (retirada de Voorsluys, 2006) ........................................................... 70

Figura 4.6 Comparativo do tempo total de execução do grupo CPU......................................70

Figura 4.7 Quantidade de rollbacks ocorridas no grupo CPU. (retirada de Voorsluys, 2006).71

Figura 5.1 Arquivo de respostas do simulador Warped. .................................................... 78

Figura 6.1 Quantidade de rollbacks ocorridos por nó no modelo CPU-Bound .......................87

Figura 6.2 Tempos de execução em segundos por nó no modelo $C P U$-Bound ........................ 88

Figura 6.3 Quantidade de rollbacks ocorridos por nó no modelo Memory-Bound ...................89

Figura 6.4 Tempos de execução em segundos por nó no modelo Memory-Bound..................89

Figura 6.5 Quantidade de rollbacks ocorridos por nó no modelo Network-Bound ...................90

Figura 6.6 Tempos de execução em segundos por nó no modelo Network-Bound...................91

Figura 6.7 Quantidade de rollbacks ocorridos por nó no modelo CPU x Rede .......................92

Figura 6.8 Tempos de execução em segundos por nó no modelo CPU x Rede .......................92

Figura 6.9 Quantidade de rollbacks ocorridos por nó no modelo CPU-Bound com notas de benchmark de rede. 
Figura 6.10 Tempos de execução em segundos por nó no modelo $C P U$-Bound com notas de benchmark de rede.

Figura 6.11 Quantidade de rollbacks ocorridos por nó no modelo Memory-Bound com notas de benchmark de CPU 95

Figura 6.12 Tempos de execução em segundos por nó no modelo Memory-Bound com notas de benchmark de CPU

Figura 6.13 Quantidade de rollbacks ocorridos por nó no modelo Network-Bound com notas de benchmark de memória.

Figura 6.14 Tempos de execução em segundos por nó no modelo Network-Bound com notas de benchmark de memória.

Figura 6.15 Quantidade de rollbacks ocorridos por nó no modelo CPU-Bound com notas de benchmark de memória 98

Figura 6.16 Tempos de execução em segundos por nó no modelo $C P U$-Bound com notas de benchmark de memória

Figura 6.17 Quantidade de rollbacks ocorridos por nó no modelo memory-Bound com notas de benchmark de rede

Figura 6.18 Tempos de execução em segundos por nó no modelo memory-Bound com notas de benchmark de rede 100

Figura 6.19 Quantidade de rollbacks ocorridos por nó no modelo Network-Bound com notas de benchmark de CPU

Figura 6.20 Tempos de execução em segundos por nó no modelo Network-Bound com notas de benchmark de CPU 


\section{Lista de Abreviaturas}

\begin{tabular}{|c|c|}
\hline AMIGO & DynAMical Flexlble SchedulinG EnvirOnment \\
\hline BGE & Backgroud Execution \\
\hline CAT & Cluster Advance Time \\
\hline CMB & Chandy-Misra-Bryant \\
\hline CPU & Central Processing Unit \\
\hline GVT & Global Virtual Time \\
\hline LTF & Lowest Timestamp First \\
\hline LVT & Local Virtual Time \\
\hline MPI & Message Passing Interface \\
\hline MRIP & Multiple Replications In Parallel \\
\hline NOW & Network of Workstations \\
\hline PAT & Processor Advance Time \\
\hline$P L$ & Processo Lógico \\
\hline PVM & Parallel Virtual Machine \\
\hline SAMs & Stability Assurance Mechanisms \\
\hline $\mathrm{RC}$ & Rollbacks Causados \\
\hline SG & Strong Group \\
\hline SG1 & Política Proposta 1 \\
\hline SG2 & Política Proposta 2 \\
\hline SRIP & Single Replications In Parallel \\
\hline $\mathrm{TCP} / \mathrm{IP}$ & Transfer Control Protocol / Internet Protocol \\
\hline TR & Total de Rollbacks \\
\hline VT & Virtual Time \\
\hline
\end{tabular}




\section{INTRODUÇão}

\subsection{Contexto}

Avaliação de desempenho é essencial devido à crescente busca por melhores recursos e, conseqüentemente, ao aumento da complexidade dos sistemas computacionais. A avaliação de um sistema está presente em todas as fases de seu desenvolvimento e de sua utilização. Primeiramente, em um projeto, faz-se necessário o desenvolvimento de modelos, visando obter uma validação inicial. Após essa fase, pode-se optar por duas vertentes visando à validação final do projeto, com a implementação de um protótipo ou do próprio sistema real ou seguindo-se na abordagem de avaliação através de modelos. No caso em que se pretende obter medidas de um sistema existente ou de um protótipo, pode-se utilizar monitores, ou se o objetivo é compará-lo com outros sistemas o uso de benchmark é bastante adequado.

A segunda abordagem é quando não se quer ou não se pode perturbar o sistema ou quando o acesso a certas características torna-se difícil, e assim avaliar através de medições fica inviável. Nesses casos, as técnicas de modelagem, mesmo para sistemas que já estão em fase final de teste ou já existem são as mais apropriadas. A partir do modelo do sistema a ser avaliado, pode-se optar por duas formas para solução do modelo obtendo resultados que permitam conclusões: solução analítica ou simulação.

A solução analítica, na maioria dos casos, implica na necessidade de se fazer algumas simplificações no modelo, para viabilizar a sua solução. Sendo assim, trata-se de uma técnica importante para avaliar as pequenas partes de um sistema ou casos em que não é necessário representar muitos detalhes desse. Não é a técnica mais adequada para a avaliação de sistemas complexos, com uma grande quantidade de características a serem analisadas. Por outro lado, solução analítica é reconhecida como um método que expressa resultados exatos, isto é, não 
estocásticos, o que facilita o desenvolvimento da avaliação. A simulação oferece uma solução a um custo relativamente baixo e com boa flexibilidade, por este motivo vem sendo muito utilizada. Entretanto, uma desvantagem dessa abordagem é o tempo elevado para obtenção de resultados confiáveis, principalmente, quando modelos complexos são considerados.

$\mathrm{Na}$ tentativa de minimizar esse problema, existem técnicas que vêm apresentando grandes avanços, como o uso de computação paralela para execução de simulações, obtendose as simulações distribuídas. A computação paralela tem como principal objetivo aumentar o desempenho e reduzir o tempo para se obter um resultado (Almasi, 1994). O desenvolvimento de um programa paralelo eficiente e a utilização de uma forma de escalonamento adequado para os processos executados paralelamente são os principais fatores para se obter sucesso.

A simulação distribuída (SD) utiliza os conceitos de computação paralela visando à redução do tempo de simulação. No caso da simulação distribuída, são identificados um conjunto de Processos Lógicos (PLs) que devem ser paralelizados.

A execução desses PLs em paralelo, deve seguir um protocolo que garanta que os eventos da simulação serão executados na mesma ordem que seguiriam no sistema real. Esses protocolos podem seguir duas abordagens básicas: a conservativa ou a otimista. A conservativa caracteriza-se por verificar previamente e garantir que nenhum evento seja executado cronologicamente fora da ordem. A otimista, que possui como principal representante o protocolo Time Warp (Fujimoto, 1990), funciona sem um controle prévio da ordem cronológica. Mas em conseqüência, ao ser detectada a ocorrência de um evento fora de ordem, o processo lógico (LP) será obrigado a retornar a um estado consistente anterior, caracterizando um rollback, e em seguida, segue-se a execução novamente, com o tempo de ocorrência na ordem correta.

Os protocolos que seguem a abordagem conservativa têm sido os mais utilizados por apresentarem um melhor desempenho. Nos protocolos conservativos, a garantia de que nunca um evento será executado fora de ordem, torna a simulação quase seqüencial e, conseqüentemente, lenta. Por outro lado, na abordagem otimista, os PLs são executados sem restrições de ordenação, tornando possível a obtenção de melhores desempenhos.

Uma característica a ser considerada na execução de uma simulação distribuída e que causa grande impacto no tempo de simulação, refere-se à política a ser utilizada para distribuir os processos lógicos nos processadores disponíveis (escalonamento). A avaliação das 
políticas de escalonamento de processos trata-se de um assunto amplamente discutido para diferentes tipos de sistemas computacionais e a definição da política mais adequada deve considerar algumas características, tais como, tipo de sistema sendo considerado, tipo de aplicação e objetivo a ser atingido com o escalonamento.

O escalonamento de processos em todas as vertentes das pesquisas em sistemas computacionais é um dos fatores decisivos para melhorar o desempenho da execução de programas paralelos. De forma análoga, o uso de um protocolo para escalonar as PLs de uma Simulação Distribuída pode ter impacto significativo no desempenho da simulação (Song et al., 2002).

\subsection{Motivação}

A simulação distribuída é uma ferramenta de avaliação de desempenho muito utilizada em todas as áreas de conhecimento e industriais, e também, muito estudada na literatura com pesquisas visando seu aperfeiçoamento. Como discutido na seção anterior, pode-se observar a relevância do uso de simulações distribuídas visando à avaliação de desempenho de alguns sistemas reais e a importância de se adotar formas de escalonamento de processos adequadas por se tratar de um fator decisivo no desempenho desses sistemas.

O escalonamento de processos em simulação distribuída pode seguir duas abordagens básicas. Na primeira abordagem, é conclusivo que uma simulação distribuída nada mais é que uma aplicação distribuída. Portanto, pode-se utilizar as políticas de escalonamento utilizadas em sistemas de propósito geral. Voorsluys, em (Voorsluys, 2006) estudou a possibilidade de aplicar os algoritmos de escalonamento não específicos para SD.

Em uma segunda abordagem, a simulação distribuída (SD) trata do estudo do balanceamento de cargas através de algoritmos específicos, como demonstrados em trabalhos abordando utilização efetiva conforme proposto por Reiher \& Jefferson (1990) e Som \& Sargent (2000), ou apresentando uma heurística de mapeamento como em (Som \& Sargent, 1993), também apresentados na literatura algoritmos probabilísticos (Som \& Sargent, 1998), algoritmos que analisam o controle de fluxo baseando-se na CPU (Sachdev et al, 2004) e algoritmos mais completos como gerenciamento de carga BGE (Carother \& Fujimoto, 2000). 
O foco deste trabalho está em fazer uma avaliação de desempenho entre as duas políticas específicas para escalonamento de processos em simulação distribuída propostas e as políticas tradicionalmente utilizadas em sistemas distribuídos em geral.

\subsection{Objetivo}

O objetivo deste trabalho é o desenvolvimento de políticas específicas para escalonamento de processos em simulação distribuída, e ainda, uma contribuição que objetiva mostrar até que ponto é interessante utilizar políticas de escalonamento tradicionais para sistemas distribuídos em geral em uma simulação distribuída, e em que situações as políticas específicas são realmente mais viáveis e necessárias. Por meio dos resultados obtidos neste trabalho pode-se ter um melhor entendimento de quando é realmente necessário o uso de políticas específicas para simulação e em que casos os algoritmos de uso geral para sistemas distribuídos são suficientes. Para o desenvolvimento desta pesquisa foram executadas e concluídas as seguintes fases:

- Investigação e análise de algoritmos de escalonamento específico para simulação distribuída;

- Criação de uma nova métrica e de uma nova técnica de captação das informações da simulação, criando-se duas novas políticas de escalonamento específicas para simulação distribuída;

- Implementação das políticas;

- Avaliação do desempenho das políticas para diferentes modelos de simulação distribuída;

- Comparação das novas políticas específicas e das políticas utilizadas no trabalho de Voorsluys (Voorsluys, 2006).

\subsection{Estrutura}

Esta dissertação está organizada com o objetivo de fornecer a base necessária para a contextualização do trabalho e criar uma discussão de diversos aspectos envolvidos no seu desenvolvimento. O escalonamento de processos e a simulação distribuída serão discutidos como atividades principais do projeto e não somente como coadjuvantes fazendo parte de um 
sistema operacional distribuído. Assim, os textos dos capítulos seguintes estão organizados do seguinte modo:

O capítulo 2 apresenta a área de simulação distribuída, abordando conceitos principais e apresentando os protocolos de sincronização conservativos e otimistas. Nesse capítulo também é apresentada a ferramenta WARPED que será utilizada neste trabalho.

O capítulo 3 discorre sobre os estudos relativos a escalonamento de processos específicos para simulação distribuída. Neste trabalho é apresentada uma nova classificação dos algoritmos de balanceamento de carga específicos para SD, contribuindo assim, para um melhor entendimento das políticas encontradas na literatura.

O capítulo 4 aborda o trabalho de Voorsluys (Voorsluys, 2006) com políticas de escalonamento tradicionais para sistemas distribuídos em geral apresentando alguns dos resultados obtidos em seu trabalho. Objetivando-se nesse capítulo uma breve apresentação destes resultados possibilitando um melhor entendimento de seu trabalho já que as políticas utilizadas por Voorsluys (Voorsluys, 2006) serão utilizadas nos testes feitos com as novas políticas desenvolvidas, apresentadas no capitulo 5 deste trabalho, com o intuito de apresentar no capítulo 6, uma avaliação de desempenho entre as três técnicas de escalonamento existentes.

O capítulo 5 apresenta as novas duas políticas de escalonamento desenvolvidas neste trabalho, demonstrando a nova métrica criada e a nova técnica de captação e tratamento de informações referentes a simulação em execução.

O capítulo 6 expõe uma avaliação de desempenho entre as três técnicas de escalonamento para simulação distribuída, tampando uma lacuna na literatura já que as avaliações existentes apresentam comparações entre políticas específicas para simulação distribuída com a Política Round Robin (RR) ou Políticas para sistemas distribuídos em geral com a Política RR.

Finalizando, o capítulo 7 apresenta a conclusão desta dissertação acompanhada das contribuições deste trabalho e das propostas para trabalhos futuros. 


\section{Simulação Distribuída}

\subsection{Considerações Iniciais}

A simulação é uma técnica de avaliação de desempenho realizada utilizando-se um modelo que representa o sistema real em estudo e um programa computacional que implementa o modelo proposto. Ela está inserida na avaliação de desempenho como uma técnica muito utilizada quando o sistema a ser avaliado não está disponível e a aplicação da técnica analítica se mostra inadequada.

A simulação distribuída caracteriza-se como a execução de uma simulação em um sistema computacional paralelo ou distribuído. Investigações sobre este tópico vêm sendo feitas há muitos anos e são plenamente justificáveis em razão à vasta aplicação dessa técnica para grandes simulações militares, de engenharia, medicina, economia, física e ciência da computação. Para essas aplicações, é muitas vezes inviável a utilização da simulação seqüencial por necessitar de um tempo muito grande para obtenção de resultados confiáveis. A Simulação Paralela prevê a execução de programas de simulação em recursos baseados em arquiteturas paralelas. No entanto, tais recursos geralmente são de acesso mais restrito se comparados a recursos computacionais de propósito gerais interligados (multi-computadores). A simulação distribuída visa à distribuição da execução de um modelo em multicomputadores (Fujimoto, 2001).

Neste trabalho será utilizado o termo Simulação Distribuída para os casos onde a execução do programa de simulação é efetuada em vários processadores, independente da plataforma de hardware utilizada (paralela ou distribuída).

Este capítulo apresenta as principais características da Simulação e de Simulação Distribuída com seus principais protocolos de sincronização. 


\subsection{Limitações da Simulação Seqüiencial}

A simulação seqüencial pode ser empregada eficientemente em muitos casos, porém não fornece um bom desempenho quando grandes sistemas com numerosas entidades e eventos são considerados. Esse tipo de simulação pode ainda ser limitado pela capacidade de memória de um único processador, o que em grandes sistemas pode inviabilizá-la (Voorsluys, 2006).

Para minimizar os altos tempos de processamento de simulações que consideram sistemas complexos, simulações distribuídas podem ser utilizadas. O maior problema de conversão de uma simulação seqüencial para uma simulação distribuída está na natureza seqüencial da execução dos eventos da primeira. A abordagem clássica de simulação seqüencial utiliza a manipulação de uma estrutura de dados chamada lista de acontecimentos futuros, ordenada de acordo com os valores de uma variável que representa o relógio da simulação (clock) que controla a passagem do tempo (Morselli, 1995; Morselli, 2000).

Esquemas básicos onde mesmo não existindo uma estrutura seqüencial como a lista de acontecimentos futuros, mas que ainda assim promovem o avanço coerente do tempo da simulação têm sido propostos e discutidos intensamente (Morselli, 2000).

\subsection{Conceitos em simulação}

Técnicas de simulação permitem imitar o comportamento de sistemas reais, baseando-se na construção e exercício de modelos (Law, 1991). Simulações podem ser desenvolvidas visando dois enfoques básicos: criação de ambientes virtuais ou avaliação de desempenho de sistemas complexos. A criação de ambientes virtuais pode estar associada a sistemas complexos, entretanto não possuem o foco na avaliação de desempenho. Como este trabalho está inserido no segundo caso, os conceitos de simulação apresentados serão sempre tratados dentro deste contexto.

Modelo é uma descrição do sistema, sendo que para cada problema específico existe um modelo apropriado. Deste modo, pode-se ter várias descrições para o mesmo sistema, cada qual para a resolução de um problema particular. Para que esses modelos sejam resolvidos através de simulação, deve-se ter uma ferramenta, como por exemplo, uma linguagem de simulação. Assim, compilando-se um programa de simulação, a descrição do sistema é traduzida em uma forma aceitável por um sistema de computação. O computador é 
então utilizado para exercitar o modelo de modo a produzir saídas que podem ser analisadas (Soares, 1990).

Sistema pode ser descrito como uma coleção de itens, entre os quais se podem encontrar ou definir alguma relação, que são objetos de estudo ou interesse (Voorsluys, 2006).

O estado do sistema é a descrição do sistema em qualquer tempo, contendo variáveis que possuem as informações necessárias para tal. As mudanças nas variáveis de estado do sistema são fundamentais para classificação dos modelos.

O desenvolvimento de simulação visando avaliação de desempenho deve seguir os seguintes passos:

1. Estudo do sistema e definiç̧ão dos objetivos;

2. Construção do modelo;

3. Determinação dos dados de entrada e saída;

4. Tradução do modelo;

5. Verificação do programa de simulação;

6. Validação do programa (modelo) de simulação;

7. Experimentação;

8. Análise dos resultados;

9. Documentação.

O estudo do sistema e a definição dos objetivos são fundamentais para uma modelagem correta visando um modelo que seja o mais próximo do real possível. O principal passo em um processo de modelagem é a definição das características do sistema em um modelo (MacDougall, 1987). O modelo deve ser uma representação do sistema dentro de uma precisão estipulada através dos objetivos da simulação (Voorsluys, 2006).

A construção do modelo possui como uma de suas mais difíceis tarefas a abstração das características essenciais, e ainda, o estabelecimento de uma relação entre elas. Para tomar esta decisão, o estudo do sistema e a definição dos objetivos devem estar bem definidos.

A geração dos dados de entrada é a fase seguinte à construção do modelo. Estes dados podem ser hipotéticos ou baseados em algum teste preliminar. Estes dados podem ser alterados conforme o modelador valide esses fatores. As variações destes fatores podem derivar de um conhecimento anterior da modelação até uma intuição. Entretanto, 
independendo da escolha dos dados de entrada eles podem obedecer dois critérios: Os dados podem ser estocásticos (probabilísticos) ou determinísticos.

A tradução do modelo deve ser feita utilizando-se de algum dos vários softwares de simulação disponíveis. A variedade vai de extensões funcionais de linguagens de programação, a linguagens específicas de simulação.

A etapa de verificação tem como objetivo determinar se o modelo traduzido executa como esperado. A validação, que é prevista como a sexta etapa, visa determinar se existe uma representação correta do sistema no modelo implementado. A experimentação e a análise dos resultados são etapas que efetivamente ocorre o exercício do modelo e uma interpretação das saídas decorrentes da simulação. É nesta fase, que se pode atestar a eficácia de todo processo de simulação.

A elaboração de documentos que expõem o desenvolvimento da simulação é uma etapa que discorre ao longo de todo processo. A documentação deve conter as especificações das características relevantes de cada fase e os resultados obtidos.

Todo processo de avaliação de desempenho por simulação pode seguir duas abordagens: Discreta, cujas variáveis dependentes possuem variações que oscilam discretamente em pontos específicos do tempo simulado, conhecidos como tempo de evento; Contínua, que ao longo do tempo simulado suas variáveis dependentes variam continuamente. Este trabalho considera simulação discreta, que por sua vez pode seguir as abordagens: processo, atividade e evento que serão definidos nos próximos parágrafos.

Na modelagem para simulação discreta há algumas características que constituem seus principais componentes. (Voorsluys, 2006) Esses componentes são:

- Entidades: significam os objetos que podem ser individualmente identificados e processados. Cada entidade possui características próprias.

- Atividade: representa a menor unidade de trabalho no sistema, porém depende da visão particular que se tem do mesmo. Uma atividade pode ser a execução de um passo de uma instrução ou a execução de uma tarefa em uma simulação macroscópica de um sistema computacional.

- Eventos: representam a mudança de estado de alguma entidade do sistema. O término de uma atividade é um evento cuja ocorrência pode iniciar outras 
atividades subseqüentes. Tais eventos controlam a seqüência de atividades dentro de um processo.

- Estado: indica características do sistema em um determinado instante de tempo.

- Relógio da simulação: constitui a variável que contém o valor do tempo simulado.

- Filas de Eventos: são estruturas usadas para modelar a espera de clientes (ou transações) por um tratamento, cuja taxa de chegada é superior à da capacidade de atendimento.

- Processo: é uma seqüência ordenada de eventos, podendo englobar várias atividades.

Um evento ocorre em um ponto isolado no tempo, no qual decisões devem ser tomadas para iniciar ou encerrar uma atividade (Soares, 1992).

Um modelo de simulação discreta pode ser visto como uma coleção de processos interativos, cada processo composto por diversas atividades e com as interações controladas e coordenadas pela ocorrência de eventos (MacDougall, 1987). A relação entre os conceitos pode ser mais bem compreendida pela figura 2.2.1.

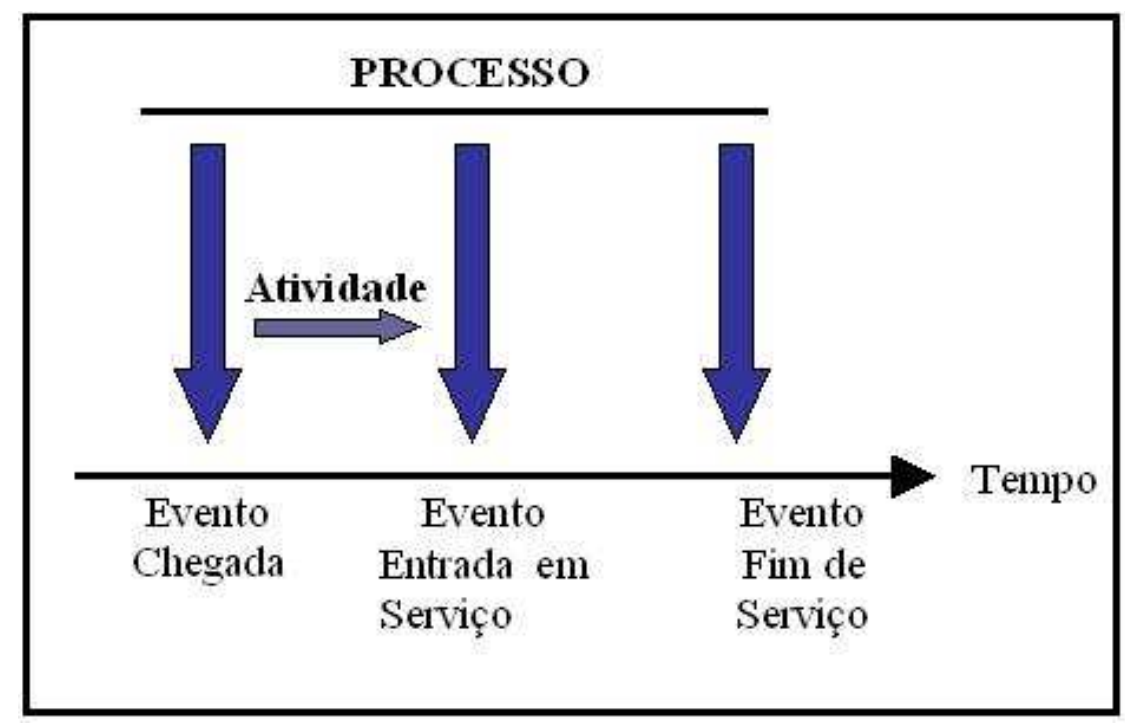

Figura 2.2.1 Relação entre Evento, Processo e Atividade (retirado de Voorsluys, 2006). 
Em simulação discreta, atividades, processos e eventos são construções utilizadas para descrever o seu comportamento. A elaboração de um modelo para simulação discreta pode ser realizada de três formas:

- Simulação orientada a eventos: a simulação do sistema é conduzida pela execução da lógica associada a cada evento, em uma seqüência ordenada no tempo;

- Simulação orientada a atividades: conforme o tempo simulado avança, as condições para o início ou fim de uma atividade são verificadas. A cada avanço no tempo, todo o conjunto de atividades é examinado para garantir que cada atividade seja considerada;

- Simulação orientada a processos: nesta abordagem o processo é utilizado para definir a estrutura e a atividade de um componente do sistema sendo modelado, existindo então uma analogia entre o sistema real e o modelo.

\subsection{Questões Relevantes em Simulação}

A competição na indústria dos computadores conduziu a descobertas e avanços tecnológicos que estão permitindo melhoras contínuas na área. A cada dia as empresas anunciam que seus produtos estão com mais opções, memória, capacidade gráfica, e maior potência computacional.

Para a maioria das empresas, os benefícios de se utilizar a simulação vão além de simplesmente fornecer uma perspectiva do futuro. Entre as várias vantagens citadas por Banks (1998) estão:

- Escolher corretamente: a simulação permite que sejam testados aspectos de mudanças propostas ou adicionais, sem que seja necessária a aquisição de recursos, ou ainda corromper operações em andamento. Fornecer argumento para se fazer a escolha correta é essencial, uma vez que depois que decisões são tomadas, e o sistema é instalado, mudanças e correções podem ser muito caras;

- Explorar possibilidades: uma das vantagens do uso de simulação é que uma vez que se desenvolveu um modelo válido da simulação, pode-se explorar 
novas políticas, procedimentos operacionais, ou métodos sem a despesa ou a interferência causada por experimentos no sistema real;

- Diagnosticar problemas: a organização de um sistema é muito complexa, sendo quase que impossível considerar todas as interações que ocorrem em um dado momento. A simulação permite que se compreendam melhor as interações entre as variáveis que fazem tais sistemas complexos. Diagnosticar problemas e obter conhecimento na importância dessas variáveis aumenta a compreensão de seus efeitos, o que pode ter consequiências benéficas para o desempenho do sistema total;

- Compressão e expansão do tempo: a simulação permite controlar o tempo, que pode ser facilmente comprimido ou expandido, permitindo a visualização de períodos longos ou então estudar fenômenos com detalhes através da diminuição da velocidade do tempo.

\subsection{Protocolos de Sincronização para Simulação Distribuída}

Nesta seção são discutidos os principais protocolos de sincronização para simulação distribuída. $\mathrm{Na}$ literatura podem ser encontrados tradicionalmente dois tipos de comportamento de uma simulação distribuída: conservativa ou otimista. Em referência a esses dois comportamentos foram desenvolvidos dois protocolos específicos: Conservativos (Misra, 1986) e otimistas (Jefferson, 1985).

As técnicas conservativas somente executam eventos seguros, enquanto algoritmos otimistas executam qualquer evento disponível, mas podem ocorrer rollbacks para corrigir execução incorreta de eventos (Song et al., 2002).

Nas simulações com protocolo conservativo, um processo lógico só tratará um evento se puder garantir que não haverá erros de causalidade, ou seja, chegar um outro evento com timestamp menor do que a do evento a ser tratado.

Um protocolo conservativo não tolera erros de causalidade, ou melhor, evitam a possibilidade da ocorrência de erros de causa e efeito, assim, sua preocupação está na determinação do momento seguro para processar um evento. Esse protocolo garante que, 
entre todas as mensagens futuras, nenhuma possuirá uma marca de tempo menor que o valor do clock local do processo (LVT) (Morselli, 2000). Essa condição essencial de cronologia é fiel às definições originais propostas por Chandy (Chandy; Misra, 1979):"Se um PL envia uma seqüência de mensagens <...( $\left.\mathrm{t}_{\mathrm{i}}, \mathrm{m}_{\mathrm{i}}\right),\left(\mathrm{t}_{\mathrm{i}+1}, \mathrm{~m}_{\mathrm{i}+1}\right) \ldots>$ para outro PL, então $\mathrm{t}_{\mathrm{i}}<\mathrm{t}_{\mathrm{i}+1} \ldots$. Isso implica que se $\mathrm{PL}_{\mathrm{i}}$ recebe $(t, m)$ de $\mathrm{PL}_{\mathrm{j}}$, então ele conhece todas as mensagens que $\mathrm{PL}_{\mathrm{i}}$, recebe de $P L_{j}$ até, e inclusive, o tempo t, porque qualquer mensagem futura terá um componente $t$ maior."

Desta forma, em uma simulação distribuída conservativa, toda vez que uma mensagem chega a um determinado PL sua marca de tempo é comparada com o valor do clock do processo lógico. Se esta marca de tempo for maior que o valor do clock então a mensagem é escalonada para seu próximo evento normalmente (Morselli, 2000). O protocolo conservativo é detalhado na seção 2.5.1.

Um protocolo otimista trabalha de uma forma diferente do conservativo uma vez que não se preocupa em evitar erros de causalidades. Isto é, ao invés de controlar a execução dos eventos previamente, ele executa todo evento disponível e, se for o caso, trata os erros detectados por meio de Rollbacks. A seção 2.5.2 apresenta maiores detalhes desse protocolo.

\subsubsection{Protocolo de Sincronização Conservativo CMB}

O protocolo conservativo $\mathrm{CMB}$ possui esse nome graças as propostas de trabalho de Chandy, Misra e Bryant, que contribuíram de forma independente para o seu desenvolvimento deste protocolo (Bryant, 1977;Chandy \& Misra, 1979). Uma característica importante é que se um PL L $\alpha$ interage com um processo L $\beta$, mensagens de L $\alpha$ para L $\beta$ são sempre geradas com valores crescentes de tempo. Lembrando que o CMB força todos os PLs conhecerem as outras PLs com quem interagem.

Existem muitas variantes para o protocolo CMB. Na sua forma básica, cada processo recebe suas mensagens em portas (entradas) separadas, considerando-se uma porta para cada processo. Cada processo deverá processar aquela mensagem que possui o menor tempo de ocorrência entre todas as mensagens armazenadas em suas entradas. Quando um processo possuir uma ou mais entradas vazias, ele não poderá processar nenhum de seus eventos, pois 
não poderá prever a chegada de mensagens defasadas. Portanto, o processo ficará bloqueado até que esta situação seja resolvida (Morselli, 2000).

O protocolo $\mathrm{CMB}$ resolve o problema de deadlock, ocorrido especialmente em simulações onde o número de troca de mensagens é bastante alto comparado com o número de portas de entrada por processo, através da utilização do conceito de mensagens nulas (mensagens com função apenas de sincronização). Estas mensagens são utilizadas para atualizar os tempos nas filas de entradas dos processos (Morselli, 2000).

\subsubsection{Protocolo de Sincronização Otimista Time Warp}

O Time Warp é o protocolo de simulação distribuída com abordagem otimista mais difundido (Fujimoto, 2000) e tem como base o paradigma de Virtual Time (VT) proposto por Jefferson (Jefferson, 1985), contendo dois componentes: o mecanismo de controle local, e o mecanismo de controle global que serão discutidos ainda nesta seção.

Na seção anterior foi discutido o protocolo conservativo CMB que se caracteriza por exigir que um evento só seja processado se existir a garantia de que o tempo dele está consistente com o tempo da simulação. O Time Warp espera que nenhuma mensagem chegue a um processo lógico com seu tempo local defasado, deixando todos os eventos que estão disponíveis serem executados.

O tempo local do processo de uma simulação referido anteriormente é conhecido na literatura como LVT (Local Virtual Time), sendo através dele que o protocolo otimista consegue sincronizar o andamento geral da simulação. Quando um PL, aqui chamado $\mathbf{P} \mathbf{L}_{\mathbf{A}}$, recebe uma mensagem do PL, aqui conhecido como $\mathbf{P L}_{\mathbf{B}}$, com o tempo defasado, o estado atual de $\mathbf{P L}_{\mathbf{A}}$ é atrasado até seu último momento consistente antes da chegada dessa mensagem. Esse retorno a um estado anterior consistente é denominado rollback. Na figura 2.5.1 é apresentado um exemplo da situação descrita anteriormente. 


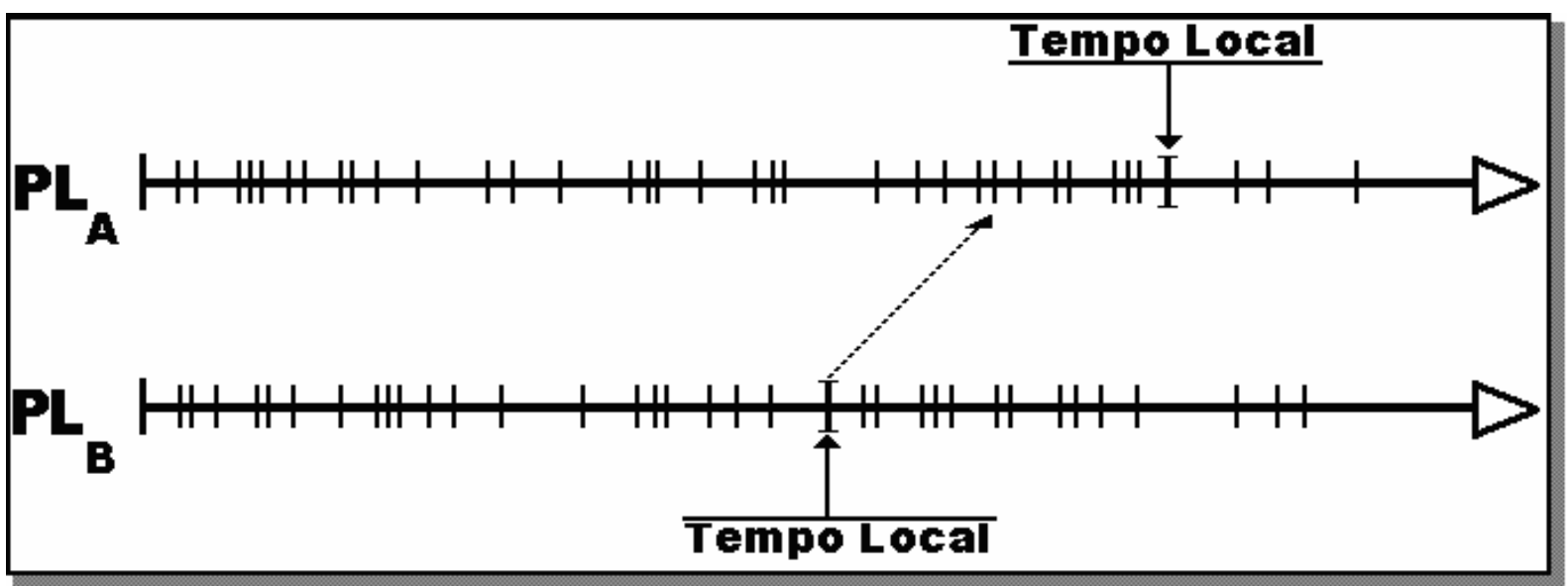

Figura 2.5.1 Representação da chegada de uma mensagem com timestamp menor que o do processo. $\mathrm{PL}_{\mathrm{B}}$ escalona um evento no "passado" do $\mathrm{PL}_{\mathrm{A}}$.

Um mecanismo de controle global é responsável pelo gerenciamento de memória e detecção do fim da simulação. Aqui, o conceito principal é o de Global Virtual Time (GVT), que é o valor correspondente ao menor valor calculado entre todos os LVTs da simulação, e todos os timestamps de mensagens enviadas, que estão em trânsito. Com o valor do $G V T$ calculado, todas as informações registradas com timestamp inferior ao seu podem ser descartadas (Hagenauer, 1999).

Existem diferentes formas para o cálculo do GVT. Na abordagem centralizada o cálculo é de responsabilidade de um processo lógico (software) ou hardware específico. Esta abordagem tem a vantagem de influenciar pouco o desempenho da simulação, porém o custo da aquisição do hardware e a complexidade de implementação são maiores. Outra abordagem é a distribuída, onde o trabalho de cálculo do GVT é distribuído por todos os processos lógicos. Esta forma pode ser aplicada de maneira local, onde cada processo lógico calcula o seu $G V T$ e depois compara com os demais, sendo o menor deles o valor final. A abordagem distribuída pode ainda ser aplicada de forma global onde um único valor é cálculo considerando-se todos os processos lógicos (Lobato et al., 2004).

Quando um evento é processado ele pode gerar novos eventos, que serão escalonados através do envio de mensagens. Se esse novo evento causar um rollback, fazendo com que eventos que já foram executados sejam retornados, o processo da simulação deve ser reiniciado a partir do último evento processado corretamente, e qualquer mensagem gerada no período em que aconteceu o retorno, deve ser cancelada com o envio de suas correspondentes 
antimensagens. Esta situação pode acarretar uma explosão em cascata de antimensagens. O mecanismo de controle local do Time Warp é o responsável pela execução dos eventos da simulação na ordem correta do timestamp desses eventos. O otimismo do protocolo consiste em permitir que os processos lógicos executem os eventos até a ocorrência de algum erro de causa e efeito, verificando quando o processo recebe uma mensagem com timestamp (Marca de tempo) menor que o $L V T$ do processo. Esta mensagem que causou o erro de causa e efeito é denominada de straggler (Fujimoto, 2000), como demonstrado na figura 2.5.2.

Os eventos processados devido ao excesso de otimismo deverão ser retornados ao último estado consistente, e providenciar as respectivas antimensagens para todas as suas mensagens geradas, veja na figura 2.5.2.

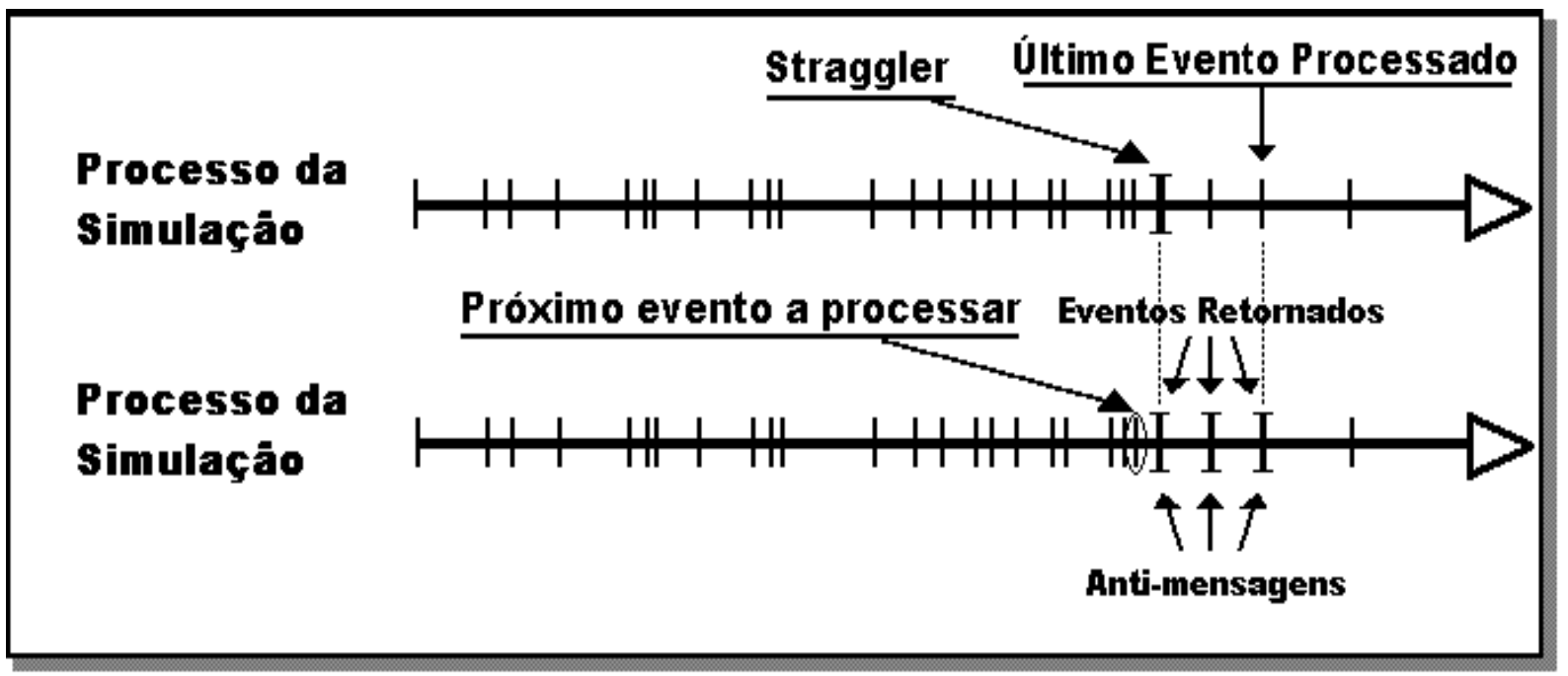

Figuras 2.5.2 Etapas envolvidas quando uma mensagem atrasada é recebida.

Efetuar o rollback é a maneira pela qual o Time Warp desfaz as computações errôneas que tenham sido efetuadas. Para poder restaurar estados, o Time Warp utiliza a lista de estado. Nesse processo de rollback, todas as mensagens enviadas, relativas aos estados que devem ser descartados, também necessitam ter seu envio anulado. Isso é feito através do envio de antimensagens (versões negativas das mensagens positivas enviadas por um processo). Se um processo lógico recebe uma antimensagem que corresponde a uma mensagem positiva que já executou, então este também deve retornar para desfazer o efeito da mensagem positiva a ser anulada. Este procedimento deve ser realizado recursivamente até que todas as computações erradas sejam canceladas (Voorsluys, 2006). 
O procedimento de salvamento de estados no Time Warp pode ser executado seguindo uma das seguintes abordagens (Lobato et al., 2004):

Copy state saving: todo o estado do processo é salvo após a execução de cada evento;

Sparse state saving: o estado do processo lógico é salvo periodicamente (fixo ou adaptativo), e quando for necessária a execução de um rollback é feita a restauração para o último estado consistente salvo antes do evento afetado.

Incremental state saving: somente as partes do processo lógico que foram modificadas são salvas, e o salvamento poderá ocorrer ou no momento em que uma variável foi modificada, ou em intervalos fixos de tempo, quando todas as variáveis que sofreram modificações são salvas. Outra questão nessa abordagem é com relação à transparência ou não do salvamento. Na primeira, a simulação se encarrega de verificar quais variáveis sofreram modificações, já na segunda o usuário é o responsável por apontar as variáveis que devem ser salvas.

Quando o rollback ocorre, a necessidade de cancelar algumas mensagens que foram enviadas para outros processos pode ser feita utilizando-se cancelamento Direto ou Indireto (Fujimoto, 1990; Lobato et al., 2004).

O cancelamento indireto de uma mensagem é feito através do envio explícito de antimensagens, e o cancelamento direto através da eliminação das mensagens enviadas diretamente nas filas dos outros processos lógicos (em caso de memória compartilhada) ou na fila de saída do próprio processo (no caso de memória distribuída) (Lobato et al., 2004). O cancelamento indireto pode ser:

- Agressivo: quando um processo efetua rollback para o tempo $T$, imediatamente são enviadas antimensagens de todas as mensagens anteriormente enviadas com timestamp maior que $T$;

- Preguiçoso: as antimensagens não são enviadas imediatamente após o rollback; espera-se a nova execução para verificar se esta não irá gerar as mesmas mensagens, sendo assim desnecessário o cancelamento dessas;

- Dinâmico: cada processo fica responsável por decidir como irá efetuar o cancelamento, agressivo ou preguiçoso. 
- Em Tentativa: um grupo de mensagens enviadas para um processo lógico pode ser cancelado por uma única antimensagem (utilizado no Tentative Time Warp).

Já o cancelamento direto pode ser agressivo ou em tentativa.

Um problema relacionado ao Time Warp é a necessidade de salvar periodicamente os estados dos processos lógicos, a sobrecarga gerada pode degradar o desempenho do mecanismo e tornar o gerenciamento de memória mais complexo. Dessa forma, a tarefa de salvar estados no Time Warp apresenta um alto custo e exige mecanismos que ajudem a minimizar a utilização do espaço de memória disponível. Diversos mecanismos para cancelamento de mensagens têm sido propostos, como por exemplo: Redução dos Estados Salvos (Das \& Fujimoto, 1993), Otimismo Limitado (Madiseti et al., 1992; Prakash \& Subramarian, 1991), Retorno de mensagens e Cancellback (Akyildiz et al., 1992).

\subsection{Ferramentas para Simulação Distribuída}

Um problema na elaboração de uma simulação é a transcrição do modelo definido pelo usuário em um programa de simulação. Para ajudar o usuário, tem-se, dentre outras ferramentas as linguagens e ambientes de simulação. Essas ferramentas oferecem ao usuário vários recursos que visam facilitar o desenvolvimento de uma simulação (Voorsluys, 2006).

O Warped é um núcleo Time Warp de domínio público, escrito em $C++$ e utiliza todas as funcionalidades de orientação a objetos disponíveis na linguagem. Foi desenvolvido pela University of Cincinnati (EUA), e está disponível para várias plataformas. Define uma interface padrão para o programador de aplicação, utilizando o ambiente de passagem de mensagens MPI (Message Passing Interface). O principal objetivo do Warped é disponibilizar para a comunidade de pesquisa um núcleo otimista que permita a análise do Time Warp (Martin et al., 2003). Esta ferramenta foi escolhida para auxiliar no desenvolvimento deste trabalho, como o ambiente que executará a simulação distribuída.

O projeto do código do Warped foi desenvolvido de forma que o usuário especifica sua aplicação usando os recursos de herança, funções virtuais e sobrecarga diretamente a partir das classes do núcleo. As classes do usuário são compiladas juntamente com o código do núcleo resultando num único arquivo executável que contém tanto o núcleo quanto a aplicação. A linkedição estática pode fazer o arquivo executável adquirir um tamanho 
razoavelmente grande, o que não representa necessariamente uma desvantagem, já que dessa forma não há a necessidade de instalar a biblioteca do Warped nas máquinas onde a simulação será executada (Voorsluys, 2006).

\subsection{Modelo PHOLD}

O modelo PHOLD - Parallel HOLD (Fujimoto, 1990b) é um modelo de carga sintética capaz de fornecer resultados que possibilitem comparações entre diferentes mecanismos de simulação paralela e distribuída, tanto otimistas como conservativos.. Ele é uma extensão do HOLD, um modelo largamente usado para avaliar o desempenho de algoritmos de listas de eventos seqüenciais.

O modelo fornecido pelo PHOLD consiste de um conjunto de objetos organizados de acordo com alguma topologia. Cada objeto comunica-se com um número fixo de vizinhos. $\mathrm{O}$ processamento de uma mensagem consiste em executar alguma computação por certo tempo e então enviar uma nova mensagem para outro objeto. $\mathrm{O}$ modelo pode ser configurado através dos seguintes parâmetros:

1. Número de objetos;

2. População de mensagens: quantidade de mensagens (eventos) que se movem entre os objetos. Para cada mensagem recebida apenas uma mensagem é enviada, por isso o número de mensagens circulando permanece sempre o mesmo;

3. Função de incremento do timestamp: se um objeto recebe um evento no tempo T, ele calcula, de acordo com alguma distribuição, um incremento / e envia um novo evento com tempo de recebimento igual a $\boldsymbol{T}+\boldsymbol{I}$;

4. Função movimento: usada para definir o destino do próximo evento a ser enviado;

5. Granulosidade computacional: define por quanto tempo (pode ser 0) o objeto ficará executando algum trabalho antes de enviar o próximo evento;

6. Configuração inicial: define a localização (no tempo e no espaço) de cada evento inicial antes que a simulação comece.

Os objetos são organizados numa topologia do tipo torus de duas dimensões. A quantidade total de objetos é definida pelo número de linhas e colunas do torus. Cada objeto pode se comunicar com quatro vizinhos, que são identificados pelas direções: norte (N), sul 
$(\mathbf{S})$, leste $(\mathbf{L})$ e oeste $(\mathbf{O})$. Além disso, um objeto pode enviar mensagens para si mesmo. Cada objeto recebe uma identificação única utilizada como nome de objeto dentro do sistema Warped.

A identificação é formada pelos números da linha e coluna na qual o objeto está posicionado, por exemplo, (2,3), ou seja, o objeto, nesse caso, esta posicionado na linha 2 e na coluna 3. A figura 2.7.1 ilustra a organização de objetos numa topologia torus, juntamente com o detalhamento da conexão de um objeto com seus quatro vizinhos.

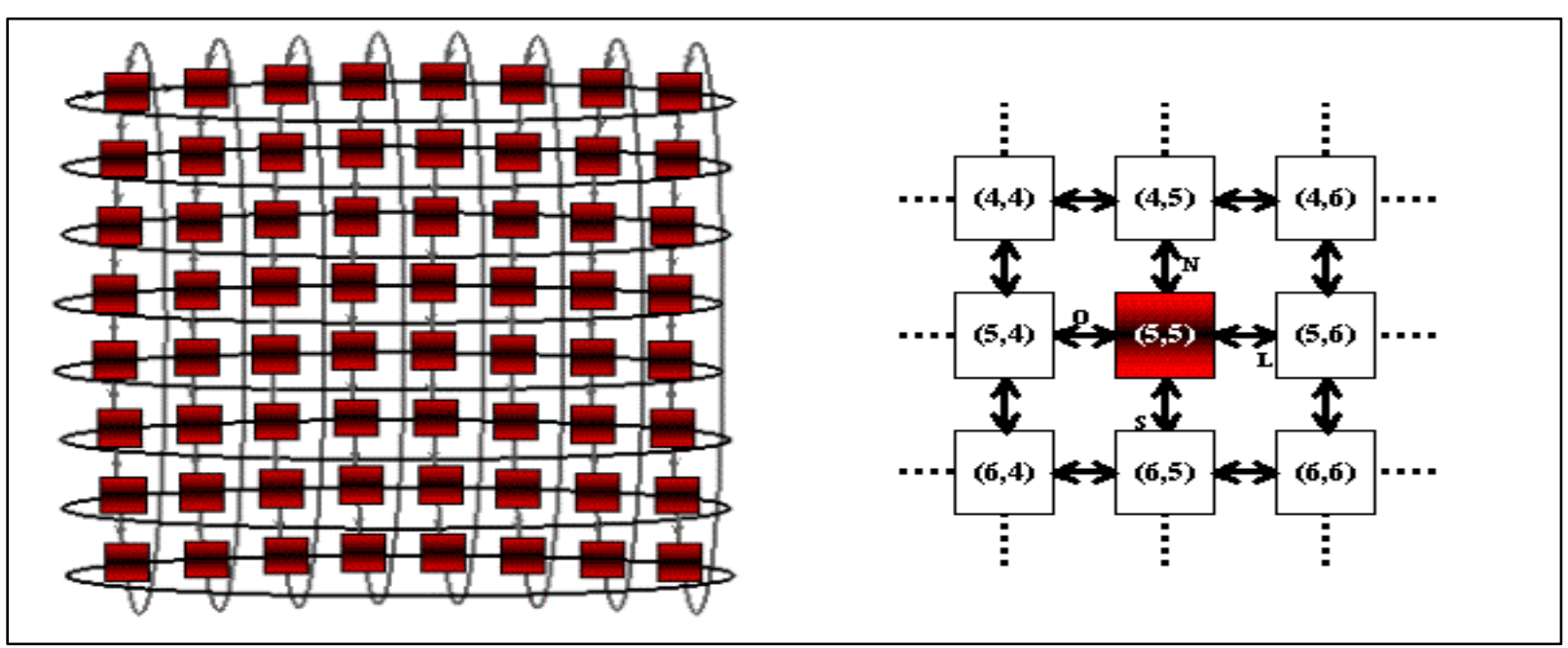

Figura 2.7.1 Organização dos objetos. ( Voorsluys, 2006)

Voorsluys (Voorsluys, 2006) utilizou o modelo PHOLD para avaliar o desempenho de políticas de escalonamento tradicionais em simulações distribuídas. O detalhamento do modelo utilizado por Voorsluys é descrito a seguir. Na função movimento, o destino da próxima mensagem depende da origem da última mensagem recebida. Há cinco opções de movimentação: para frente, para trás, para a direita, para a esquerda e para si mesmo. Uma dessas direções será escolhida de acordo com as probabilidades escolhidas pelo usuário.

As probabilidades são definidas em porcentagem e a escolha é feita de acordo com uma distribuição uniforme. Por exemplo, quando um objeto recebe uma mensagem do vizinho oeste e a variável aleatória gerada define que a movimentação deve ser para frente, a próxima mensagem será enviada para o vizinho leste. 
Para casos onde a última mensagem foi originada pelo próprio objeto, considera-se a localização da última fonte diferente de si mesmo. A tabela 2.7.1 mostra outras opções de movimentação possíveis.

\begin{tabular}{|c|c|c|c|c|}
\hline Fireçäo & Sul & Leste & Norte & Oeste \\
\hline Frente & Norte & Oeste & Sul & Leste \\
\hline Trás & Sul & Leste & Norte & Oeste \\
\hline Direita & Leste & Norte & Oeste & Sul \\
\hline Esquerda & Oeste & Sul & Leste & Norte \\
\hline
\end{tabular}

Tabela 2.7.1 Tabela de escolha do receptor da próxima mensagem.

A granulosidade foi simulada por Voorsluys (Voorsluys, 2006) através da inserção de um cálculo de multiplicação de matrizes no processamento de um evento. O tamanho do atraso a ser inserido pode ser controlado pelo tamanho das matrizes. Além do parâmetro que define o tamanho médio das matrizes, é possível especificar um desvio padrão que controla a diferença na quantidade de trabalho de um objeto para outro. Esses dois parâmetros são utilizados para gerar números aleatórios de acordo com uma distribuição normal. As quantidades de linhas e colunas das duas matrizes são definidas por esses números aleatórios, que são gerados apenas uma vez, durante a inicialização do objeto. Dessa forma, o tamanho do trabalho (atraso) de um determinado objeto permanece constante durante toda a simulação e não depende dos eventos.

Para determinar a localização inicial de cada evento do tempo, é calculado um número aleatório distribuído uniformemente no intervalo entre 0 e o tempo virtual máximo de inicialização dos eventos.

A definição do modelo $P H O L D$ não define o tempo máximo de duração da simulação. Nos testes realizados por Voorsluys (Voorsluys, 2006), foi utilizado um mecanismo do Warped que permite definir um tempo virtual máximo de duração para qualquer simulação. 
Assim que o último GVT calculado é maior ou igual ao valor máximo definido, a simulação é finalizada.

Pelo fato de Voorsluys (Voorsluys, 2006) ter implementado este modelo no Warped e utilizá-lo como base para os testes de seu trabalho e os experimentos com o modelo PHOLD mostrado sua utilidade para avaliar o desempenho do mecanismo Time Warp em diferentes situações, ele será usado neste trabalho.

\subsection{Considerações Finais}

A Simulação está contextualizada na computação como um programa computacional que implementa um modelo com o intuito de imitar um fenômeno real.

A idéia de usar simulação distribuída para resolução de muitos problemas, como ganho de tempo, redução de custos e outras vantagens que se obtém com seu uso, tem se mostrado promissora.

Para a correta execução paralela dos processos lógicos que compõe a simulação, protocolos de sincronização devem ser adotados e, esses podem ser divididos em conservativos, como o $C M B$, ou otimistas como o Time Warp, sendo o último o protocolo que será usado neste trabalho.

Um outro ponto que deve ser analisado é qual a política de escalonamento mais adequada para execução dos processos paralelos definidos em uma simulação distribuída. Nesse sentido, a literatura cita algumas políticas específicas para simulação e outras de propósito geral. No capítulo 3 algumas políticas específicas são apresentadas. O capítulo 3 apresenta ainda uma comparação entre as políticas estudadas. 


\section{Escalonamento EM Simulação Distribuída}

\subsection{Considerações Iniciais}

Sistemas baseados em recursos, que podem atender diferentes tipos de requisições, são freqüentes em diversas áreas do conhecimento. Normalmente, essas requisições devem ser distribuídas para os recursos, seguindo alguma política. Essa prática se chama escalonamento. Mais especificamente, o escalonamento de processos é caracterizado pela distribuição de tarefas para os recursos computacionais disponíveis.

Quando se discute escalonamento de processos é necessário o cuidado de separar duas características distintas, o escalonamento utilizando um único processador ou utilizando vários processadores. O foco deste trabalho está no segundo tipo mencionado.

O escalonamento de processos para vários processadores, feito em um sistema distribuído, possui características distintas quando se torna necessário pensar nas variáveis do sistema como um todo. Escolher os processadores mais adequados e que trarão um melhor desempenho na execução de uma determinada tarefa é um dos segredos principais do escalonamento.

Os algoritmos de escalonamento de processos de uso geral, construídos para plataformas computacionais distribuídas são geralmente destinados ao gerenciamento dos processos de programas paralelos. Uma das principais atividades realizadas por esses algoritmos é o mapeamento dos processos aos processadores disponíveis, isto é, escolher qual processo deve ser executado em qual processador. Muitas vezes isso é feito baseando-se em informações sobre a plataforma e sobre as aplicações. As informações coletadas pelos mecanismos responsáveis devem ser baseadas em métricas relacionadas com o desempenho da aplicação paralela, para que a correta utilização dessas informações possa contribuir para o aumento do desempenho do sistema. Por exemplo, um determinado algoritmo pode se basear em informações sobre a utilização do processador para decidir como será feito o mapeamento 
dos processos aos processadores. Nesse caso, uma decisão sensata seria atribuir mais processos aos processadores que estão sendo menos utilizados, buscando a maximização da utilização dos recursos disponíveis (Voorsluys, 2006).

O desempenho de uma simulação distribuída também está sujeito a influências da plataforma e das características do modelo de simulação. Diversas técnicas para otimizar o desempenho de uma simulação podem ser encontradas na literatura (Carothers \& Fujimoto, 2000), dentre elas, destacam-se as técnicas de escalonamento e balanceamento de carga. O objetivo deste capítulo é apresentar os algoritmos de escalonamento e balanceamento de carga para simulação distribuída.

Os algoritmos desenvolvidos especificamente para simulação distribuída apresentam algumas semelhanças e diferenças com relação aos algoritmos de uso geral. Em alguns casos, os algoritmos de uso geral mostram-se inadequados para o uso na simulação distribuída, principalmente devido aos tipos de informações nas quais as decisões são baseadas (Boukerche \& Das, 1997; Deelman \& Szymanski, 1998).

Tem-se, inicialmente, neste capítulo, uma continuidade da revisão bibliográfica apresentando formas de escalonamento específicas para simulação distribuída. Para facilitar a análise das políticas de escalonamento disponíveis na literatura, propõe-se nesta dissertação, uma classificação das políticas de escalonamento para simulação otimista, segundo o momento em que é considerado o balanceamento. Essa classificação é apresentada na seção 3.2. Na seção 3.3 faz-se uma comparação entre as políticas de escalonamento específicas para simulação distribuída, visando facilitar uma melhor análise dessas políticas e a identificação de lacunas que poderiam indicar pontos a serem investigados para proposta de novas políticas.

\subsection{Classificação de Políticas Específicas para Protocolos Otimistas}

Os algoritmos de escalonamento específicos para protocolos otimistas encontrados na literatura têm um objetivo em comum, utilizar técnicas para evitar a ocorrência de rollbacks elevando a eficiência da simulação. Como em um rollback deve-se voltar no tempo com a execução da simulação, cancelando eventos já executados, a eficiência alcançada na simulação torna-se inversamente proporcional ao número de rollbacks. No trabalho de Voorsluys (Voorsluys, 2006) são apresentados alguns algoritmos para escalonamento de 
processos utilizando características específicas de simulação distribuída. Neste trabalho esses mesmos algoritmos são apresentados, adicionando-se uma análise mais profunda de cada um deles.

Nesta seção é apresentada uma nova classificação das políticas específicas para SD's otimistas pesquisadas. Existem algoritmos que apresentam técnicas de balanceamento de carga que possuem uma só característica, ou seja, trabalham em tempo de execução ou em tempo de mapeamento e outros que usam mais de uma técnica e aqui são classificadas em três classes:

- Balanceamento em tempo de execução

- Balanceamento em tempo de mapeamento

- Balanceamento misto

\subsubsection{Balanceamento em Tempo de Execução}

As técnicas de balanceamento em tempo de execução são algoritmos que fazem um monitoramento de informações específicas da simulação em andamento, tomando decisões de balanceamento de carga no desenrolar da simulação.

\subsubsection{Algoritmo visando Utilização Efetiva do Processador (Reiher \& Jefferson, 1990)}

A Utilização Efetiva, representada pela letra grega $\mu$ (mi), representa a computação útil ou mais especificamente a porcentagem de eventos que são executados e que não sofrem rollbacks. O algoritmo de Reiher e Jefferson (Reiher \& Jefferson, 1990) é baseado na Utilização Efetiva $(\mu)$ da simulação com o intuito de alterar o mapeamento dos Processos Lógico (PL's) aos Processadores.

A idéia fundamental é fazer um balanceamento de carga através do balanceamento de $\mu$. Durante a execução o algoritmo as utilizações de cada PL e a carga do processador são calculas de forma periódica. Tomando PLn como o Processo Lógico de número n, pode-se afirmar que a notação $P \operatorname{Ln}(\mu)$ significa o valor da utilização efetiva do processo lógico $\mathrm{n}$. Por exemplo, $P L_{2}(3)$ significa que o valor da utilização efetiva do processo lógico 2 é 3 . As letras gregas $\alpha$ e $\beta$ são utilizadas para representar o número do processo lógico (PL) inicial e final, 
respectivamente. Por exemplo, considerando-se que o processador 2 possui 3 PL's $\left(\mathrm{PL}_{2}, \mathrm{PL}_{3}\right.$, $\mathrm{PL}_{4}$ ), então, pela definição $\alpha$ vale 2 e $\beta$ vale 4 . A carga do processador que será representada pela letra grega $\kappa($ capa $)$ é calculada da seguinte forma:

$$
\kappa=\sum_{n=\alpha}^{\beta} \operatorname{LPn}(\mu) ; \forall \alpha \in \boldsymbol{\aleph} ; \forall \beta \in \boldsymbol{\aleph}
$$

A carga do processador será igual à soma das utilizações dos PL's mapeados naquele processador. Ao detectar-se que a carga não está balanceada, os PL's do processador sobrecarregado (por exemplo, $\mathrm{P}_{1}$ ) são migrados para os processadores $\mathrm{P}_{\mathrm{n}}$ menos sobrecarregados. A idéia desta migração é causar um equilíbrio entre as taxas de progresso dos PL's. Um PL que executa mais rápido tem uma chance maior de rollbacks causados pelos PL's lentos e sua $\mu$ é considerada baixa, entretanto as chances dos PL's mais lentos sofrerem rollback é muito menor e com isso apresentam uma utilização alta.

Para melhor entendimento do funcionamento desta política é apresentada uma situação (figura 3.1) com três processadores (P1, P2 e P3) de um sistema paralelo qualquer, com uma primeira distribuição de PL's com seus valores de carga de trabalho. Em uma primeira análise do sistema, pode-se perceber uma sobrecarga de P1 (PL1, PL2). O processador P2 (PL5, PL4) possui uma carga de trabalho muito menor e poderá evoluir mais rapidamente do que o resto dos PL's do sistema. Pode-se calcular a carga $(\kappa)$ dos 3 processadores utilizando a definição apresentada anteriormente, obtendo-se os seguintes valores: P1 $(\kappa=0,9), \mathrm{P} 2 \quad(\kappa=0,3), \mathrm{P} 3$ $(\kappa=0,8)$. Neste primeiro mapeamento, o algoritmo em tempo de execução percebe que necessita migrar PL's de P1 para P2, desta forma ele estará equilibrando a execução dos PL's da simulação e evitando rollbacks.

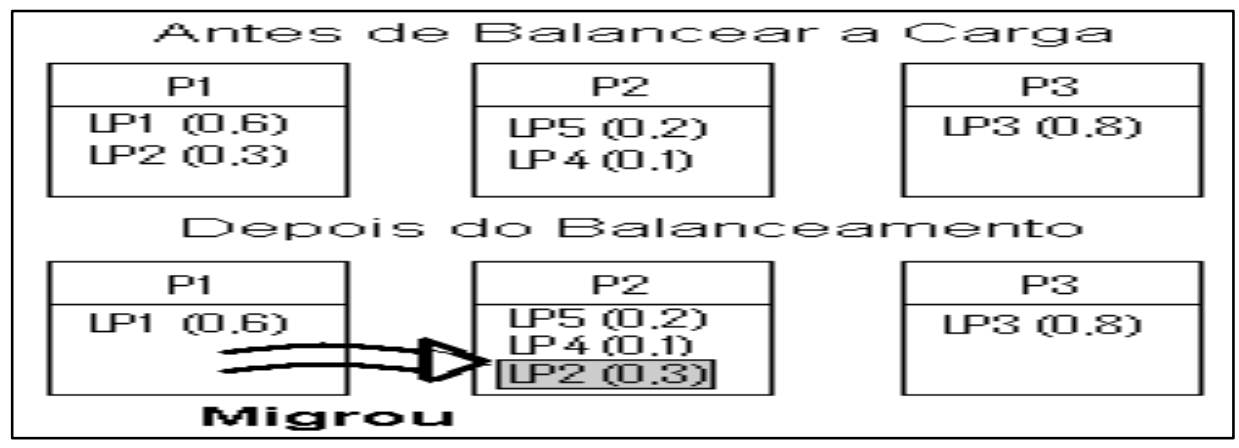

Figura 3.1 Migração de processos pela política de utilização efetiva. 


\subsubsection{Algoritmo utilizando uma métrica com Relógio Local (Burdof \& Marti, 1993)}

A idéia fundamental neste algoritmo é corrigir as diferenças existentes nas taxas de progresso dos PL's, sendo portanto, característico da classe que tem a visão de balanceamento de carga em tempo de execução.

O algoritmo com relógio local mapeia, em tempo de execução, os valores dos relógios virtuais locais de cada PL do sistema, visando a fazer o balanceamento do sistema e evitar a ocorrência de rollbacks. Baseado nos valores obtidos calcula-se a média e o desvio padrão e através desses valores o balanceamento de carga é realizado.

Tomando $\lambda$ (lambda) como a média dos valores dos relógios virtuais dos PL's do Sistema e $\omega$ (ômega) a média dos valores dos relógios dos PL's de um determinado processador P1. Tem-se que,

se $\omega>\lambda \Rightarrow$ PL's $\in$ P1 estão avançando muito rápido.

Assim são migrados os PL's de outros processadores para P1 diminuindo desta forma a velocidade de progresso dos PL's de P1.

Os PL's de valor de relógio local abaixo de $\lambda$ (num fator de desvio padrão) são escolhidos para migrarem para os processadores com PL's com relógios locais maiores. Desta forma, consegue-se equilibrar em tempo de execução a velocidade de progresso das PL's da simulação e conter o número de rollbacks no sistema.

\subsubsection{Algoritmo Probabilístico (Som \& Sargent, 1998)}

Esta política apesar de pertencer à mesma classe dos demais algoritmos que fazem o balanceamento de carga em tempo de execução tem uma abordagem diferente, pois não faz nos processadores um mapeamento de seus processos. O objetivo deste mecanismo é empregar algoritmos probabilísticos para escolher o melhor evento para ser executado em um determinado momento.

Este algoritmo faz uso de distribuições aleatórias que são geradas através de dados sobre eventos passados. O fundamento principal é fazer uma estimativa probabilística de um evento e saber as chances de ocorrer um rollback causado por uma mensagem straggler. 
O trabalho de Som e Sargent (Som \& Sargent, 1998) apresenta uma comparação com o algoritmo LTF (Lowest Timestamp First). O LTF é um algoritmo muito utilizado para gerenciar a fila de eventos, organizando os eventos pelo seu timestamp, sendo que os de menor valor são colocados na frente da fila. No algoritmo probabilístico tem-se como objetivo colocar na frente da fila os eventos com menor chance de rollbacks e que não necessariamente são os de menor timestamp. Este algoritmo é focado somente nos rollbacks causados por straggler não se preocupando com aqueles causados por outras causas, como por exemplo, pelas anti-mensagens.

\subsubsection{Balanceamento em Tempo de Mapeamento}

Os algoritmos desta classe são caracterizados por fazerem um mapeamento dos dados da simulação antes de iniciar a sua execução e assim tomar a decisão de como distribuir as PL's nos processadores. Na literatura pesquisada foi encontrado apenas um algoritmo com essas características que será discutido a seguir.

\subsubsection{Algoritmo utilizando heurística de Mapeamento (Som \& Sargent, 1993)}

Os algoritmos apresentados nas seções anteriores, tiveram como característica o balanceamento de carga em tempo de execução. Este algoritmo não faz este tipo de controle, mas tem, como algumas políticas já apresentadas, o objetivo de igualar a velocidade de progresso dos PL's e assim diminuir a ocorrência de rollbacks.

Duas tarefas são utilizadas para realizar o trabalho deste algoritmo. A primeira é identificar eventos que possam sofrer rollbacks quando forem executados, sendo esses chamados eventos de risco. A segunda tarefa é a criação de uma heurística com o intuito de atrasar a execução dos eventos de risco. Os eventos caracterizados com chance de ocorrência de rollbacks são definidos do seguinte modo:

“Se um processo lógico PLi pode escalonar eventos em um processo lógico PLj, então PLi pode causar rollback em PLj" (Voorsluys, 2006).

Som e Sargent (Som \& Sargent, 1993) consideram que um modo eficiente de se conseguir atrasar os eventos de risco, evitando assim a ocorrência de rollbacks, é colocar os PL's envolvidos no evento em um mesmo processador. 
Na figura 3.2 é mostrada uma situação que os processadores P1, P2 e P3 ainda vazios, pois ainda não foi iniciada a simulação, aguardam processamento, e no momento do inicio da simulação são verificados os PL's que estão classificados no grupo dos eventos de risco (Lk). Após a realização do mapeamento dos PL's pertencentes a Lk o algoritmo se encarrega de fazer o balanceamento de carga distribuindo os PL's do grupo Lk em um único processador (P3 neste caso) e os demais PL's nos outros processadores. Assim P3 terá uma carga de processamento que fará com que a velocidade do progresso dos eventos de risco diminua e com isso reduz as chances de rollbacks.

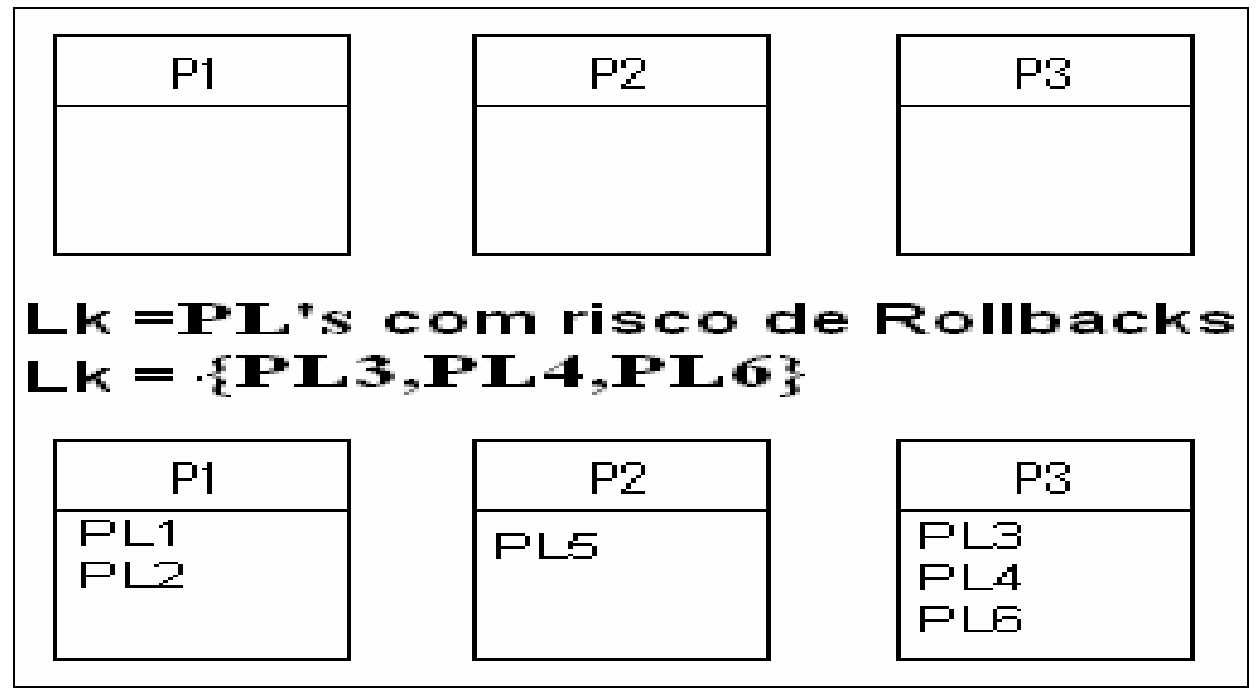

Figura 3.2 Balanceamento feito através de uma heurística de mapeamento.

\subsubsection{Balanceamento Misto}

Neste caso os algoritmos utilizam mais de uma técnica para fazer um balanceamento eficiente e assim evitar o máximo possível a ocorrência de rollbacks. Este balanceamento é caracterizado também por algoritmos que possuem a preocupação com o uso de carga externa no sistema. Entende-se carga externa por processos que utilizam processamento do sistema, mas não fazem parte da simulação em desenvolvimento.

\subsubsection{Strong Groups (Som \& Sargent, 2000)}

Este algoritmo utiliza o conceito já apresentado anteriormente, a utilização efetiva $(\mu)$ e inova pela introdução do conceito de Strong Groups (SG). Este algoritmo foi classificado como um balanceamento misto porque possui 2 estágios, o primeiro é o mapeamento dos 
processos no inicio da simulação identificando os PL's e seus respectivos SG's e o segundo fazendo a migração em tempo de execução para balanceamento do sistema.

Os SG's são caracterizados como um conjunto de PL's que possuem uma forte influência entre si. Estes conjuntos, também chamados de grupos, podem ser identificados com uma análise criteriosa do grafo de interconexão feito para descrever o modelo de simulação. Percebe-se assim a necessidade de ter um bom conhecimento de como o modelo se comporta para que se consiga distinguir da melhor forma possível os Strong Groups.

Som e Sargent (Som \& Sargent, 2000) mostram que, sem qualquer intervenção no mapeamento dos processos, as velocidades de progresso entre os PL's do mesmo SG, por motivo das fortes dependências entre si, convergem para o mesmo valor.

Este algoritmo tem como objetivo utilizar informações sobre o mapeamento e assim equilibrar as velocidades de progresso dos SG's da simulação em execução. Para conseguir essa igualdade, buscam-se valores específicos para os PL's de um mesmo SG. Como comentado anteriormente, os PL's de um mesmo SG tendem a ter a mesma velocidade de progresso, então basta aplicar um fator $\beta$ à esta taxa de progresso de todos os PL's do mesmo grupo.

A velocidade de progresso é diretamente proporcional à utilização do PL, assim para ajustar a velocidade basta aplicar o fator $\beta$ aumentando ou diminuindo a utilização. Assim, em tempo de execução, é feita a migração dos PL's para alcançar a utilização já calculada. Conseguindo desta forma aproximar o progresso de todas as SG's da simulação e assim evitar a ocorrência de rollbacks.

\subsubsection{Carga BGE (Background Execution) (Carothers \& Fujimoto, 2000)}

Este algoritmo possui uma característica diferente das demais políticas anteriores, pois além de trabalhar o balanceamento de carga ele trata da adaptação dos processadores disponíveis à simulação tendo uma preocupação extra com a carga externa. Este trabalho possui como meta obter desempenho executando em background em sistemas distribuídos heterogêneos e podendo ser compartilhado por outros usuários, que caracteriza a carga externa. Esta política faz um mapeamento dos PL's do sistema no inicio da simulação e os agrupa em clusters. Em tempo de execução, o algoritmo se responsabiliza pelo balanceamento 
de carga e do controle de quais processadores usar, caracterizando-se um balanceamento misto.

Sabe-se que as cargas externas são muito difíceis de serem controladas pelo protocolo de simulação, assim este algoritmo trata do dinamismo de quais processadores usar em tempo de execução.

Nesta política a migração não é feita visando apenas um PL e sim um conjunto de PL's aqui chamados de cluster.

A política que implementa a carga BGE possui duas métricas fundamentais de controle o PAT (Processor Advance Time) e o CAT (Cluster Advance Time). A primeira é referente a um processador $\mathrm{P} 1$ qualquer e a segunda é referente a um cluster $\mathrm{C} 1$ qualquer.

Considerando a letra grega $\theta$ (teta) como o valor do tempo real e $\gamma$ (gama) como o valor do tempo virtual e ainda considerando o valor de utilização efetiva $\mu$ (mi) atribuindo-se a ele valores de 0 a 10, sendo 10 a não ocorrência de rollbacks, pode-se afirmar que:

$$
\begin{aligned}
& \mathrm{PAT}=\Delta \theta_{p} \text { se } \Delta \theta_{p}=\theta_{f}-\theta_{0} \mathrm{e} \\
& \theta_{f}-\theta_{0}=\gamma_{\mathrm{p}} \quad \therefore \Delta \theta=\gamma_{\mathrm{p}} \forall \mu=10
\end{aligned}
$$

Assim PAT é a variação de tempo real $\left(\Delta \theta_{p}\right)$ de P1 gasto em uma unidade de tempo virtual $\left(\gamma_{\mathrm{p}}\right) \operatorname{com} \mu=10$.

$$
\begin{aligned}
& \mathrm{CAT}=\Delta \theta_{c} \text { se } \Delta \theta_{c}=\theta_{f}-\theta_{0} \mathrm{e} \\
& \theta_{f}-\theta_{0}=\gamma_{\mathrm{c}} \therefore \Delta \theta=\gamma_{\mathrm{c}} \forall \mu=10
\end{aligned}
$$

Assim CAT é a variação de tempo real $\left(\Delta \theta_{c}\right)$ de $\mathrm{C} 1$ gasto em uma unidade de tempo virtual $\left(\gamma_{\mathrm{c}}\right) \operatorname{com} \mu=10$.

Observadas as dependências, pode-se afirmar que o PAT de um processador P1 é uma métrica calculada através dos CAT's dos clusters pertencentes a P1.

Através da análise dos valores dos PAT's se obtém uma fotografia do sistema, se o algoritmo perceber que os valores estão diferentes uns dos outros, então existem PL's com a velocidade de progressão maior que outras, portanto será necessário o balanceamento. 
A primeira fase do balanceamento é identificar o emissor e o receptor. O emissor será o processador de PAT maior que os demais do sistema. O receptor será o processador de PAT menor e que o custo de transmissão seja vantajoso para o sistema. Assim que forem identificados o emissor e o receptor, será feita a migração do cluster mais apropriado visando ao balanceamento de carga do sistema, como mostrado na figura 3.3.

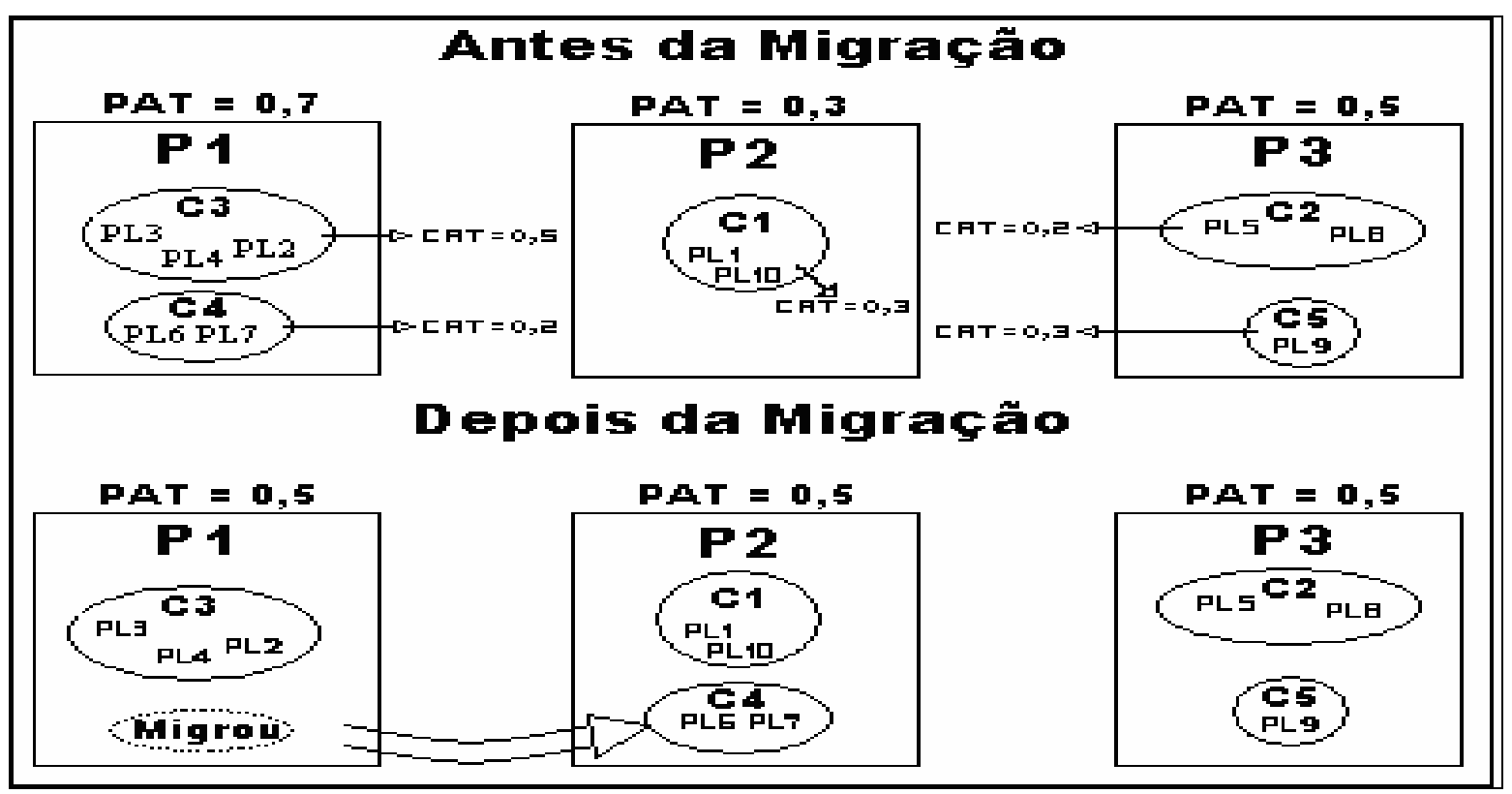

Figura 3.3 Balanceamento feito pelo algoritmo de Carga BGE.

Nesse caso o emissor P1 migrou o Cluster C4 para o receptor P2 equilibrando os PAT's e dessa forma igualando as velocidades de progressão dos PL's, conseguindo assim evitar a ocorrência de rollbacks. Antes de fazer a migração, o algoritmo calcula dois PAT's para o emissor e dois para o receptor. O primeiro é o valor do PAT no momento atual antes da migração e o segundo é um valor hipotético calculado considerando o custo da migração se o PAT hipotético mostrar que melhorará a situação no sistema em relação ao PAT atual, daí ocorre a migração, caso contrário mantém o sistema inalterado naquele momento.

Como este algoritmo foi projetado para ser usado em uma plataforma que também pode ser compartilhada com outros usuários, ocorrerá como na figura 3.4, o caso em que não compensará para o sistema utilizar o processador P1, pois a carga externa esta fazendo P1 ter um PAT muito alto. Assim esta política migrará C4 para P2 por ter o menor PAT e suspenderá P1 do sistema. O algoritmo continuará calculando o PAT de P1, caso o valor dele reduza duas vezes o valor de quando foi suspenso, então P1 será novamente integrado a simulação. 


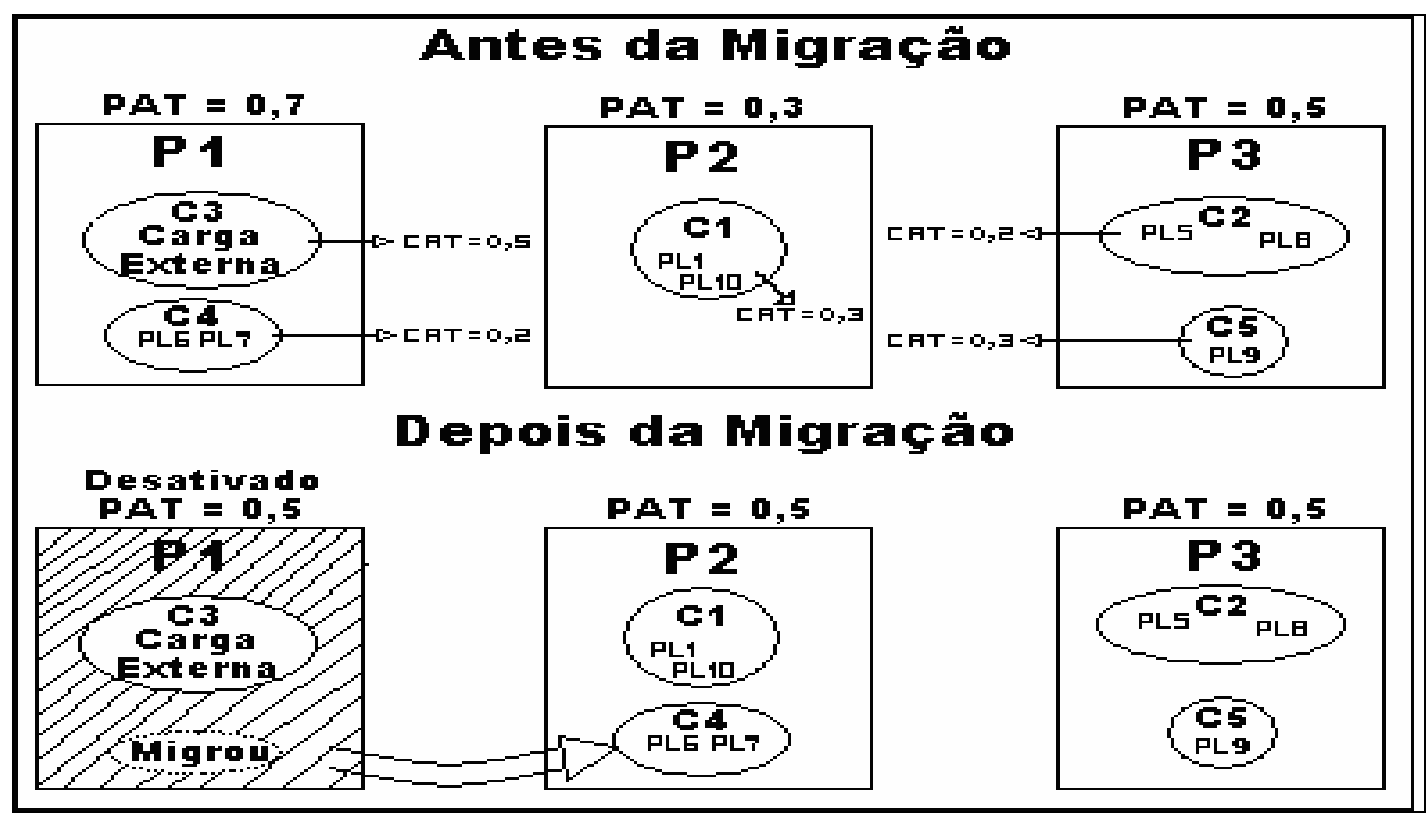

Figura 3.4 Balanceamento feito pelo algoritmo de Carga BGE.

\subsection{Comparação entre as Formas de Escalonamento Específicas}

Nesta seção serão feitas comparações entre todas as formas de escalonamento específicas para simulação distribuída pesquisadas.

Na tabela 3.1 são apresentadas comparações entre todas as políticas de escalonamento para simulação distribuída pesquisadas na literatura, discutidas e apresentadas neste capítulo. Sete tópicos são considerados para a comparação:

- Dificuldade de implementação;

- Sobrecarga gerada pelo algoritmo em tempo de execução;

- Influência do usuário da Simulação;

- Métrica(s) em que a política se baseia;

- Se a política considera ou não carga externa;

- Se durante a execução é utilizada a técnica de migração de PL's;

- Classificação do tipo de balanceamento de carga. 


\begin{tabular}{|c|c|c|c|c|c|c|c|c|}
\hline Políticas & $\begin{array}{l}\text { Dificuldade de } \\
\text { Implementação }\end{array}$ & $\begin{array}{c}\text { Sobrecarga } \\
\text { gerada pelo } \\
\text { algoritmo em } \\
\text { tempo de } \\
\text { execução }\end{array}$ & $\begin{array}{c}\text { Sobrecarga } \\
\text { gerada pelo } \\
\text { algoritmo em } \\
\text { tempo de } \\
\text { mapeamento }\end{array}$ & $\begin{array}{c}\text { Influência do } \\
\text { usuário da } \\
\text { Simulação }\end{array}$ & $\begin{array}{c}\text { Métricas em } \\
\text { que as políticas } \\
\text { se baseiam }\end{array}$ & $\begin{array}{c}\text { Considera } \\
\text { Carga } \\
\text { Externa? }\end{array}$ & $\begin{array}{c}\text { Usa } \\
\text { migração? }\end{array}$ & $\begin{array}{c}\text { Classificação } \\
\text { do tipo de } \\
\text { balanceamento }\end{array}$ \\
\hline $\begin{array}{l}\text { Utilização } \\
\text { Efetiva }(\mu)\end{array}$ & Razoável & Ocorre & Não Ocorre & Não tem & $\begin{array}{l}\text { Utilização } \\
\text { Efetiva do } \\
\text { Processador }\end{array}$ & Não & Sim & $\begin{array}{l}\text { Tempo de } \\
\text { Execução }\end{array}$ \\
\hline $\begin{array}{l}\text { Média com } \\
\text { Relógios do } \\
\text { Sistema }\end{array}$ & Razoável & Ocorre & Não Ocorre & Não tem & $\begin{array}{l}\text { Relógio Virtual } \\
\text { Local dos LP's }\end{array}$ & Não & Sim & $\begin{array}{l}\text { Tempo de } \\
\text { Execução }\end{array}$ \\
\hline $\begin{array}{l}\text { Algoritmo } \\
\text { Probabilístico }\end{array}$ & Alta & Ocorre & Não Ocorre & Não tem & $\begin{array}{c}\text { Estimativas } \\
\text { Probabilísticas } \\
\text { de um Evento }\end{array}$ & Não & Não & $\begin{array}{l}\text { Tempo de } \\
\text { Execução }\end{array}$ \\
\hline $\begin{array}{l}\text { Heurística de } \\
\text { Mapeamento }\end{array}$ & Razoável & Não Ocorre & Ocorre & Não tem & $\begin{array}{l}\text { Eventos de } \\
\text { Risco e } \\
\text { Heurística de } \\
\text { Mapeamento }\end{array}$ & Não & Não & $\begin{array}{c}\text { Tempo de } \\
\text { Mapeamento }\end{array}$ \\
\hline Strong Groups & Alta & Ocorre & Ocorre & Não tem & $\begin{array}{c}\text { Strong Groups } \\
\text { e Utilização } \\
\text { Efetiva }\end{array}$ & Não & Sim & Misto \\
\hline Carga BGE & Muito Alta & Ocorre & Ocorre & $\begin{array}{l}\text { Tem } \\
\text { influência }\end{array}$ & PAT e CAT & Sim & Sim & Misto \\
\hline
\end{tabular}

Tabela 3.1 Comparação entre as formas de escalonamento específicas

\subsubsection{Dificuldades de Implementação}

A dificuldade de implementação é proporcional às métricas e migrações exigidas pela política em questão. A política Utilização Efetiva (Reiher \& Jefferson, 1990) apresenta uma implementação não trivial uma vez que exige migração em tempo de execução. Por outro lado, o cálculo da métrica utilizada não apresenta grande complexidade, sendo assim não fácil, mas razoável de ser implementada. A política que usa o relógio virtual local dos PL's (Burdorf \& Marti, 1993) possui a mesma dificuldade de implementação que a política da Utilização Efetiva por possuírem as mesmas características em relação as métricas e a migração de PL's.

No algoritmo probabilístico (Som \& Sargent, 1998) percebe-se uma diferença fundamental em relação aos outros algoritmos, pois este não se baseia no problema de mapeamento de processos e não faz migração. A alta complexidade de implementação dessa política está ligada à métrica utilizada que calcula a probabilidade de ocorrência de rollbacks em determinado evento e assim escolhe a sequiência mais promissora a ser executada. 
Na política que utiliza Heurística de Mapeamento (Som \& Sargent, 1993) migração não é considerada nem é utilizado o conceito de utilização efetiva. Sua complexidade de codificação resume-se em dois pontos fundamentais: identificação de eventos de risco e criação de uma heurística para "atrasar” a execução destes eventos.

No algoritmo que utiliza o conceito de strong groups (Som \& Sargent, 2000), percebese grande dificuldade de implementação em dois pontos: na migração de processos, e na métrica utilizada que visa a obtenção de valores ideais para identificar os PL's de um mesmo SG.

A Carga BGE (Carothers \& Fujimoto, 2000) possui características únicas e distintas a todas as outras políticas apresentadas. A primeira característica fundamental é a sua preocupação com a carga externa, que desativa um processador que possa estar sobrecarregado com processos não pertencentes à simulação em execução e que pode estar prejudicando o andamento desta. A segunda é a migração, feita por clusters e não mais por PL's como as demais políticas utilizam. Possui duas métricas PAT e CAT que precisam ser recalculadas freqüentemente. Devido a estas características sua implementação é de uma complexidade muito mais alta em relação às demais.

\subsubsection{Sobrecarga Gerada pelo Algoritmo em Tempo de Execução e/ou Tempo de Mapeamento}

A sobrecarga é mais um ponto importante a ser discutido e comparado entre as políticas de escalonamento porque pode se tratar de um "gargalo" na execução da simulação.

A classificação das políticas específicas para simulação otimista apresentada pelo autor deste trabalho na seção 3.2 está diretamente ligada à sobrecarga gerada tanto em tempo de execução quanto em tempo de mapeamento.

Analisando a tabela 3.1 percebe-se que algoritmos cuja classe do tipo de balanceamento é em tempo de execução, a sobrecarga gerada em tempo de execução é claramente percebida e a sobrecarga ocorrida em tempo de mapeamento não existe. Ao contrário do que ocorre com políticas pertencentes à classe que possui tipos de balanceamento em tempo de mapeamento, pois sua sobrecarga ocorre em tempo de mapeamento e não existe em tempo de execução. 
Voltando a atenção novamente para tabela 3.1, tanto a política que utiliza o conceito de Strong Groups (Som \& Sargent, 2000) quanto à da Carga BGE (Carothers \& Fujimoto, 2000), classificadas como Balanceamento Misto, possuem sobrecarga gerada pelo algoritmo em tempo de execução e em tempo de mapeamento, reforçando ainda mais a idéia de que o tipo de sobrecarga esta diretamente ligada ao tipo de balanceamento.

\subsubsection{Influência do Usuário da Simulação}

Com exceção da Carga BGE (Carothers \& Fujimoto, 2000), todas as políticas de escalonamento para simulação distribuída apresentadas neste trabalho, têm como característica a dedicação exclusiva do sistema, ou seja, a simulação deve estar sendo executada no sistema distribuído sozinha, sem que concorra com outros programas ao mesmo tempo. Portanto, para que os dados coletados sejam confiáveis o sistema deverá estar isolado e não deve ter nenhum tipo de influência externa, incluindo o usuário.

Entre as técnicas apresentadas, a Carga BGE é a única que trata uma possível influência no sistema e permite que o sistema não esteja necessariamente isolado, podendo assim a simulação ser executada concomitantemente com outros programas. Sua técnica de análise da sobrecarga dos processadores contribui para que o usuário possa rodar outros programas ao mesmo tempo em que a simulação esteja em execução, influenciando diretamente no sistema. Se algum processador ficar muito sobrecarregado, esse poderá prejudicar o andamento da simulação e assim ele é desativado do grupo, reduzindo a influência no sistema.

\subsubsection{Métrica(s) em que as Políticas se Baseiam}

Cada política utiliza uma ou mais métricas para atingir uma melhor distribuição dos PL's da simulação nos processadores do sistema, os objetivos principais são reduzir o número de rollbacks e alcançar uma melhor eficiência, sendo a última muito dependente da primeira.

A política apresentada por Reiher e Jefferson (1990) é fundamentalmente baseada em uma única métrica, a utilização efetiva do processador.

Os Strong Groups (Som \& Sargent, 2000) consideram o mesmo conceito de utilização efetiva da política anterior de uma forma diferente. Nesse caso, a utilização efetiva é 
associada aos Strong Groups (SG's) que separam em grupos os PL's considerados dependentes uns dos outros.

A métrica baseada no relógio virtual local dos PL's de uma simulação foi apresentada por Burdorf e Marti (1993), sendo uma política que calcula a média geral dos relógios do sistema e compara com o relógio local de cada PL.

No algoritmo probabilístico (Som \& Sargent, 1998) é apresentada uma métrica que calcula e oferece estimativa probabilística para definir uma sequiência de eventos que atinja uma melhor eficiência.

Há duas métricas principais no trabalho apresentado por Som e Sargent (1993), os chamados eventos de risco, que são eventos que possuem chance de promover rollbacks, e a heurística de mapeamento que deve ser utilizada para atrasar esses eventos.

Na carga BGE (Carothers \& Fujimoto, 2000) são apresentadas 2 métricas: PAT e CAT. A primeira é medida conforme a carga do processador, ou seja, quanto maior a PAT mais sobrecarregado o processador, ela é responsável pela retirada de um processador do sistema distribuído utilizado na simulação. Já a CAT é calculada através de medições do tempo de CPU considerando os eventos processados de um cluster (Grupo de PL's).

\subsubsection{Políticas que Consideram Carga Externa e/ou usam Migração}

De todas as políticas estudadas para execução deste trabalho, apenas uma se preocupa com cargas externas à simulação. A Carga BGE apresentada por Carothers e Fujimoto (2000) permite que outros programas executem, no sistema, ao mesmo tempo em que a simulação distribuída esteja em andamento.

Das seis políticas existentes na tabela apenas duas não usam a técnica de migração de PL's. A primeira é a do algoritmo probabilístico, pois sua base é formada em uma fila de eventos a serem distribuídas e executadas, e a segunda é a política que utiliza a heurística de mapeamento que faz todo seu balanceamento antes de iniciar a simulação, não havendo durante a execução nenhum outro tipo de movimentação de PL's. 
A migração em tempo de execução utilizada pela política desenvolvida por Reiher e Jefferson (1990) se baseia em calcular a utilização efetiva do processador e migrar os PL's dos processadores sobrecarregados para os menos carregados.

Os relógios locais dos PL's são a métrica principal apresentada no trabalho de Burdorf e Marti (1993), esta verifica os PL's que estão avançando mais rapidamente que os outros e assim faz a migração de PL's mais lentos para o processador dos PL's mais rápidos com o intuito de reduzir rollbacks na simulação.

Na política que utiliza o princípio de SG's, a característica principal da migração de PL's é visando que todos os Grupos "andem” na mesma velocidade, equilibrando a taxa de utilização efetiva em um "foco" estabelecido.

A migração na Carga BGE depende diretamente dos resultados de suas duas métricas, tendo o intuito principal do balanceamento de carga do sistema. Existem dois diferenciais principais dessa política em relação às outras, uma é que ela migra um cluster (grupo de PL's) e não faz migração de um só PL, outra peculiaridade é que antes da migração é feito um cálculo da situação atual do sistema e calcula-se também a situação hipotética futura depois da migração. Caso seja percebida uma vantagem na situação futura, então é feita a migração.

\subsubsection{Classificação do Tipo de Balanceamento}

Existem três classes de balanceamento de carga: Tempo de Execução, Tempo de Mapeamento e Misto.

Três das seis políticas apresentadas pertencem à classe de balanceamento de carga em tempo de execução: utilização efetiva, média com relógio local e algoritmo probabilístico. A primeira faz seu balanceamento recalculando a utilização efetiva de cada processador constantemente e se necessário efetuando migrações de PL's. Na segunda política o cálculo da média dos relógios de cada PL e a comparação com seus relógios locais é feita repetidas vezes durante a simulação e se necessário feitas as migrações. O algoritmo probabilístico refaz repetidamente o cálculo das estimativas, remontando sempre a sequiência de eventos ideal. 
A política que trabalha com a heurística de mapeamento esta classificada como balanceamento em tempo de mapeamento porque todos os cálculos das métricas e distribuições dos PL's nos processadores são feitos somente antes do inicio da simulação.

A técnica dos SG's possui 2 fases, a primeira faz uma mapeamento da conexão entre as PL's verificando quais possuem maior influência entre si e assim constrói os SG's, depois de definida e passada esta fase, inicia-se a simulação e em tempo de execução são feitos cálculos para encontrar valores de utilização bons para que ocorra a migração dos PL's, equilibrando a velocidade de execução das SG's. Por estas características, pode-se afirmar que esta política está incluída em uma classe cujo balanceamento é misto.

Finalizando, a carga BGE faz um mapeamento prévio dos PL's do sistema antes do inicio da simulação e os agrupa em clusters, depois o controle do balanceamento de carga e de quais processadores usar é feito em tempo de execução, caracterizando-se assim como um balanceamento misto.

\subsection{Considerações Finais}

Os algoritmos de escalonamento de processos de uso geral, construídos para plataformas computacionais distribuídas, são geralmente destinados ao gerenciamento dos processos de programas paralelos.

Os algoritmos feitos especificamente para simulação distribuída apresentam algumas semelhanças e algumas diferenças com relação aos algoritmos de uso geral. Em especial, as diferenças existentes muitas vezes tornam os algoritmos de uso geral menos adequados para o uso na simulação distribuída, principalmente por causa dos tipos de informações nas quais as decisões são baseadas (Boukerche \& Das, 1997; Deelman \& Szymanski, 1998). Neste capítulo foram apresentadas as principais políticas para a simulação otimista.

Uma das contribuições deste trabalho foi apresentar neste capítulo uma classificação das políticas específicas para simulação otimista existentes na literatura. Especificando três classes principais: Balanceamento em tempo de execução, balanceamento em tempo de mapeamento e balanceamento misto. 


\section{AVAliaÇÃo de DESEMPENHO do USO DE Políticas de Escalonamento Tradicionais}

\subsection{Considerações iniciais}

Este capítulo trata da avaliação de desempenho de simulações que utilizam políticas de escalonamento tradicionais desenvolvidas para sistemas distribuídos, mostrando as vantagens de se usar essas técnicas em comparação à utilização de Round Robin. Como o objetivo deste trabalho é propor novas políticas de escalonamento, específicas para simulação distribuída, e compará-las com as tradicionais, apresenta-se neste capítulo o trabalho de Voorsluys (Voorsluys, 2006) onde são discutidos resultados significativos e que poderão ser utilizados para viabilizar a comparação pretendida. Essas políticas não consideram dados específicos da simulação e sim dados estáticos que foram gerados por benchmarks, sempre considerando a potência computacional de cada elemento de processamento do cluster.

O intuito principal do trabalho de Voorsluys (2006) é mostrar ganhos satisfatórios em seus estudos de casos avaliados, nele foi conseguido reduzir em até $24 \%$ o tempo de execução e atingir uma redução de $79 \%$ dos rollbacks causados. Deixando claro que em alguns casos, as técnicas convencionais podem ser utilizadas, atingindo-se ganhos significativos em simulações distribuídas (Voorsluys, 2006).

\subsection{Modelos Simulados}

Alguns parâmetros do modelo PHOLD podem ser ajustados visando uma configuração específica do que se quer simular de acordo com os objetivos. Quando o objetivo é analisar um modelo de simulação com características Network-Bound, Memory-Bound e CPU-Bound, deve-se ajustar corretamente a quantidade de objetos, população de mensagens e valor de processamento por evento. Possibilidades estas oferecidas pelo modelo PHOLD. 
Os modelos utilizados por Voorsluys (Voorsluys, 2006) foram divididos em três grupos, onde para cada grupo, foi utilizado no momento da execução da simulação, uma política de escalonamento de objetos baseados em um dos benchmarks: rede, memória e CPU. Cada modelo tem ajustes específicos para caracterizar uma maior ou menor utilização de um recurso (rede, memória,CPU). As tabelas 4.1, 4.2 e 4.3 a seguir, apresentam os ajustes utilizados para cada modelo dos grupos de rede, memória e CPU.

$\mathrm{Na}$ primeira coluna das tabelas a seguir é definido o nome do modelo, na segunda a quantidade de objetos (PL's) que farão parte do referido modelo. A terceira coluna contém o numero total de mensagens geradas pelos objetos na simulação. Na quarta coluna é especificado o tamanho da matriz calculada sendo assim nessa coluna é definido o grau de processamento do modelo executado. Na quinta e última coluna é definida a probabilidade de navegação das mensagens. Por exemplo, no modelo R1 as probabilidades para a mensagem navegarem para frente, atrás, direita, esquerda e enviar a mensagem pra si são de $20 \%$ cada.

\begin{tabular}{|c|c|c|c|c|}
\hline \multirow[b]{2}{*}{ Modelo } & \multicolumn{4}{|c|}{ Parâmetros } \\
\hline & Objetos & $\begin{array}{l}\text { População } \\
\text { Mensagens }\end{array}$ & Trabalho & $\begin{array}{c}\text { Probabilidades de } \\
\text { Navegação } \\
\text { (frente/atrás/direita/esquerda/próprio) }\end{array}$ \\
\hline R1 & 1000 & 2000 & $0 \times 0$ & $20,20,20,20,20$ \\
\hline R2 & 1000 & 4000 & $0 \times 0$ & $20,20,20,20,20$ \\
\hline R3 & 5000 & 10000 & $0 \times 0$ & $20,20,20,20,20$ \\
\hline R4 & 5000 & 20000 & $0 \times 0$ & $20,20,20,20,20$ \\
\hline R5 & 5000 & 20000 & $0 \times 0$ & $50,10,20,20,0$ \\
\hline
\end{tabular}

Tabela 4.1 Modelos do Grupo Rede (retirada de Voorsluys, 2006)

Pode-se observar que os modelos do grupo rede não possuem nenhuma configuração para processamento, pois a configuração do parâmetro trabalho está zerada para todos. Isso ocorre, pois o interesse neste grupo é possuir modelos cujas características principais são as grandes populações de mensagens entre objetos. 


\begin{tabular}{|c|c|c|c|c|}
\hline \multirow[b]{2}{*}{ Modelo } & \multicolumn{4}{|c|}{ Parâmetros } \\
\hline & Objetos & $\begin{array}{l}\text { População } \\
\text { Mensagens }\end{array}$ & Trabalho & $\begin{array}{c}\text { Probabilidades de } \\
\text { Navegacão } \\
\text { (frente/atrás'direita/esquerda/próprio) }\end{array}$ \\
\hline M1 & 10000 & 20000 & $0 \times 0$ & $20,20,20,20,20$ \\
\hline M2 & 10000 & 40000 & $0 \times 0$ & $20,20,20,20,20$ \\
\hline M3 & 15000 & 15000 & $0 \times 0$ & $20,20,20,20,20$ \\
\hline M4 & 15000 & 15000 & $0 \times 0$ & $5,5,5,5,80$ \\
\hline
\end{tabular}

Tabela 4.2 Modelos do Grupo Memória (retirada de Voorsluys, 2006)

No grupo memória percebe-se, assim como no grupo rede, o parâmetro "Trabalho" zerado, isso ocorre pelo mesmo motivo do anterior. Neste grupo observam-se modelos que possuem grande numero de objetos visando uma grande utilização da memória.

\begin{tabular}{|c|c|c|c|c|}
\hline \multirow[b]{2}{*}{ Modelo } & \multicolumn{4}{|c|}{ Parâmetros } \\
\hline & Objetos & $\begin{array}{l}\text { População } \\
\text { Mensagens }\end{array}$ & Trabalho & $\begin{array}{c}\text { Probabilidades de } \\
\text { Navegação } \\
\text { (frente/atrás/direita/esquerda/próprio) }\end{array}$ \\
\hline C1 & 1000 & 2000 & $50 \times 0$ & $20,20,20,20,20$ \\
\hline $\mathrm{C} 2$ & 1000 & 2000 & $50 \times 50$ & $20,20,20,20,20$ \\
\hline $\mathrm{C3}$ & 1000 & 2000 & $50 \times 25$ & $20,20,20,20,20$ \\
\hline $\mathrm{C4}$ & 5000 & 10000 & $50 \times 0$ & $20,20,20,20,20$ \\
\hline $\mathrm{C5}$ & 5000 & 10000 & $50 \times 50$ & $20,20,20,20,20$ \\
\hline C6 & 5000 & 10000 & $50 \times 25$ & $20,20,20,20,20$ \\
\hline $\mathrm{C7}$ & 5000 & 20000 & $50 \times 0$ & $20,20,20,20,20$ \\
\hline C8 & 5000 & 20000 & $50 \times 25$ & $20,20,20,20,20$ \\
\hline
\end{tabular}

Tabela 4.2 Modelos do Grupo CPU (retirada de Voorsluys, 2006) 
No grupo CPU, os modelos possuem uma grande diversificação na configuração do parâmetro "trabalho", sendo o mais significativo, já que é nele que se define o grau de processamento do modelo especificado.

Nesta seção foram apresentados os modelos utilizados no trabalho de Voorsluys (Voorsluys, 2006), a seguir são apresentados resultados obtidos na simulação destes modelos.

\subsection{Resultados obtidos}

Serão apresentados nesta seção alguns resultados obtidos por meio de experimentos realizados em um ambiente dedicado. A intenção de ilustrar o trabalho de Voorsluys (Voorsluys, 2006) e reforçar que as políticas utilizadas por ela também foram aplicadas nos testes do capitulo 6 desta dissertação, tem o intuito de fazer uma avaliação completa e oferecer uma comparação entre as políticas Round Robin, tradicionais (sistemas distribuídos em geral), e as duas novas políticas apresentadas no capitulo 5 desta dissertação. No trabalho de Voorsluys, foram utilizados benchmarks das máquinas com o intuito de auxiliar no particionamento dos objetos. As máquinas utilizadas nos testes com suas características são apresentadas na figura 4.1 .

\begin{tabular}{|c|c|c|}
\hline Máquina & ID & Configuraçōes \\
\hline Lasdpc14 & 3 & AMD Duron 1.2 Ghz Cache 64 KB 256 MB RAM HD \\
\hline Lasdpc15 & 2 & Pentium 4 2.0 Ghz Cache 256 KB 256 MB RAM HD \\
\hline Lasdpc16 & 1 & Pentium 3 600 MHz Cache 64 KB 256 MB RAM HD \\
\hline Lasdpc17 & 0 & AMD Athlon XP 2000+ 1.6 Ghz Cache 256 KB 256 MB RAM HD \\
\hline
\end{tabular}

Figura 4.1 Máquinas utilizadas nos testes.

\subsubsection{Políticas Baseadas em valores de Benchmarks}

Os experimentos foram realizados com a rede isolada e as máquinas disponíveis apenas para os testes. Foram realizados três grupos de teste, baseados em aplicações que utilizam fundamentalmente: rede, memória e CPU. A política de escalonamento tradicional utilizada baseia-se no benchmark considerado como mais adequado para cada tipo de modelo distinto (Voorsluys, 2006). 


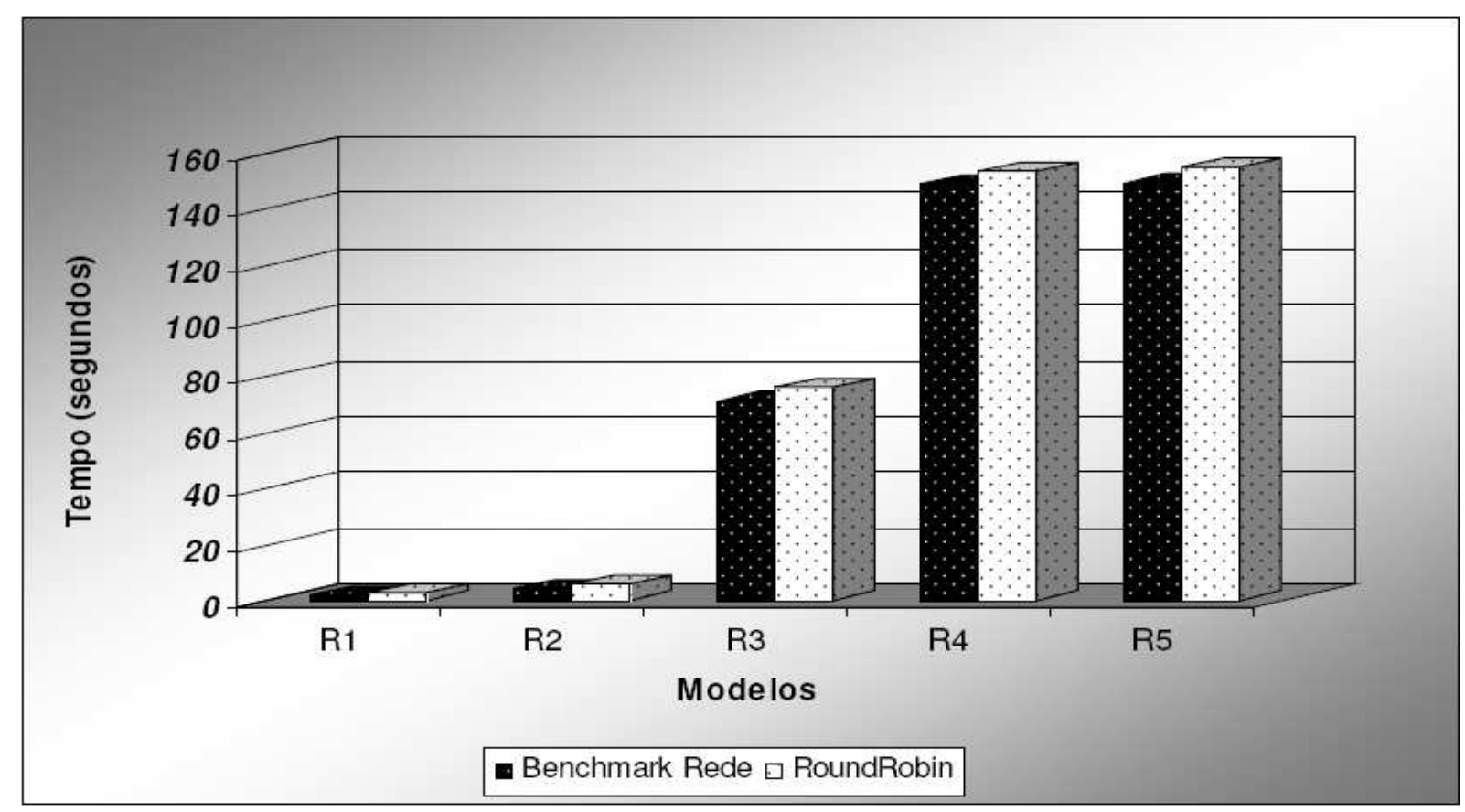

Figura 4.2 Comparativo do tempo total de execução dos modelos do grupo rede.

(retirada de Voorsluys, 2006)

Nas figuras 4.2 e 4.3 são apresentados, através de gráficos comparativos, o desempenho de modelos com características do grupo rede, a política tradicional utilizada foi baseada no benchmark de rede.

As colunas pretas representadas nos gráficos correspondem à execução de modelos cuja política baseou-se em informações do benchmark de rede e as colunas brancas representam à utilização da política que particiona os objetos igualmente entre os computadores (Round Robin) usando os mesmos modelos do primeiro. 


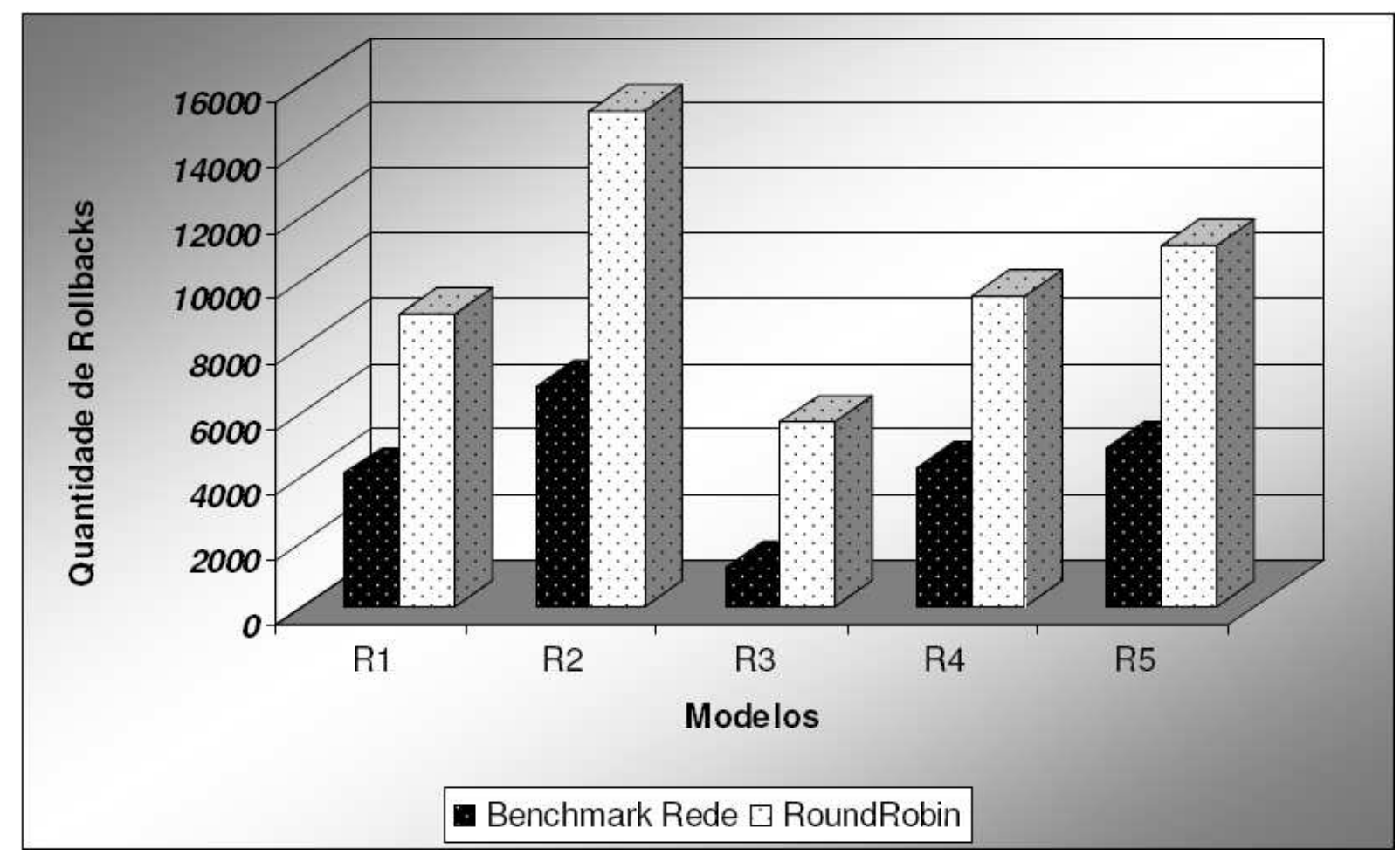

Figura 4.3 Comparativo da quantidade de rollbacks durante a execução dos modelos do grupo rede. (retirada de Voorsluys, 2006)

A figura 4.3 apresenta um gráfico que compara a quantidade de rollbacks em cada modelo já especificado anteriormente. É possível observar que a quantidade de rollbacks na utilização de round-robin (colunas brancas), foi efetivamente superior ao caso onde foi usado o particionamento que considerou as informações do benchmark (colunas pretas). É percebida no modelo R3, a mais significativa redução de rollbacks de todos os outros 78,9\%, considerando também que os demais obtiveram uma considerável redução de $55,6 \%$ em média (Voorsluys, 2006).

Os modelos deste grupo são diferentes entre si tanto em quantidade de objetos quanto no tamanho da população de mensagens. Pode-se perceber que o uso de uma política contendo informações da plataforma utilizada tem uma influência considerável na redução de rollbacks. Como a política utilizada proporcionou um balanceamento de carga mais eficiente, a progressão dos objetos foi feita de maneira uniforme diminuindo desta forma a quantidade de rollbacks (Voorsluys, 2006).

Nos próximos dois gráficos (figura 4.4, figura 4.5) são apresentados os desempenhos obtidos, em tempo e quantidade de rollbacks com modelos pertencentes ao grupo memória. 


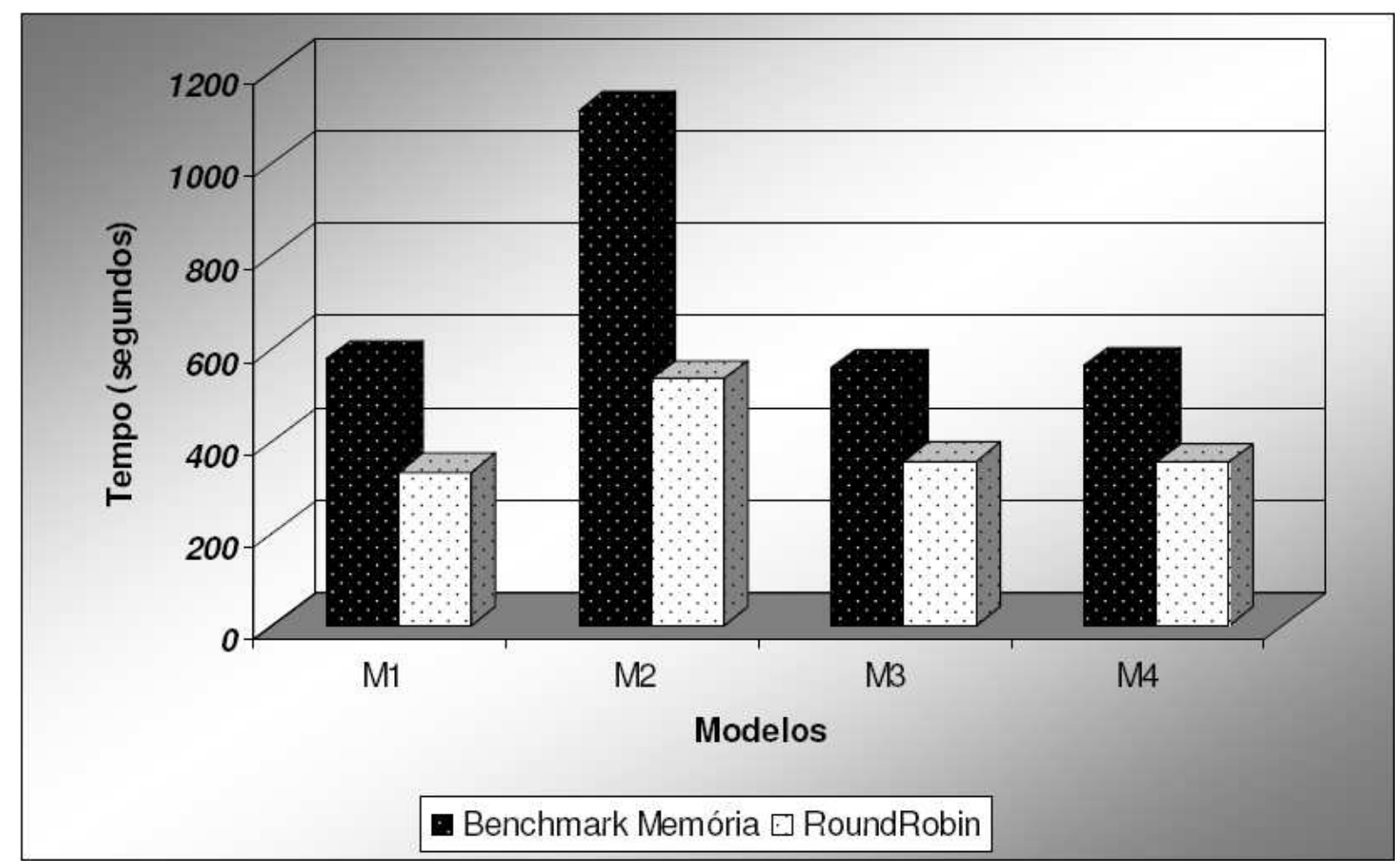

Figura 4.4 Comparativo do tempo total da execução dos modelos do grupo memória.

(retirada de Voorsluys, 2006)

Observando-se os gráficos percebe-se que os resultados obtidos por Voorsluys utilizando o benchmark de memória na heurística da política adotada não foram satisfatórios. Em todas as simulações desse grupo a eficiência do round-robin foi superior à política que utilizou o benchmark de memória.

No gráfico apresentado na figura 4.5 pode-se observar que a quantidade de rollbacks ocorridos foi muito alta, e pode ser afirmado que os resultados do tempo e da eficiência foram diretamente afetados por essa situação. Analisando-se os resultados relativos ao rollback, pode-se observar o impacto acentuado da política utilizada. Por exemplo, o "melhor caso", entre as execuções dos modelos (coluna branca) desse grupo, sofreu 45.265 rollbacks a mais que a execução do mesmo modelo com round-robin. No pior caso este número chega em 265.812 rollbacks a mais (Voorsluys, 2006). 


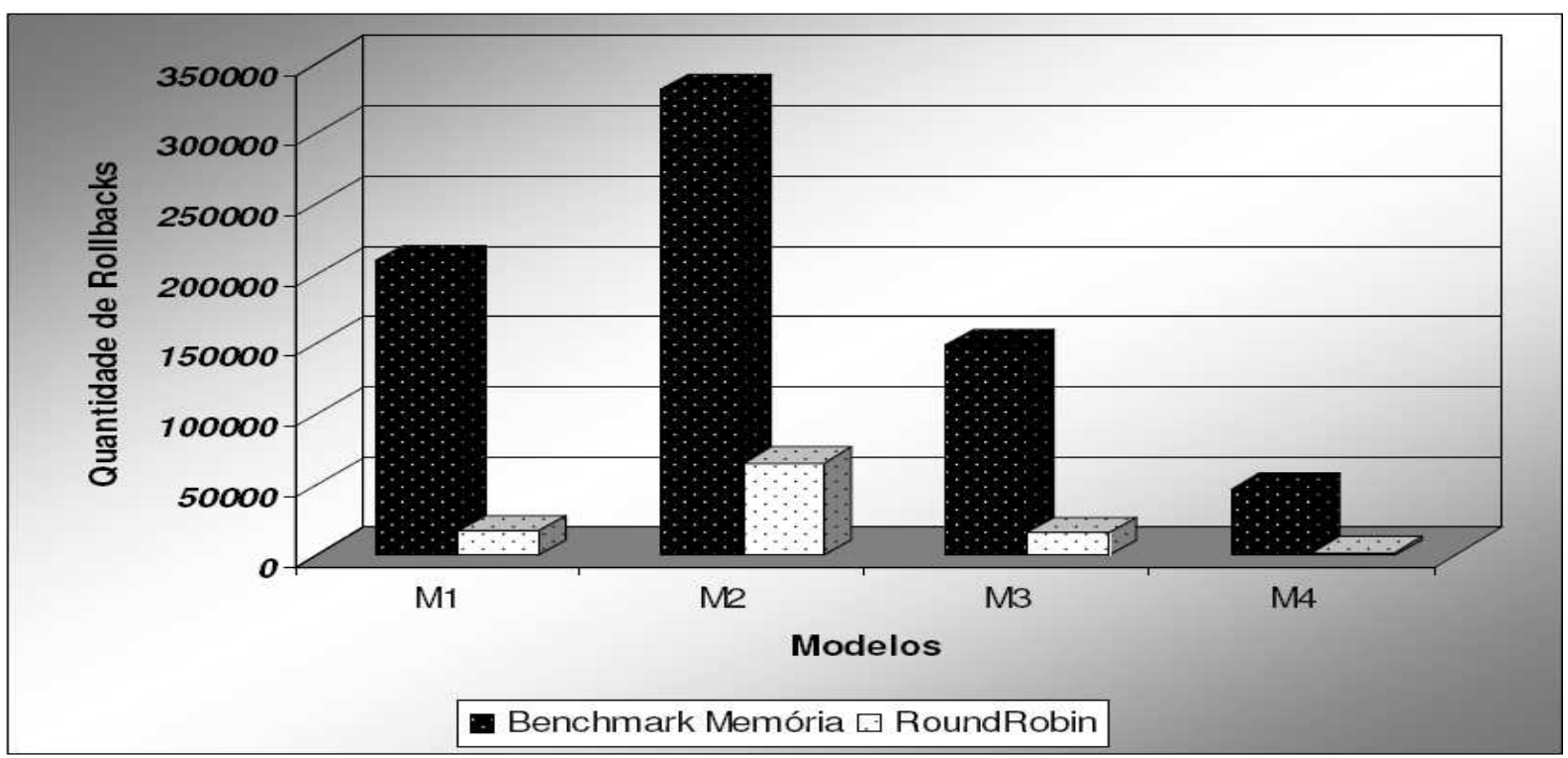

Figura 4.5 Comparativo da quantidade de rollbacks ocorridas na execução dos modelos do grupo memória. (retirada de Voorsluys, 2006)

O gráfico da figura 4.6 mostra os tempos de execução do Grupo $C P U$. Percebe-se uma redução do tempo final de execução quando utilizado o escalonamento baseado no benchmark $C P U$, exceto os modelos $\mathrm{C} 7$ e C8. A redução média entre os modelos do grupo $C P U$, excluindo os modelos $\mathrm{C} 7$ e C8, foi de $22,8 \%$ no total comparado ao obtido com Round-Robin.

Na figura 4.7 percebem-se resultados expressivos no grupo $C P U$, a redução de $88 \%$ (modelo C1) caracterizou-se como o melhor caso. Já no modelo C7 ocorreu o menor ganho, $25 \%$ de redução. Obtendo este grupo a expressiva média de $53,4 \%$ de redução de rollbacks.

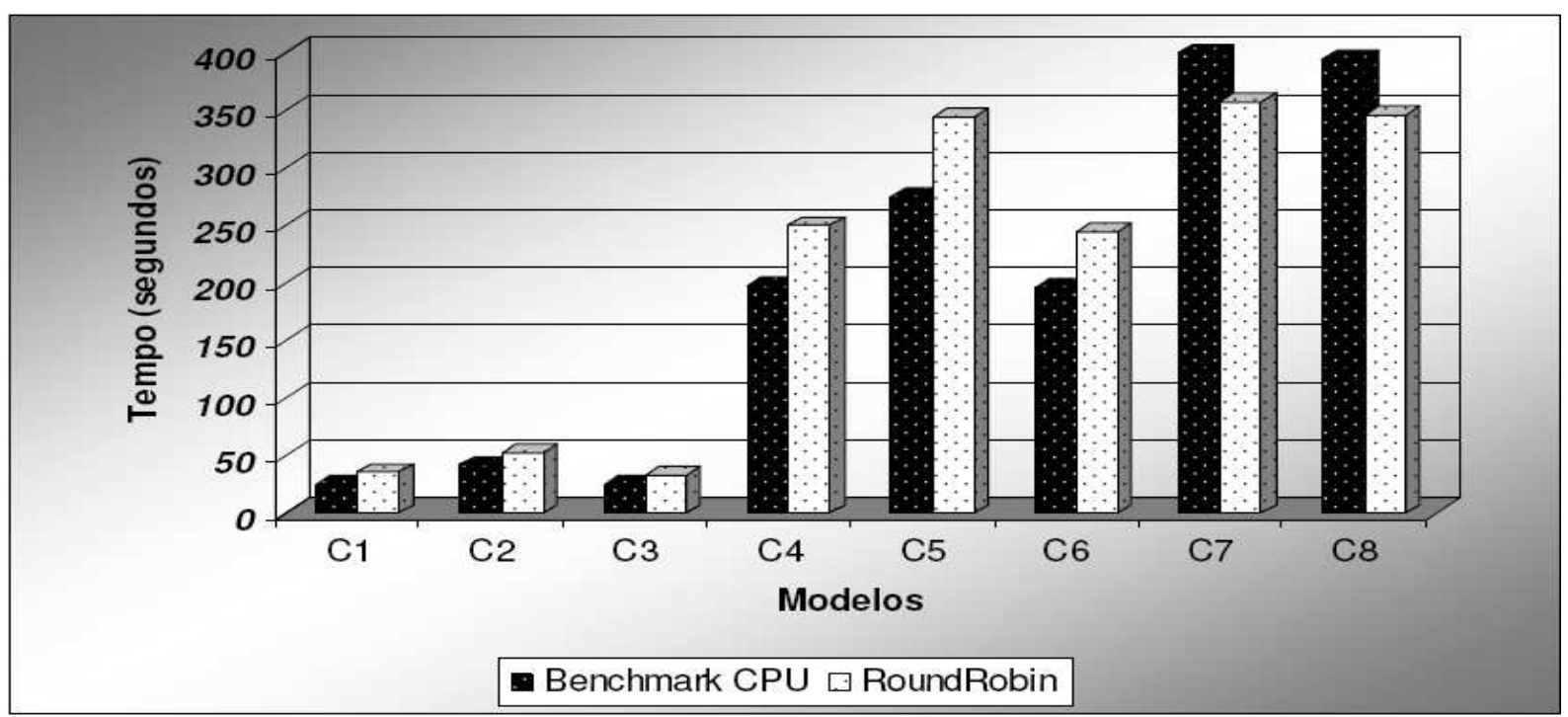

Figura 4.6 Comparativo do tempo total de execução do grupo CPU.

(retirada de Voorsluys, 2006) 


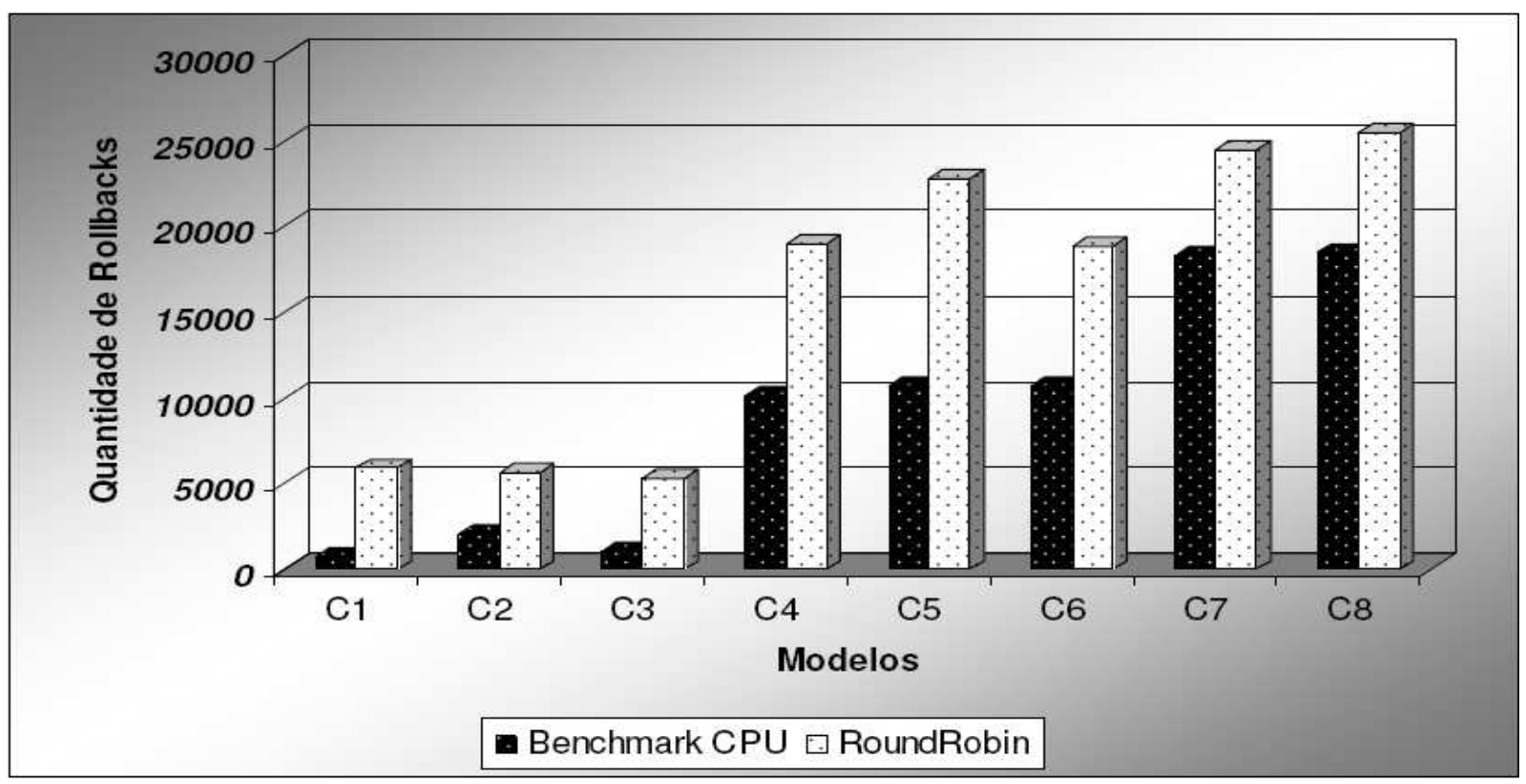

Figura 4.7 Quantidade de rollbacks ocorridas no grupo CPU. (retirada de Voorsluys, 2006)

\subsection{Considerações finais}

Existia nos estudos de escalonamento de processos em SD uma lacuna aberta e o trabalho de Voorsluys a preencheu. Foi mostrado neste capítulo, através da pesquisa realizada por Voorsluys, que existe a possibilidade de se ter um serviço de qualidade considerando apenas informações estáticas da plataforma para escalonar processos em uma simulação distribuída. Dependendo dos objetivos e do tempo do usuário para a execução da simulação foi demonstrado que é interessante o uso de políticas tradicionais que ignoram características da simulação.

Nesta seção percebe-se que é adequado o uso de políticas convencionais principalmente se não se dispõe de tempo para desenvolvimento de uma nova política e também quando faltam os conhecimentos necessários para sua implementação.

Assim, o trabalho apresentado nesta dissertação (capitulo 6) avaliando o desempenho de escalonamento utilizando duas novas políticas, que serão apresentadas no capítulo 5, e comparando-as com a técnica de escalonamento apresentadas por Voorsluys (Voorsluys, 2006) contribuirá para a avaliação de políticas de escalonamento para execução de simulações distribuídas. 


\section{Proposta de novas Políticas}

\subsection{Considerações iniciais}

Existem na literatura trabalhos que apresentam políticas de escalonamento específicas para simulação distribuída otimista, como as apresentadas no capitulo 3 desta dissertação. Entretanto, em alguns casos, suas implementações são ineficientes quando as características de transmissão de dados pela rede e a capacidade de processamento do sistema não são adequadas. $\mathrm{O}$ caso das políticas que utilizam migração de processos é um exemplo que requer recursos especiais para obtenção de bons resultados. Essas políticas além de consumir processamento para cálculo e verificação do reajuste da carga em tempo de processamento da simulação, sobrecarregam a rede com a migração dos processos.

Outras duas políticas específicas, comentadas no capítulo 3, que não utilizam migração de processos são: algoritmos probabilísticos (Som \& Sargent, 1998) e Heurística de Mapeamento (Som \& Sargent, 1993). A primeira possui um algoritmo de alta complexidade de implementação e exige uso de processamento para o escalonamento em tempo de execução, ou seja, a simulação concorre com a política de escalonamento pelo uso do processador. A segunda pertence à classe de políticas que fazem o escalonamento em tempo de mapeamento, não utilizando processamento para cálculo e distribuição das cargas em tempo de execução. Nesse caso, a técnica para previsão de quais processos lógicos possuem maior chance de apresentarem rollbacks é de alta complexidade. Concluindo, ambas as técnicas, apesar de eficientes, possuem uma complexidade de implementação que pode inviabilizar a execução da simulação.

As duas novas políticas apresentadas nesta dissertação possuem características que diferem das demais em três pontos fundamentais. O primeiro ponto refere-se aos cálculos das cargas a serem distribuídas no sistema e ao escalonamento dos processos que não concorrem com a simulação pelo uso do processador. O escalonamento dos processos e a execução da 
simulação ocorrem em momentos distintos. O segundo ponto que diferencia a política proposta é a facilidade de implementação, já que o cálculo da métrica apresentada e a manipulação de dados da simulação não são tão complexos quanto às demais políticas. $\mathrm{O}$ terceiro ponto de destaque nas novas políticas desenvolvidas é a nova abordagem apresentada, que permite a obtenção dos dados relacionados a carga imposta pelos processos lógicos com dados reais, possibilitando a obtenção não somente uma previsão, mas uma real noção do comportamento do modelo simulado, possibilitando um escalonamento dos processos mais eficiente.

Apesar de diversos trabalhos discutirem algoritmos de escalonamento específicos para simulação distribuída e desses trabalhos possuírem objetivos semelhantes, há diferenças tanto na abordagem utilizada quanto na forma em que essas abordagens são empregadas. Cabe destacar que praticamente todas as abordagens propostas podem trazer benefícios para a simulação, desde que empregadas nas condições apropriadas.

A maioria dos trabalhos que avaliam a utilização de algoritmos de escalonamento para simulação distribuída apresenta comparações entre o tempo de execução utilizando a política Round Robin para escalonamento dos processos lógicos e o tempo utilizando um algoritmo específico. O trabalho de Voorsluys (Voorsluys, 2006) apresenta uma abordagem diferente, avaliando uma política tradicional de escalonamento (Round Robin) com outras políticas de propósito geral para sistemas distribuídos, cobrindo assim uma lacuna que existia na literatura.

Mas ainda existe um nicho em avaliação de políticas para simulação distribuída, que é comparar os resultados de políticas de propósito geral, como os obtidos no trabalho de Voorsluys (Voorsluys, 2006), com políticas específicas para simulação distribuída.

As políticas propostas neste trabalho são comparadas com políticas de propósito geral, diferentes de Round Robin. Assim, investigam-se as situações em que os algoritmos tradicionais fornecem um serviço melhor, ou equivalente, que as políticas específicas para SD propostas e quando a utilização de políticas que consideram as características da simulação distribuída é mais atraente.

Nos casos em que as políticas de propósito geral oferecem um resultado semelhante ao de políticas específicas, as primeiras devem ser escolhidas, uma vez que oferecem maior flexibilidade e facilidade de uso, visto que estarão mais facilmente disponível em diferentes 
sistemas. Desta forma, é importante identificar em que casos as políticas específicas atingem melhores resultados e devem ser adotadas.

As plataformas de uso geral não são dotadas de algoritmos de escalonamento específicos para simulação, mas sim de algoritmos convencionais que tem vantagens comprovadas com aplicações paralelas. As informações obtidas nesse estudo comparativo, onde serão analisadas diferentes situações e aplicações, ajudarão a identificar os casos em que a flexibilidade dos algoritmos convencionais deve ser valorizada, e os casos em que deve-se enfocar no desempenho utilizando-se as políticas específicas.

Nesse contexto, foi desenvolvida neste trabalho uma nova concepção no tratamento de dados para um melhor escalonamento dos processos e apresentada duas novas políticas de escalonamento para simulação distribuída. Neste capítulo, as duas políticas propostas são apresentadas e discutidas.

\subsection{Desenvolvimento das Políticas}

O funcionamento da política de propósito geral implementada por Voorsluys (Voorsluys, 2006) baseia-se em dar notas aos processadores através de resultados de benchmarks que são executados previamente em cada máquina a ser utilizada. Em uma segunda fase, adota-se um escalonamento baseando-se nas notas obtidas com os benchmarks. As simulações são executadas diversas vezes até obter-se um resultado com a margem de erro desejada. No trabalho de Voorsluys as simulações foram repetidas 15 (quinze) vezes.

Considerando o procedimento para obtenção de resultados confiáveis, descrito no parágrafo anterior, e o objetivo de implementar uma política específica para SD (Simulação Distribuída) que apresentasse um melhor desempenho que as tradicionais, optou-se por captar os dados da primeira execução da simulação e, baseando-se nas características observadas na primeira execução, substituir o escalonamento original. Dessa forma, os algoritmos de escalonamento a serem considerados nesta dissertação baseiam-se nas seguintes etapas:

I. Executar uma vez a simulação de um determinado modelo utilizando um algoritmo de escalonamento de propósito geral. Essa simulação será referenciada como simulação base.

II. Coletar dados da simulação. 
III. Determinar novo escalonamento para os processos lógicos, baseando-se nos resultados coletados.

IV. Executar as repetições necessárias da simulação.

O maior desafio é encontrar quais características da simulação seriam coletadas no passo II e como cada uma seria utilizada para determinar o novo escalonamento no passo III. Os valores obtidos serão utilizados para definir a carga que deverá ser imposta a cada processador (isso é, número de processos lógicos) e assim fazer uma melhor distribuição da carga no sistema. Pretende-se no decorrer deste capítulo, apresentar algumas formas de como os dados obtidos de uma simulação base podem ser utilizados e avaliar a adequabilidade da forma de utilização proposta.

Para avaliar as propostas levantadas durante o estudo realizado foi utilizada a metodologia e as ferramentas apresentadas na seção 5.2.1. A seção 5.2.2 apresenta os estudos realizados e as justificativas para as métricas propostas. A apresentação da proposta final das duas políticas a serem avaliadas encontra-se na seção 5.3.

\subsubsection{Metodologia para Avaliação das Políticas Propostas}

O modelo sintético PHOLD, inserido no núcleo do simulador Warped por Voorsluys, serviu de base para a implementação das duas políticas utilizadas nos testes para esta dissertação. Depois de um estudo minucioso do núcleo do simulador Warped e do modelo PHOLD, optou-se por não fazer modificações no núcleo do simulador com o intuito de mantê-lo o mais próximo do utilizado por Voorsluys (Voorsluys, 2006), viabilizando a comparação das conclusões deste trabalho com as do trabalho anterior.

O Warped oferece 14 informações sobre a execução das simulações em arquivo, tais como:

- Tempo Total da Simulação;

- Quantidade de Eventos Processados;

- Quantidade de eventos desfeitos por rollback;

- Quantidade de eventos consolidados (não desfeitos); 
- Quantidade total de rollbacks;

- Quantidade de rollbacks primários e secundários;

- Tempo útil que foi gasto com processamento de eventos consolidados

- Tempo gasto com rollbacks;

- Eventos processados por segundo;

- Eventos consolidados por segundo do tempo útil e total;

- Tempo de espera por mensagens;

- Rollbacks causados por máquina.

Estes dados são suficientes para captar as informações necessárias, e calcular as novas notas de benchmark e depois através de um código em shell script fazer as 15 execuções do mesmo modelo com as novas cargas. Um modo conhecido de captar informações, fazer cálculos e manipular arquivos sem a necessidade de alterações no código do simulador, que é escrito em C++ e necessita de compilação, é a utilização de scripts. Assim optou-se pela utilização da linguagem de programação Python para implementação das políticas utilizadas neste trabalho.

Para otimizar a coleta das informações das 15 repetições foi criado outro script para coleta dos resultados e criar um arquivo já com as médias e desvios padrões referente a execução de um determinado modelo da simulação. Esse script identifica automaticamente a quantidade de repetições e faz os cálculos de forma automatizada. Desta forma todo ciclo de execução da simulação como: captação dos dados, cálculos das métricas, execução das políticas de escalonamento, balanceamento das cargas, captação de informação, tratamento das informações e armazenamento de todos os dados é feito automaticamente sem nenhum tipo de alteração no núcleo do simulador, garantindo que os dados são gerados pelo mesmo núcleo utilizado no trabalho de Voorsluys (Voorsluys, 2006). 


\subsubsection{Determinação da nova métrica}

Nesta seção são apresentados o desenvolvimento e as justificativas para as métricas propostas nesta dissertação. Os resultados apresentados na figura 5.1 e que representam os dados obtidos da execução de uma simulação base serão utilizados em toda seção visando facilitar o entendimento. No desenvolvimento da métrica inicialmente, verificou-se quais dados podem ser captados do arquivo de respostas do simulador Warped (fig. 5.1).

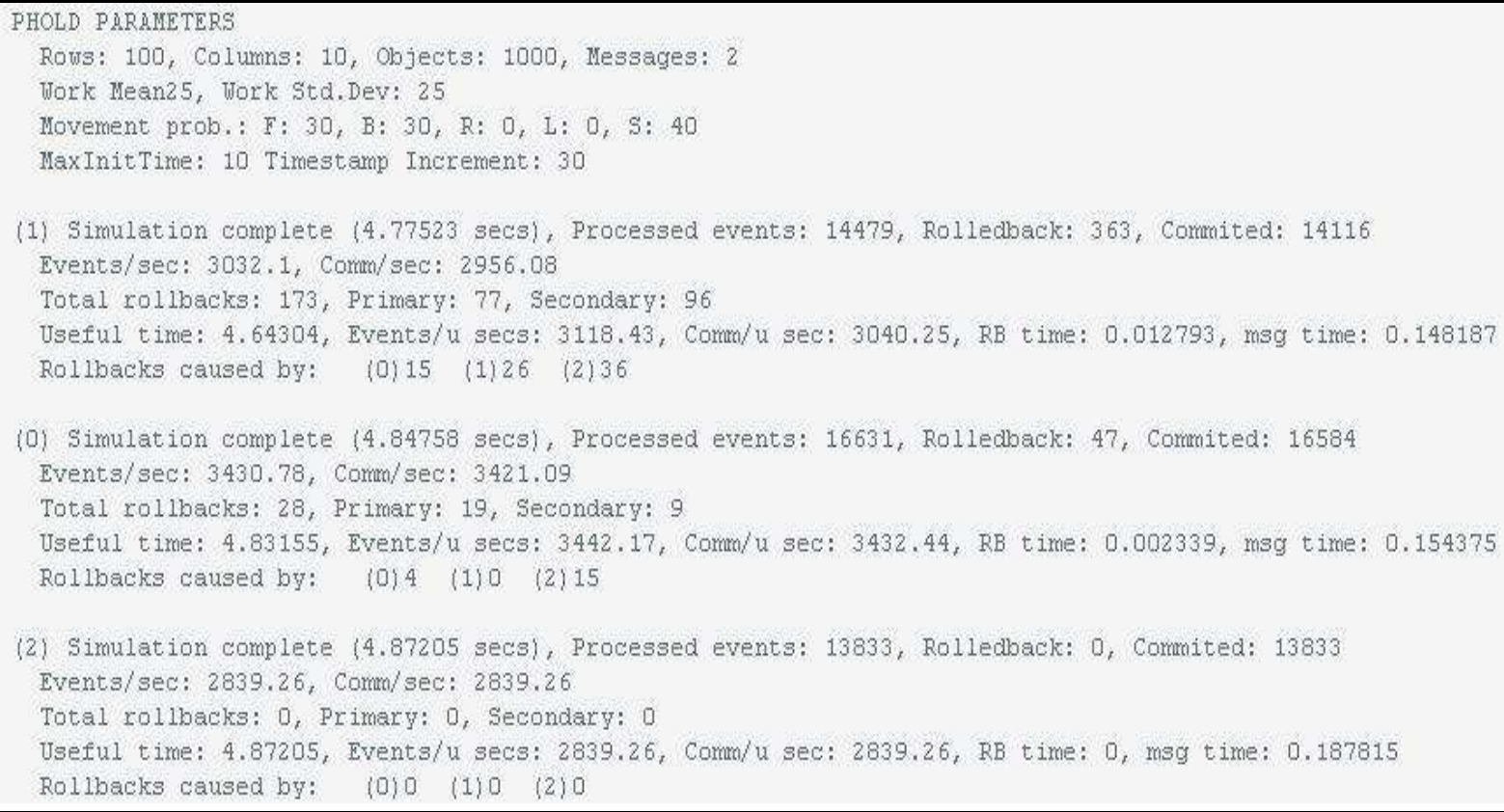

Figura 5.1 Arquivo de respostas do simulador Warped.

Primeiramente, tem-se a necessidade de encontrar entre todos os processadores, o que obteve maior número de rollbacks. No arquivo de respostas, os dados referentes a cada processador são apresentados na frente do número correspondente ao nó do cluster. Como exemplo pode-se citar o resultado obtido em uma simulação base apresentado na figura 5.1. Nota-se que o processador 1 (P1) possui um total de rollbacks (TR) maior que os demais (173), podendo-se assim afirmar que P1 está executando mais rápido do que os demais processadores. Nos dados de P1 (fig. 5.1) depois do total de rollbacks tem-se na seqüência rollbacks primários e secundários que foram causados durante a simulação, na penúltima linha são apresentados dados sobre os tempos de simulação e na última linha os rollbacks causados em P1 por outros processadores. Para os cálculos da métrica, inicialmente interessa apenas o total de rollbacks e os rollbacks causados por outros processadores (RC). 
Depois de determinado o processador que sofre o maior número de rollbacks (P1), deve-se procurar o processador que mais causou rollbacks em P1. No caso da figura 5.1, o processador $2(\mathrm{P} 2)$ com 36 rollbacks causados $(\mathrm{RC})$ em $\mathrm{P} 1$. Em seguida divide-se $\frac{R C}{T R} \mathrm{e}$ obtêm-se um valor que, considerando os valores apresentados, ou seja, 36 (RC) dividido por 173 (TR) tem-se 0,21. A proposta inicial é que esse valor seja adicionado a nota de P1 (do arquivo de notas de benchmark), tornando assim a carga dele maior e desacelerando a sua execução.Conseqüentemente, o TR de P1 deverá ser menor nas próximas execuções.

Executando-se alguns testes percebe-se que existiam modelos em que essa política inicial funciona bem e outros que os resultados ficavam muito ruins. Os piores resultados nesse caso são os modelos de rede, que após uma análise dos resultados e da métrica utilizada constata-se uma falha esclarecida a seguir.

Considerando-se que um modelo como o de rede possua um número pequeno no total de rollbacks, por exemplo: P1 produziu um TR igual a 3, e P2 produziu um RC igual a 2 em P1, utilizando a regra $\frac{R C}{T R}$, tem-se um valor de 0,67 e esse valor é muito alto para ajustar pesos que vão até 1 (arquivo de notas de Benchmark). Ou seja, aumenta-se a carga de P1 em mais de $60 \%$. Percebe-se assim uma grande desproporcionalidade no ajuste. Uma saída para sanar este problema é inverter os resultados, ou seja, subtrair 1 pelo valor alcançado. Desta forma, reduzem-se significativamente a influência. Entretanto, o ajuste continua alto para uma distribuição de cargas mais justa. Analisando esses resultados percebe-se a necessidade de fazer um controle dos valores de TR. Após diversos testes realizados, obtém-se um bom ajuste para TR inferiores a 100. Os ajustes são apresentados a seguir:

TR $>0$ e TR $<25$ aplicam-se o valor $0,1(1 \%)$

TR $>24$ e TR $<50$ aplicam-se o valor $0,2(2 \%)$

TR $>49$ e TR $<75$ aplicam-se o valor $0,3(3 \%)$

TR > 74 aplica-se a regra de inversão do valor da métrica apresentada anteriormente

Encontrada a solução para o problema de valores pequenos de TR, o próximo ajuste na métrica surge com o intuito de melhorar o balanceamento, a idéia baseia-se em considerar, no cálculo, a quantidade de nós do cluster, podendo-se ajustar os pesos em todos os nós e não 
somente no mais rápido. Dessa forma, considerando-se os dados apresentados na figura $5.1 \mathrm{o}$ resultado do cálculo $\frac{R C}{T R}=0,21$, demonstrado anteriormente, deve ser dividido pelo número total de nós do cluster, neste caso são 3, assim calcula-se 0,21 dividido por 3 obtendo-se 0,07 . Tendo-se este resultado, a redistribuição das cargas se apresenta da forma a seguir: soma-se a P1 (processador com maior número de TR) 0,07 em sua nota de benchmark e subtrai-se o mesmo valor dos demais processadores. Obtendo-se um melhor equilíbrio no balanceamento.

Após vários testes e ajustes, tem-se uma métrica que aplicada às duas novas políticas, apresentadas na seção 5.3, apresenta um escalonamento mais justo, obtendo-se assim, como resultados apresentados no capitulo 6, um melhor balanceamento das cargas e redução dos tempos de simulação.

\subsection{As Novas Políticas}

Esta seção tem como objetivo apresentar a métrica final e as duas políticas utilizadas nos testes apresentados no capitulo 6. O foco principal dessa nova abordagem é analisar a quantidade de rollbacks ocorridos na simulação base e utilizar esses dados em uma nova métrica de balanceamento objetivando-se um melhor escalonamento da carga para cada elemento de processamento do Cluster. Obtendo-se assim uma redução de rollbacks e por conseqüência redução no tempo de simulação.

Duas abordagens são apresentadas, a diferença entre elas baseia-se na forma de balanceamento utilizado na simulação base: Round Robin ou políticas de propósito geral.

Tem-se na primeira execução da simulação (simulação base) resultados específicos de cada nó do cluster como quantidade Total de Rollbacks ocorridos e quantidade de Rollbacks causados pelos outros nós (RC). Com estes dados pode-se verificar qual nó está mais rápido, pois é este que realiza mais rollbacks (TR).

Tem-se como objetivo a redução da velocidade de processamento do nó mais rápido e aumentar proporcionalmente a velocidade dos outros nós, desse modo as cargas são distribuídas justamente evitando-se a ocorrência de rollbacks. Deve-se então calcular o ajuste nas notas de benchmark .

Inicialmente, deve-se encontrar o nó com maior número de rollbacks (TR), em seguida deve-se encontrar o maior número de rollbacks causados pelos outros nós (RC). 
O próximo passo é calcular $\frac{R C}{T R}$ obtendo-se um valor que deve ser dividido pelo número total de nós do cluster. O valor obtido deve ser somado à nota de Benchmark do nó que possui maior número de TR.

Para obter um bom balanceamento, os pesos dos outros nós necessitam também ser ajustados. Primeiramente, encontra-se o valor RC de cada nó, onde ocorre o maior número de TR sendo este dividido pelo maior TR. O resultado obtido deve ser dividido pelo número total de nós do cluster. Esse valor deve ser subtraído da nota de benchmark do nó que causou o respectivo valor de rollbacks.

Com o intuito de esclarecer algumas dúvidas pode-se apresentar um exemplo contendo um nó 2 (P2) que possui o maior número de TR na simulação base (por exemplo, 100 no total). Se o nó 0 for responsável por 30 ocorrências de Rollbacks, dividi-se 30 por 100 obtendo-se 0,30. Esse valor deve ser dividido pelo número total de nós, (por exemplo, 3). Assim o valor 0,10 deverá ser subtraído da nota de benchmark do nó 0. Dessa forma, a carga reduzirá e a velocidade de processamento aumentará.

Deve-se lembrar que a nota alterada deverá ser referente à qual política está servindo de base para o cálculo da métrica. Por exemplo, se a política for Round Robin a nota de benchmark será sempre o mesmo valor para todos os nós. Se a política for a convencional então os cálculos devem ter como base as notas dadas pelos benchmarks para cada nó.

\subsection{Considerações Finais}

Existem vários trabalhos que apresentam políticas para execução de simulação distribuída com protocolo otimista. O trabalho de Voorsluys (Voorsluys, 2006) faz uma avaliação entre a política Round Robin com políticas convencionais de sistemas distribuídos em geral e para execução das simulações foi implementado o modelo PHOLD no kernel do Warped.

No período de testes ainda com as políticas convencionais, teve-se a idéia da criação de uma nova política que utiliza dados específicos de uma determinada simulação distribuída. Após diversos ajustes e testes, foi definida uma métrica que visa à obtenção de um escalonamento mais justo e um balanceamento melhor do que utilizando as políticas convencionais. 
São apresentadas duas novas políticas utilizando a nova métrica, a primeira utiliza os pesos do Round Robin e a outra utiliza os pesos da política convencional em sistemas distribuídos.

A implementação das políticas e da coleta e armazenamento dos dados foi feita utilizando Phyton e a automatização das execuções das simulações através de shell script. Optou-se por não modificar o núcleo do simulador Warped nem do modelo sintético PHOLD para garantir que as conclusões obtidas fossem compatíveis com as obtidas por Voorsluys (Voorsluys, 2006).

Neste capitulo foram apresentados a criação, o desenvolvimento e a implementação das duas políticas de escalonamento para simulação distribuída utilizando dados específicos da simulação em execução. No próximo capitulo são apresentados os resultados e uma avaliação de desempenho dos testes feitos com as políticas Round Robin, Geral (políticas convencionais) e as duas novas desenvolvidas. 


\section{Testes E Resultados}

\subsection{Considerações iniciais}

Neste capitulo são discutidos os resultados alcançados com a execução de simulações distribuídas utilizando as duas políticas sugeridas por este trabalho, comparando-as com políticas convencionais para sistemas distribuídos. Inicialmente, os modelos que serão considerados e a plataforma que será utilizada para execução das simulações são apresentados. Na seção 6.4 são apresentados e analisados os resultados obtidos, detalhando-se o comportamento de cada política e discutindo-se em que casos é vantajosa a utilização de políticas específicas para SD.

\subsection{Definição dos Modelos}

Nos experimentos realizados utilizou-se o modelo sintético PHOLD implementado na ferramenta Warped. O PHOLD permite definir uma grande diversidade de modelos, baseando-se em formas e quantidade de comunicação, uso de CPU e número de objetos ativados. Assim, foi necessário estipular que tipos de modelos seriam considerados, objetivando satisfazer as metas deste trabalho. Os experimentos foram feitos utilizando as políticas Round Robin, as políticas convencionais para sistemas distribuídos em geral e as novas duas políticas desenvolvidas, que se beneficiam de informações especificas das simulações em execução.

Todos os testes foram feitos em um ambiente dedicado, ou seja, na execução das simulações o sistema não tem nenhum outro tipo de programa dividindo os recursos.

Os valores das notas dadas pelos benchmark são usados conforme o modelo que esta sendo utilizado. Para cada tipo de aplicação ou modelo, é usada uma nota de benchmark específica. E as novas políticas utilizam estas notas para o reajuste do balanceamento de carga 
na execução das simulações. Os modelos utilizados nestes experimentos possuem as características network-bound, cpu-bound e memory-bound.

Foram coletados vários dados dos testes executados, os mais importantes são o tempo total e a quantidade total de rollbacks que ocorreram na simulação.

Foi utilizado este modelo permite diversas configurações possibilitando uma infinidade de modelos, sendo inviável a utilização de todas elas, assim definiu-se quatro modelos cujas características são encontradas na tabela 6.1 a seguir.

\begin{tabular}{|c|c|c|c|}
\hline Modelos & Objetos & Mensagens & Processamento \\
\hline CPU & 1000 & 2000 & $50 \times 50$ \\
\hline Memória & 2000 & 2000 & $0 \times 0$ \\
\hline Rede & 1000 & 100000 & $0 \times 0$ \\
\hline CPU x Rede & 1000 & 100000 & $50 \times 50$ \\
\hline
\end{tabular}

Tabela 6.1 Modelos utilizados na execução das simulações.

Foram nestes experimentos também cruzadas informações dos benchmarks aplicando um fatorial completo, com o intuito de analisar o comportamento da simulação se as notas dadas pelos benchmarks forem invertidas. Por exemplo, pegou-se um modelo CPU-Bound e utilizou notas de Memory-Bound. Todos os cruzamentos possíveis foram feitos e testados, na tabela 6.2 encontra-se o esquema operacional dos experimentos.

\begin{tabular}{|c|c|c|c|}
\hline Notas Modelos & CPU & Memória & Rede \\
\hline CPU & O & \\
\hline Memória & & \\
\hline Rede & & & \\
\hline
\end{tabular}

Tabela 6.2 Esquema operacional dos experimentos (fatorial completo).

Com a apresentação dos modelos já expostos (tabela 6.1) e o esquema operacional dos experimentos definidos, na próxima seção é exposta a plataforma utilizada para os testes das simulações. 


\subsection{Plataforma Utilizada}

A plataforma física utilizada foi um cluster de três computadores do tipo PC's, sendo uma arquitetura MIMD com memória distribuída pertencente ao Laboratório de Sistemas Distribuídos e Programação Concorrente (LaSDPC) do Instituto de Ciências Matemática e de Computação (ICMC) da Universidade de São Paulo (USP) e executa o sistema operacional Linux.

A configuração dos computadores é distinta tornando o sistema heterogêneo que se comunica por uma rede Ethernet $100 \mathrm{Mbps}$, esta característica torna os resultados mais atraentes devido aos objetivos dos testes e para uma avaliação de desempenho coerente com as metas estabelecidas neste trabalho, que é medir a capacidade de balanceamento de carga das políticas em uma plataforma heterogênea. A tabela 6.3 especifica os computadores utilizados no cluster, a primeira coluna define o numero identificador da máquina, a segunda as características do processador, na terceira a capacidade de memória e todos os computadores estão conectados com a mesma capacidade de transferência como demonstrado na quarta coluna.

\begin{tabular}{|c|c|c|c|}
\hline Nós & Processador & Memória & Rede \\
\hline 0 & Athlon XP $1.7 \mathrm{GHz}$ & $768 \mathrm{MB}$ & $100 \mathrm{Mbps}$ \\
\hline 1 & Pentium III $500 \mathrm{MHz}$ & $256 \mathrm{MB}$ & $100 \mathrm{Mbps}$ \\
\hline 2 & Pentium IV $2.0 \mathrm{GHz}$ & $512 \mathrm{MB}$ & $100 \mathrm{Mbps}$ \\
\hline
\end{tabular}

Tabela 6.3 Especificação dos computadores do cluster utilizado.

Para avaliar a plataforma utilizada foi executado em cada máquina um benchmark específico para definir as cargas que são utilizadas pelas políticas para escalonar os processos lógicos da simulação. Na tabela 6.4 são apresentadas as notas dos benchmarks com as características cpu-bound, memory-bound e network-bound na seqüência em relação às colunas da tabela. 


\begin{tabular}{|c|c|c|c|}
\hline Nós & CPU & Memória & Rede \\
\hline 0 & 1,000 & 0,605 & 1,000 \\
\hline 1 & 0,782 & 0,473 & 0,999 \\
\hline 2 & 0,909 & 1,000 & 0,998 \\
\hline
\end{tabular}

Tabela 6.4 Notas dos benchmarks dadas aos nós do cluster utilizado.

Os benchmarks utilizados para os experimentos foram os mesmos utilizados por Voorsluys (Voorsluys,2006). Para CPU foi utilizado o SSbench, para Memória o Stream e para avaliar a rede utilizou-se Ping Pong.

\subsection{Resultados Obtidos}

Esta seção é dividida em duas outras seções, na primeira (seção 6.4.1) serão apresentados resultados dos testes executados com os modelos utilizando suas respectivas notas de benchmark, este esquema é definido por um " $\mathrm{X}$ " na tabela 6.2 e possui a definição dos modelos básicos. A segunda seção será o cruzamento das notas de benchmark com outros modelos estes esquemas são representados na tabela 6.2 por um circulo e por um triângulo.

Nos gráficos deste trabalho são apresentadas as médias de tempo e quantidade de rollbacks das quinze repetições executadas com cada modelo especificado nas seções a seguir.

\subsubsection{Modelos Básicos}

Todos os resultados são comparativos entre as políticas Round Robin (RR), políticas para sistemas distribuídos em geral (Geral), nova política específica baseada nas políticas para sistemas distribuídos em geral (SG1) e nova política específica baseada na política Round Robin (SG2).

Na figura 6.1 percebe-se que com modelos cpu-bound, a política Round Robin é a que causa maior número de rollbacks. Fica clara, no gráfico, a redução do número total de rollbacks quando utilizadas as políticas SG1 e SG2.

A política Geral reduziu na média da quantidade total de rollbacks na simulação em relação à RR em 84\%, e a SG1 reduziu ainda mais, 87\% em relação à própria Geral. 
O nó 1 foi o que obteve maior média de rollbacks seguido pelos nós 3 e 2 pela ordem. Analisando o comportamento do nó 1, a política SG1 reduziu a zero à quantidade de rollbacks causados na simulação e manteve bem baixo a média dos demais nós comprovando um perfeito balanceamento da carga.

A política SG2 como é baseada no Round Robin teve um resultado pior que o SG1, mas mesmo assim reduziu a média da quantidade de rollbacks em relação ao RR em 16\% mostrando que mesmo em menor proporção no caso da SG2, a métrica utilizada nas políticas SG1 e SG2 fazem uma melhor distribuição das cargas e por consequiência reduzindo a quantidade total de rollbacks na simulação.

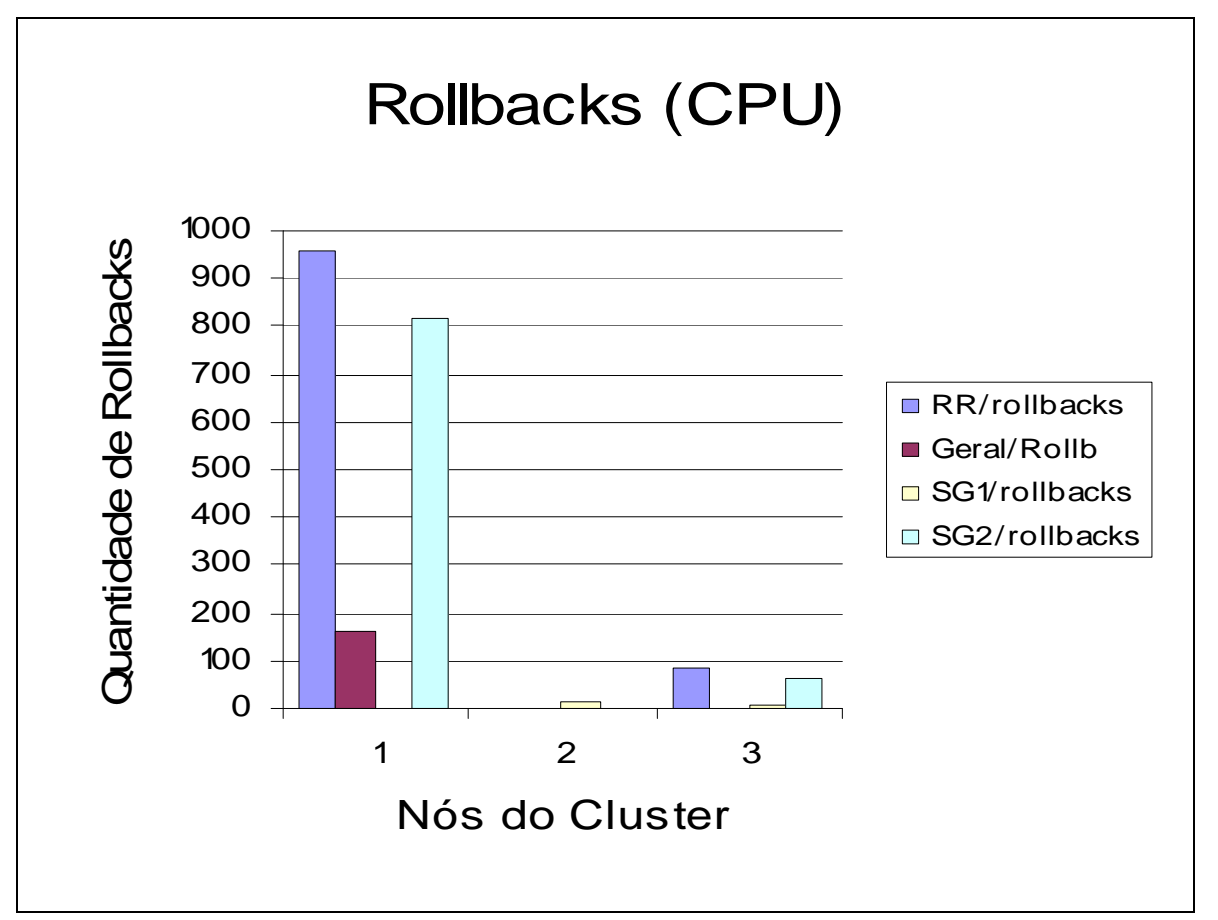

Figura 6.1 Quantidade de rollbacks ocorridos por nó no modelo CPU-Bound

Na figura 6.2 percebe-se uma redução de tempo quando aplicada à política SG1 em relação à política geral e uma pequena redução da SG2 em relação ao Round Robin.

No gráfico (figura 6.2) evidencia-se que utilizando as políticas SG1 e SG2 que garantem uma redução de rollbacks (figura 6.1) houve reflexos no tempo de execução da simulação. 


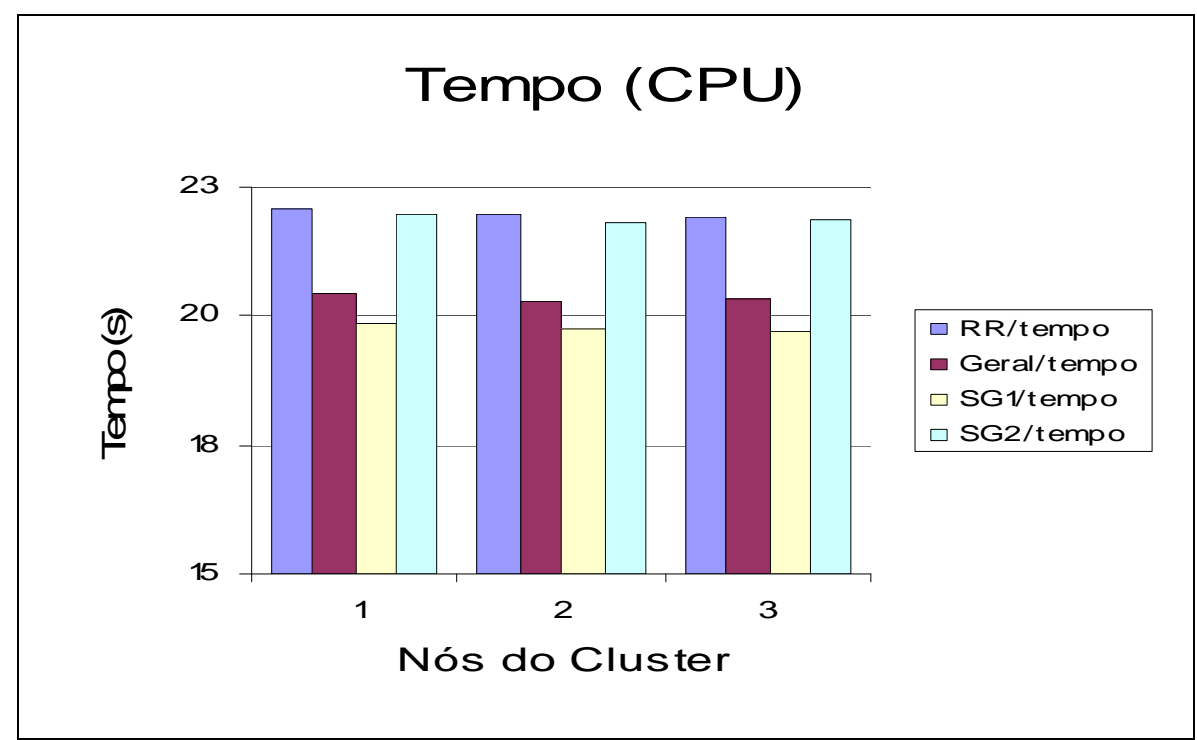

Figura 6.2 Tempos de execução em segundos por nó no modelo $C P U$-Bound

Já no modelo Memory-Bound (figura 6.3) os resultados não apresentam uma melhora na quantidade de rollbacks conforme esperado.

No trabalho de Voorsluys (Voorsluys, 2006) em nenhum modelo a política Geral consegue ser mais eficiente do que a RR. Neste caso não foi diferente, percebe-se que o modelo memória apresentado neste trabalho, quando utilizada a política Geral a quantidade de rollbacks aumenta consideravelmente.

A utilização da política SG1 não atua como a melhor opção, ao contrário da SG2 que consegue obter uma redução de $8 \%$ na média dos rollbacks causados na simulação quando utilizada a política RR.

No modelo de memória apresentado percebe-se que quando utilizada a política SG2, que se baseia nas cargas do Round Robin, obtêm-se o menor número de rollbacks das quatro políticas avaliadas. 


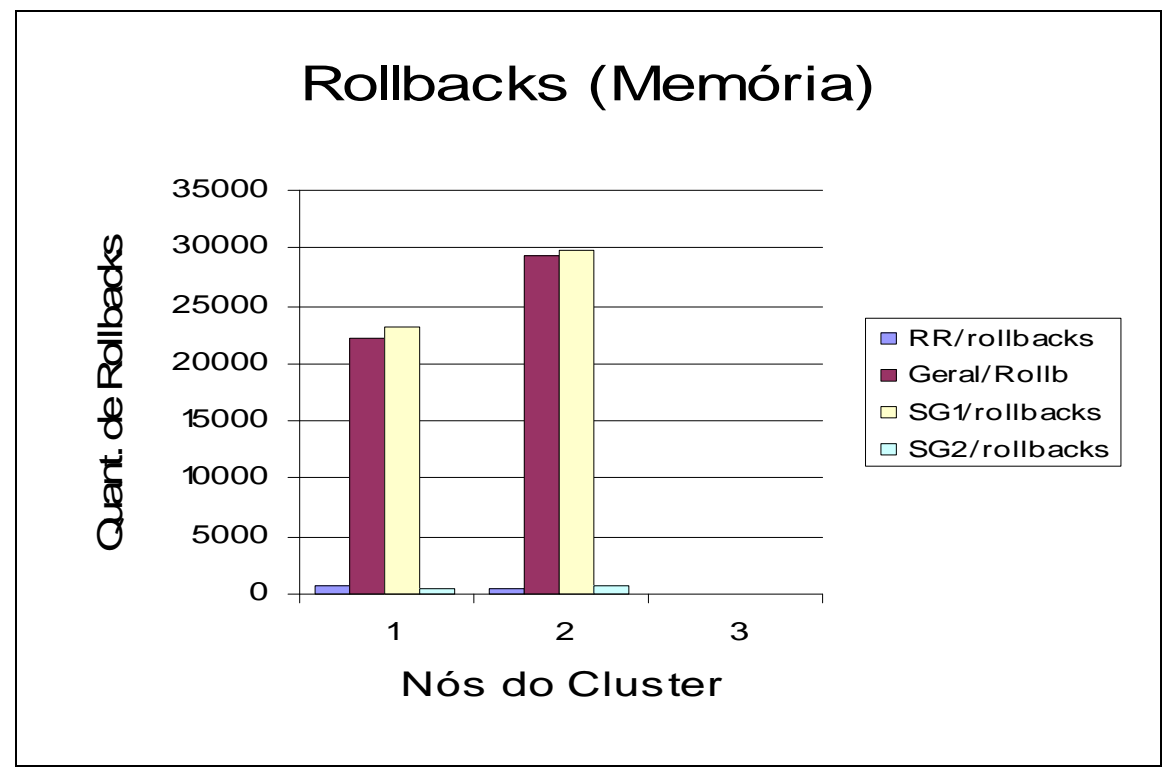

Figura 6.3 Quantidade de rollbacks ocorridos por nó no modelo Memory-Bound

O gráfico que expõe o tempo decorrido de simulação no modelo Memory-Bound (figura 6.4), mostra certa equivalência entre os tempos da política SG1 com política que utiliza métodos convencionais de escalonamento (Geral) e da SG2 com Round Robin. Entretanto há uma pequena redução no tempo quando aplicada a política SG2 em relação à política RR, mostrando-se a mais eficiente e constatando a importância da análise dos rollbacks ocorridos em uma simulação.

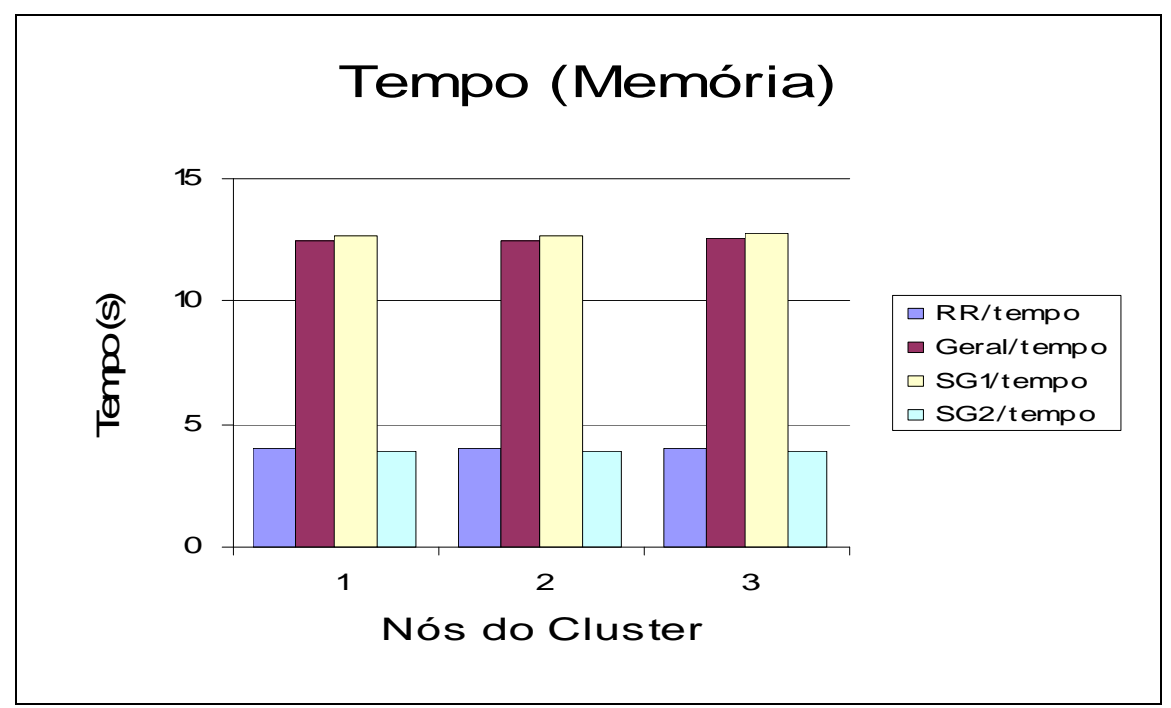

Figura 6.4 Tempos de execução em segundos por nó no modelo Memory-Bound 
Seguindo com os resultados, no modelo Network-bound, o gráfico da figura 6.5 mostra uma redução na média de rollbacks em $7 \%$ quando aplicada à política convencional para sistemas distribuídos (Geral).

Fica evidenciado também, através da figura 6.5, que a política SG1 melhora em 19\% em relação à Geral, e consequentemente se mostrando uma política mais eficiente no escalonamento do que a RR.

No modelo memory-bound, a política que mostrou maior poder de balanceamento de carga e uma redução acentuada na média do total de rollbacks ocorridos na simulação foi a SG2.

Mesmo a política SG2 empatando na média da quantidade de rollbacks totais ocorridos na simulação com a política SG1, a SG2 reduziu em $25 \%$ a quantidade de rollbacks em relação à política que usa os “pesos” como referência, que é a Round Robin.

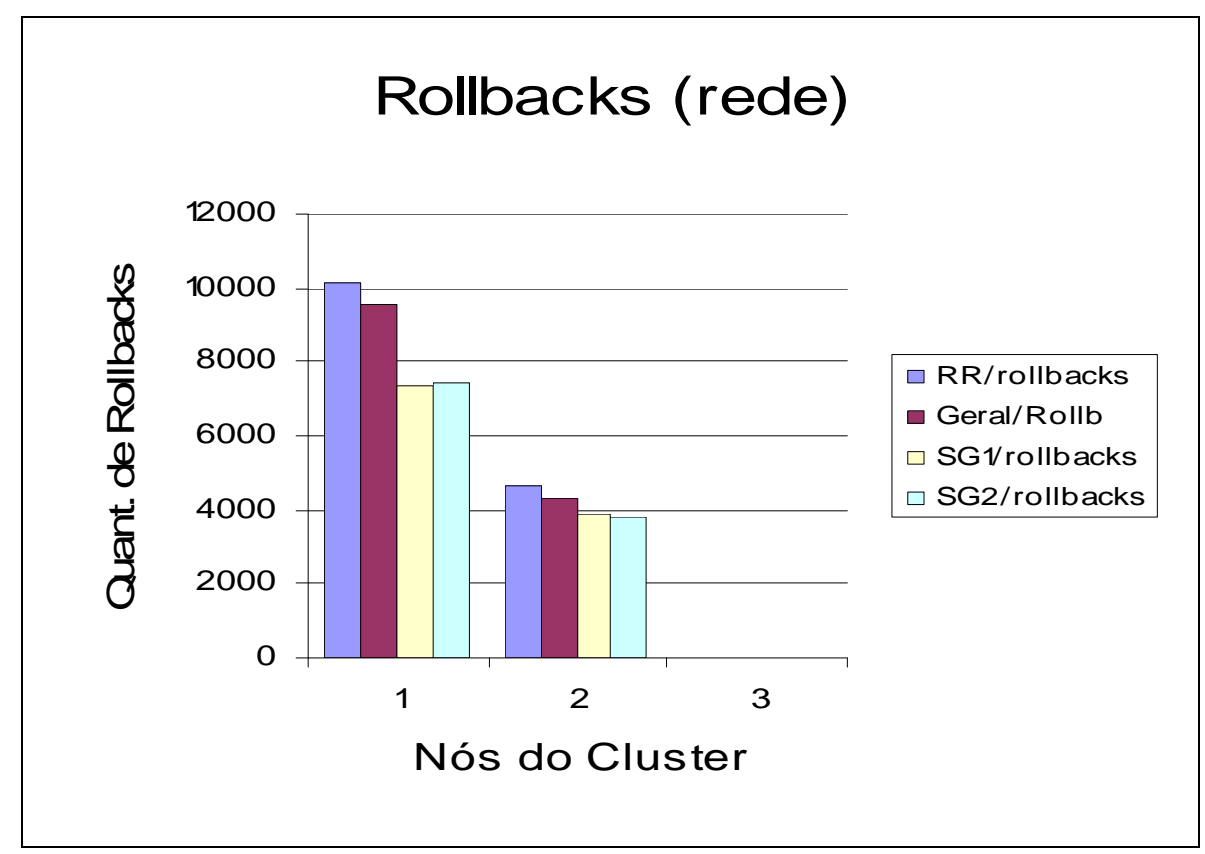

Figura 6.5 Quantidade de rollbacks ocorridos por nó no modelo Network-Bound

A figura 6.6 é mostra os resultados em tempo de simulação e verifica-se que com a redução de rollbacks exposta na figura 6.5 reduziu-se o tempo de execução de todos os nós no cluster demonstrando-se que as políticas SG1 e SG2 são mais eficientes que as demais. 


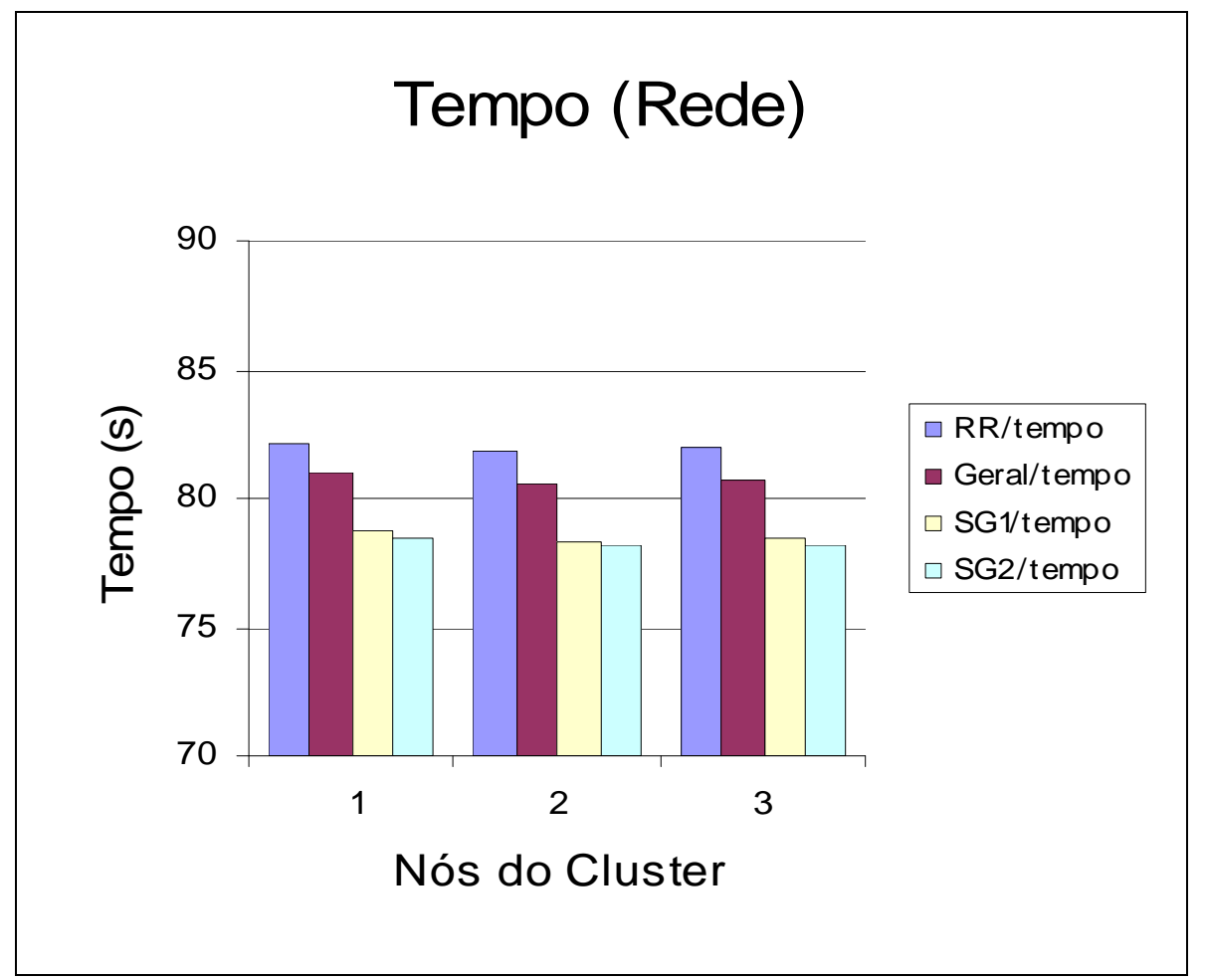

Figura 6.6 Tempos de execução em segundos por nó no modelo Network-Bound

O Modelo CPU x Rede tem como características o cruzamento das notas de benchmark de CPU com as de Rede, sendo feita uma média simples das duas notas e passadas para o arquivo de notas de benchmark.

O gráfico da figura 6.7 mostra o comportamento dos nós em relação à média da quantidade de rollbacks ocorridos na simulação. Percebe-se que o uso da política de uso geral reduz em $29 \%$ a média da quantidade de rollbacks ocorridos em relação à política Round Robin.

O uso das políticas SG1 e SG2 reduzem a quantidade de rollbacks no nó 1 e aumenta um pouco no nó 3 percebendo-se assim um balanceamento entre os nós.

A política SG1 teve um bom desempenho em relação á média do total de rollbacks ocorridos na simulação, tomando-se como referência a política que utiliza notas de benchmark para fazer o escalonamento dos processos, a SG1 reduziu em $10 \%$ esta média. A SG1 obteve a menor média de rollbacks das quatro políticas aqui avaliadas. 
A política $\mathrm{SG} 2$, em relação à política $\mathrm{RR}$, também teve um resultado satisfatório, nos testes ela reduziu em $6 \%$ a média do total de rollbacks ocorridos na simulação.

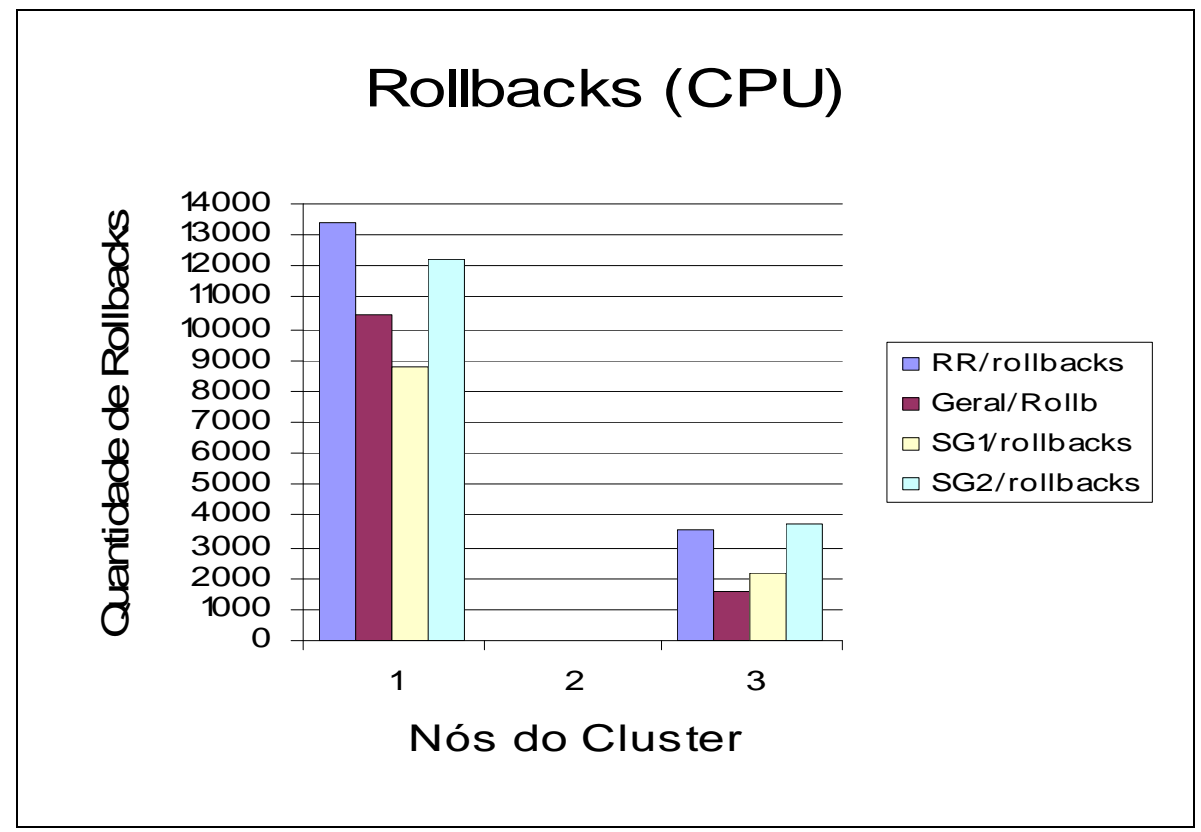

Figura 6.7 Quantidade de rollbacks ocorridos por nó no modelo CPU x Rede

$\mathrm{Na}$ figura 6.8 fica claro que o bom balanceamento das cargas que ocorre quando aplicada as políticas SG1 e SG2, como demonstrado na figura 6.7, reduziu o tempo de execução de todos os nós do cluster quando comparadas às políticas RR com SG2 e Geral com SG1.

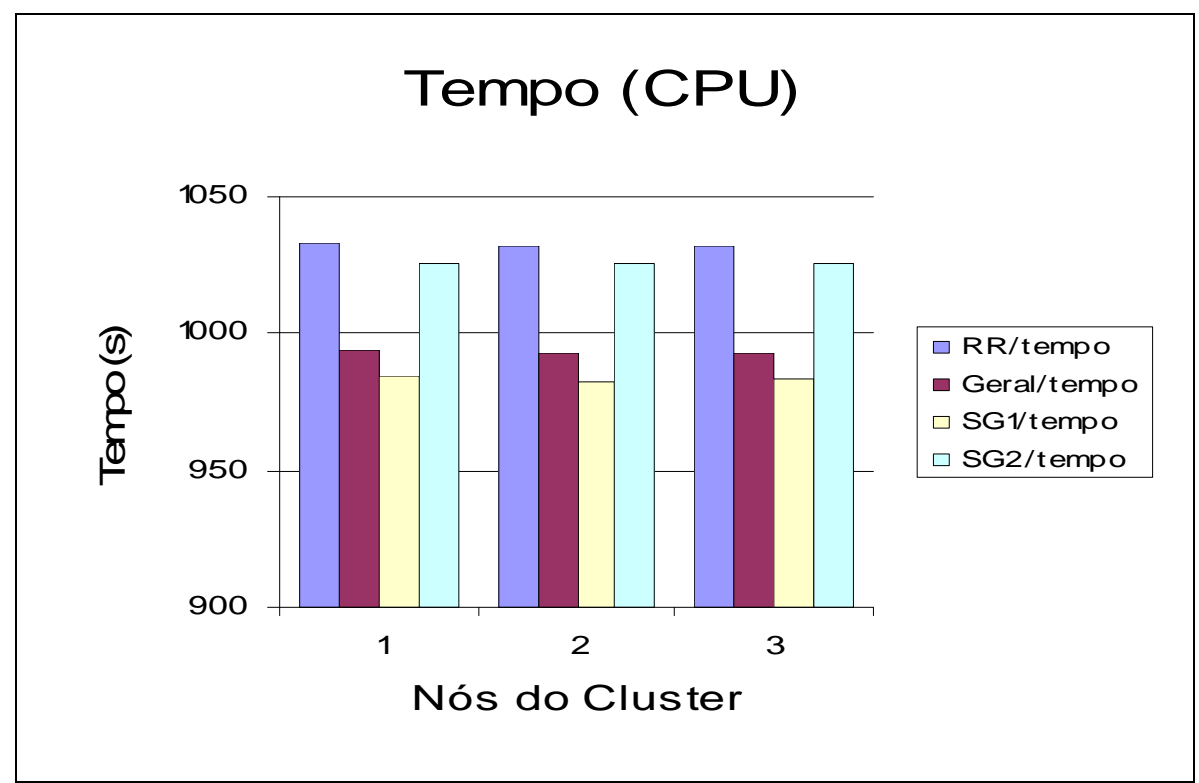

Figura 6.8 Tempos de execução em segundos por nó no modelo CPU x Rede 
Nesta seção foi mostrada que os resultados dependem muito da política a ser usada em uma simulação. O conhecimento prévio da arquitetura usada e a utilização de benchmarks para fazer o escalonamento de uma simulação distribuída mostram-se, com exceção do modelo de memória, com melhores resultados do que a utilização do modelo Round Robin.

A política SG1, cujo balanceamento parte das notas de benchmark, e a política SG2 baseada no Round Robin, mostram que conseguem no pior dos casos se equipararem ao Round Robin e a Política Geral e na maioria das vezes reduzir a quantidade de rollbacks e o tempo de simulação.

Na próxima seção serão demonstrados resultados referentes ao cruzamento de modelos com notas de benchmark conforme exposto na tabela 6.2.

\subsubsection{Modelos Cruzados}

Nesta seção serão apresentados resultados de simulações cujos modelos foram executados usando notas de benchmark diferentes das usadas na seção anterior. Na figura 6.9 é exposto o número de rollbacks ocorridos nos nós, quando executada uma simulação com modelo CPU-Bound e notas de benchmark de rede.

Observa-se no gráfico a seguir que, neste modelo, mesmo utilizando notas não compatíveis com a realidade da arquitetura, obteve-se uma redução de 5\% na média da quantidade de rollbacks da política convencional em relação ao RR.

Melhores resultados ainda foram percebidos nas políticas SG1 e SG2 que mesmo aumentando um pouco a quantidade de rollbacks no nó 3 reduziu significamente a ocorrência no nó 1 . A política SG1 reduziu em $14 \%$ a média do total de rollbacks ocorridos em relação à quando aplicada a política Geral, tendo para si o menor número de rollbacks das demais.

A SG2 teve um bom resultado sendo que a sua quantidade total de rollbacks ocorridos se aproximou muito da SG1, mas como esta política toma como referência as cargas do RR, a SG2 teve um maior poder de balanceamento neste caso, reduzindo em 16\% a média de rollbacks em relação à da política $\mathrm{RR}$. 


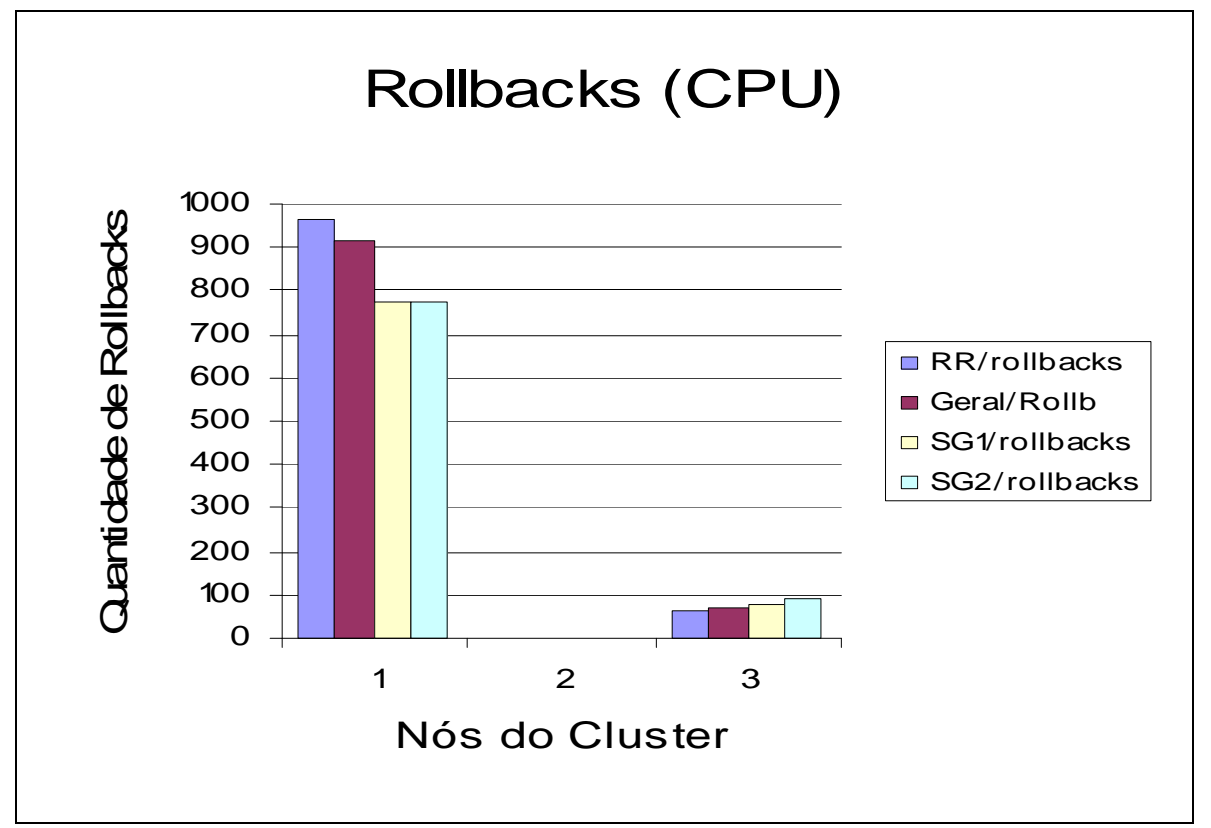

Figura 6.9 Quantidade de rollbacks ocorridos por nó no modelo CPU-Bound com notas de benchmark de rede

No gráfico a seguir (figura 6.10) demonstra mais uma vez que devido à redução de rollbacks na simulação, graças à aplicação de políticas que visam reduzir este tipo de evento, fica claro que existe, neste caso, mesmo que pequena, uma redução de tempo na execução deste modelo utilizando as políticas SG1 e SG2.

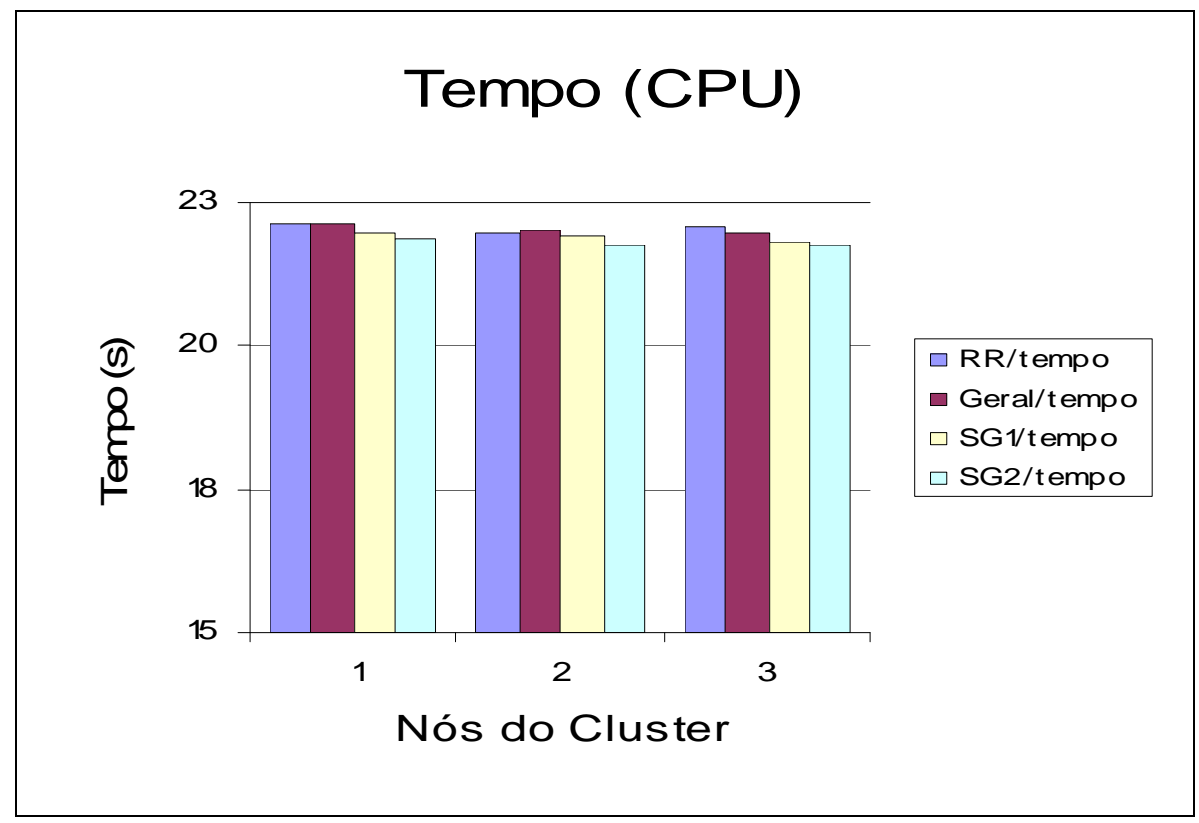

Figura 6.10 Tempos de execução em segundos por nó no modelo $C P U$-Bound com notas de benchmark de rede 
Os próximos resultados (figura 6.11) mostram o número de rollbacks causados no modelo memory-bound utilizando notas de benchmark de CPU.

Mais uma vez, como todos os testes apresentados até aqui, utilizando o modelo memory-bound, a política que utiliza notas dadas por benchmark (Geral) aumentou significamente a quantidade de rollbacks ocorridos nessa simulação. Entretanto, percebe-se que diferentemente do modelo usando notas de memória, esse modelo teve uma boa redução de rollbacks quando utilizadas as políticas SG1 e SG2.

A política SG1, quando aplicada, reduziu em $15 \%$ a média de rollbacks ocorridos na política Geral, mas como a política Geral obteve um resultado muito ruim, a SG1 não conseguiu uma média boa em relação às políticas SG2 e RR. Em compensação, como a SG2 toma por base as cargas do RR, ela conseguiu reduzir em $21 \%$ a média de rollbacks ocorridos tomando como referência a média do Round Robin.

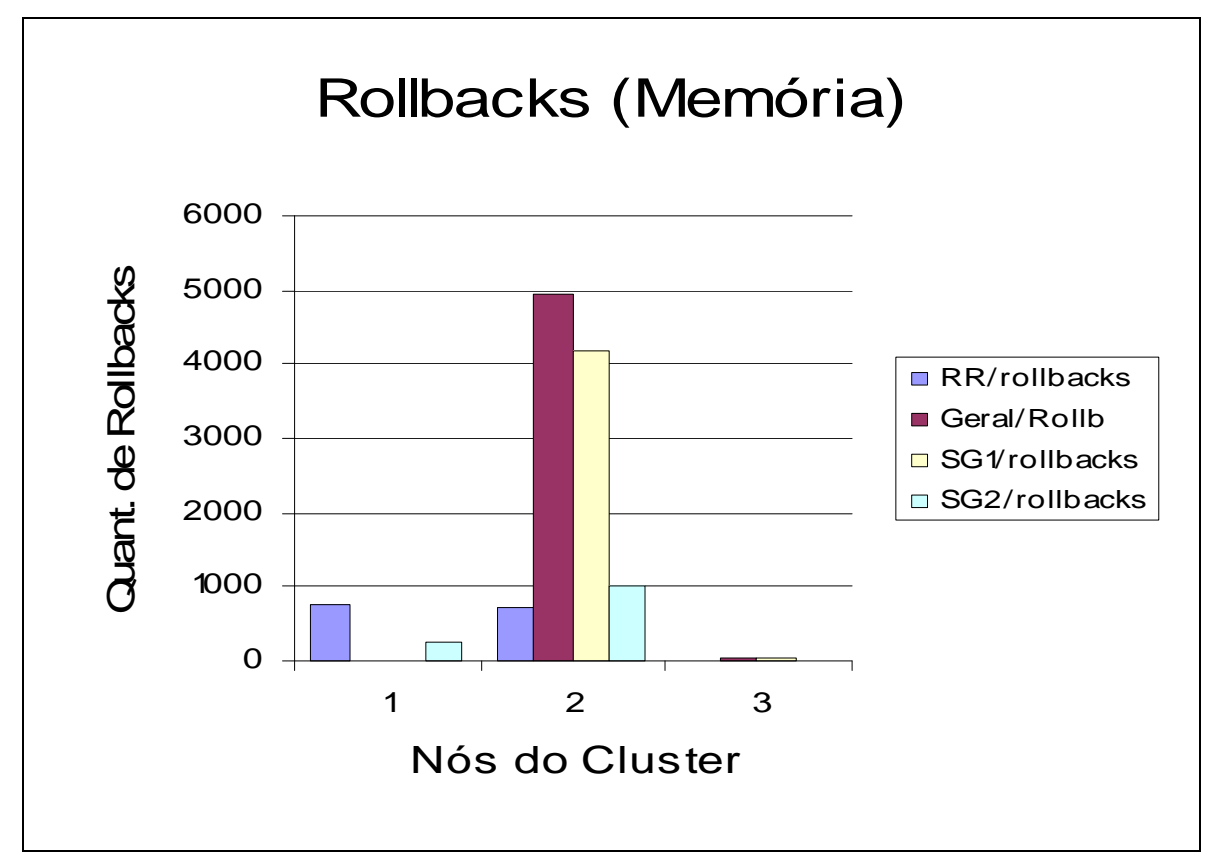

Figura 6.11 Quantidade de rollbacks ocorridos por nó no modelo Memory-Bound com notas de benchmark de CPU

Graças à redução de rollbacks apresentada, obteve-se uma redução de tempo na execução de todos os nós do cluster e conseqüentemente uma redução no tempo total da simulação. Esta redução de tempo é ilustrada no gráfico da figura 6.12. 


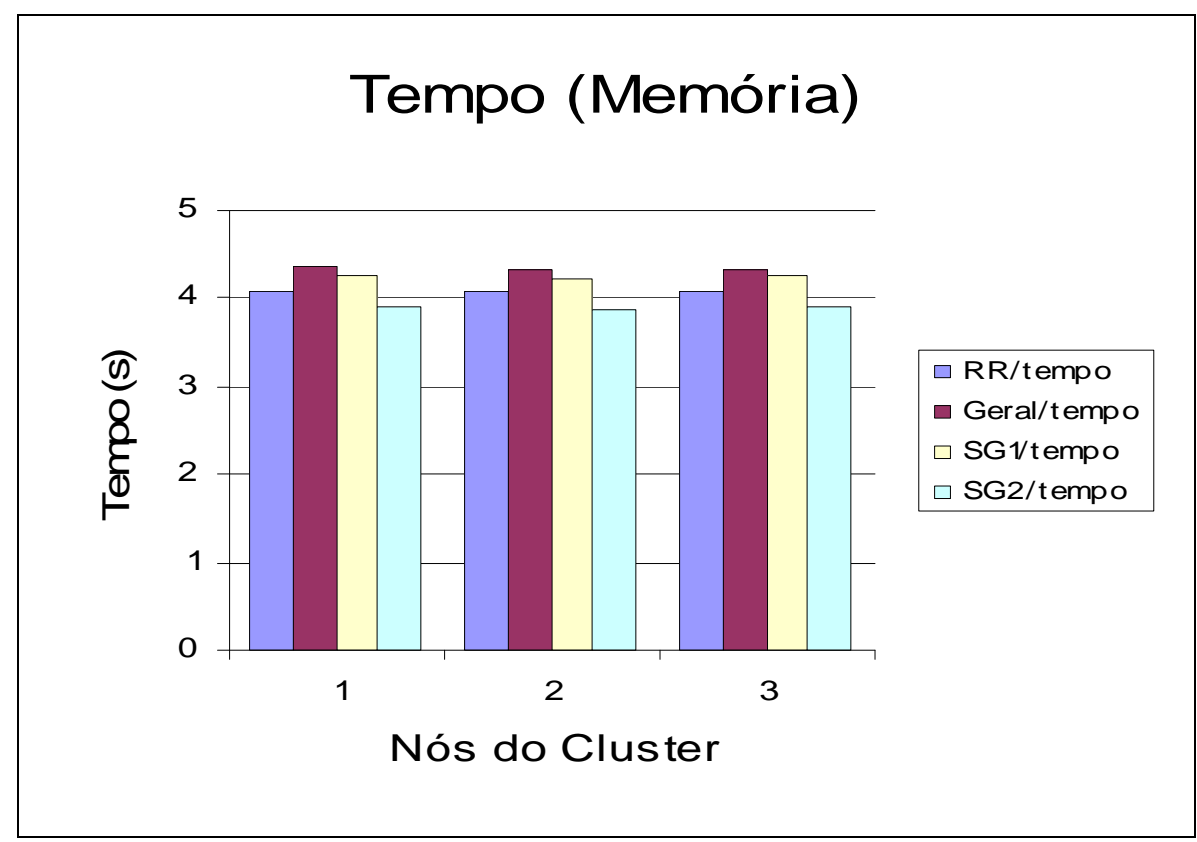

Figura 6.12 Tempos de execução em segundos por nó no modelo Memory-Bound com notas de benchmark de CPU

O último modelo do primeiro cruzamento de dados proposto e representados por um triângulo na tabela 6.2 é o modelo Network-Bound com notas de benchmark de memória.

Na figura 6.13 percebe-se que o modelo convencional (Geral), como é baseado nas notas de um benchmark não específico, piora muito em relação ao Round Robin.

O SG1 que se baseia nas notas da política Geral para o cálculo de sua métrica e assim fazer o balanceamento de carga, também apresenta uma alta quantidade de rollbacks e consegue reduzir apenas $1 \%$ da média apresentada pela política Geral.

Entretanto, quando aplicada a política SG2, esta consegue imprimir uma redução de $21 \%$ em relação à Política RR. Tornando-se a política, que neste modelo, obteve a menor média de ocorrência de rollbacks entre as políticas aqui apresentadas. 


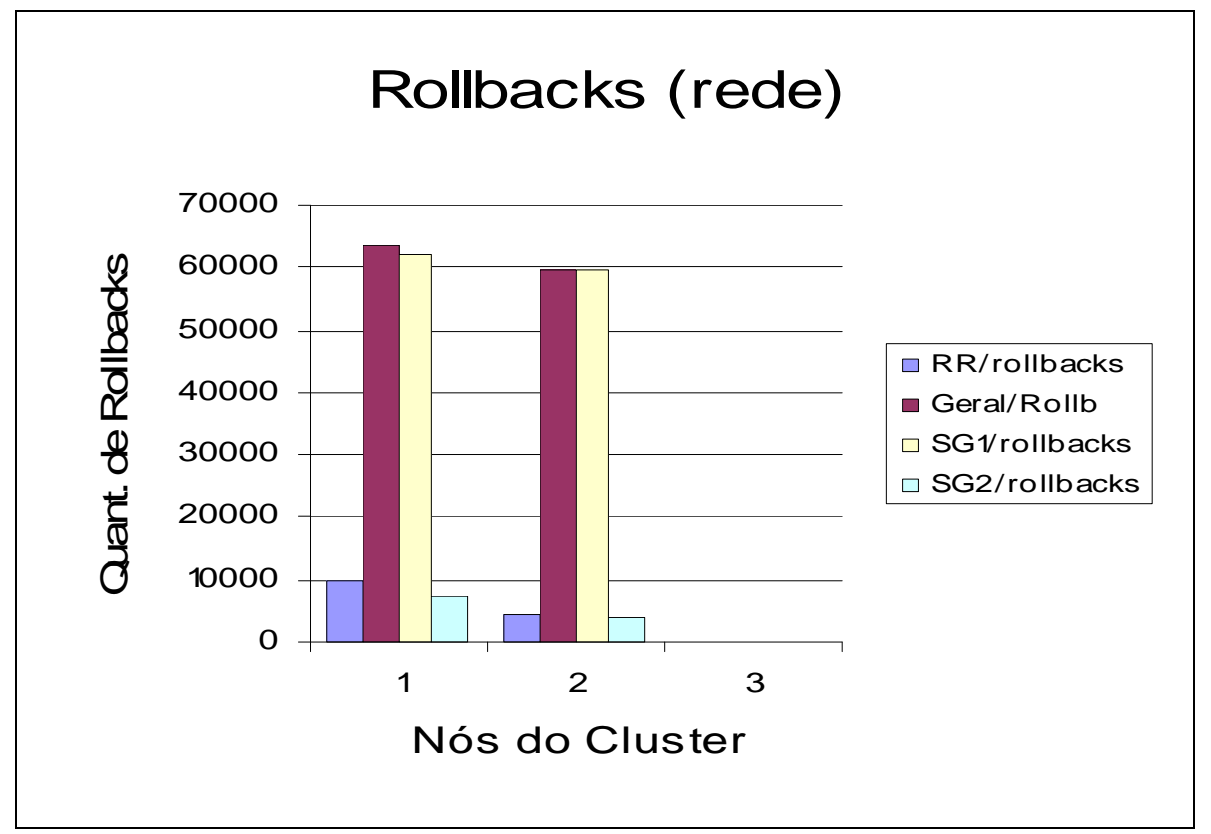

Figura 6.13 Quantidade de rollbacks ocorridos por nó no modelo Network-Bound com notas de benchmark de memória

O modelo SG2 se comporta melhor que o RR obtendo assim o melhor resultado do teste neste modelo. Mais uma vez confirmando a importância de reduzir a ocorrência de rollbacks em uma simulação que utiliza protocolos otimistas, como time warp, que é utilizado neste trabalho. Na figura 6.14 tem-se um resultado proporcional ao esperado se analisarmos a quantidade de rollbacks ocorridas neste modelo.

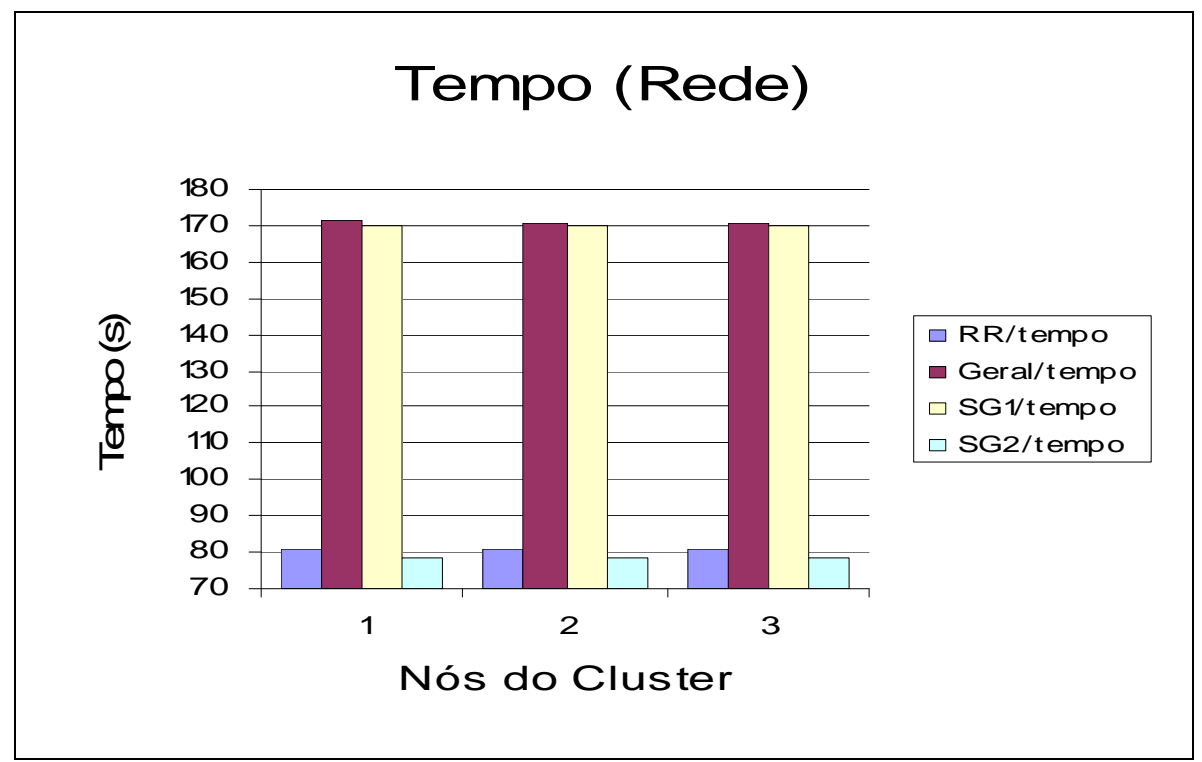

Figura 6.14 Tempos de execução em segundos por nó no modelo Network-Bound com notas de benchmark de memória 
A partir daqui são apresentados resultados referentes ao segundo cruzamento, que é representado por um circulo na tabela 6.2. Tem-se, em um primeiro momento, resultados com o modelo CPU-Bound com notas de benchmark de memória.

No gráfico exposto na figura 6.15, fica claro, que a troca das notas de CPU por memória foi catastrófica para o modelo convencional (Geral) visto os resultados percebidos.

A política SG1 onde sua métrica se baseia nas notas dadas pela política convencional (Geral) também teve um resultado cuja média de rollbacks foi maior que a política Round Robin.

A política SG2, como sua métrica se baseia nas cargas do Round Robin, conseguiu reduzir em $10 \%$ a média de rollbacks obtida pela política RR.

Neste modelo apresentado, a política SG2 se apresentou novamente, como a melhor opção para se obter um melhor balanceamento, pois foi a política com a menor média da quantidade de rollbacks ocorridos na simulação das outras três políticas avaliadas nesta dissertação.

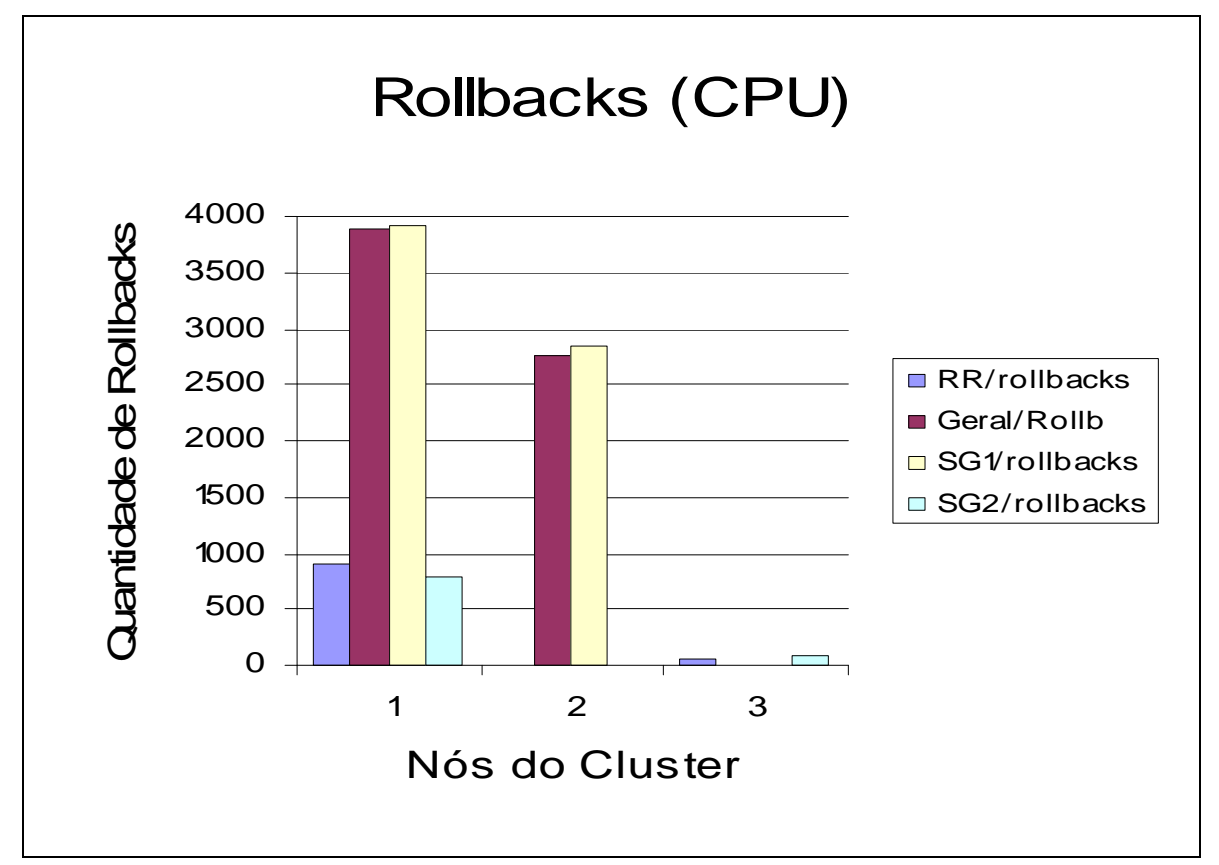

Figura 6.15 Quantidade de rollbacks ocorridos por nó no modelo CPU-Bound com notas de benchmark de memória 
A seguir, na figura 6.16, é demonstrada a redução de tempo da simulação quando utilizada a política SG2 em relação à política RR. Esta redução, como nos testes anteriores, foi graças à redução de ocorrência de rollbacks na simulação deste modelo utilizando a SG2.

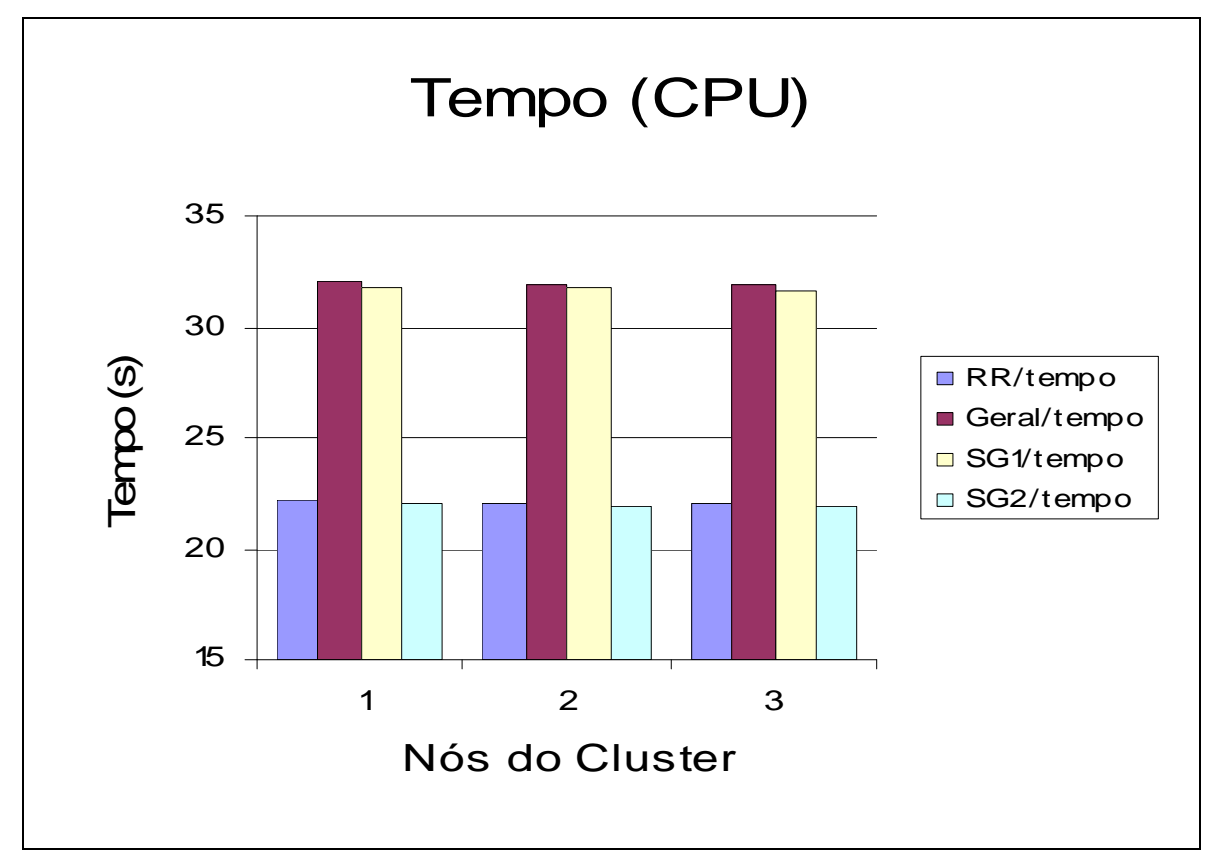

Figura 6.16 Tempos de execução em segundos por nó no modelo $C P U$-Bound com notas de benchmark de memória

O segundo modelo deste segundo cruzamento é com o modelo memory-bound utilizando as notas de benchmark de rede.

Neste modelo em particular foi obtido o melhor resultado da política convencional e das políticas SG1 e SG2 tratando-se de modelos de memória ou memory-bound (figura 6.17).

A política Geral pela primeira vez consegue um resultado melhor que a política Round Robin, isso se deve as notas de rede que foram usadas neste modelo. Como a rede utilizada é muito próxima da homogenia, ou seja, as notas dadas aos processadores possuem valores muito próximos, esta política teve um balanceamento cujos pesos foram semelhantes ao da política RR. Obtendo desta maneira notas mais balanceadas do que o RR, portanto, conseguiu reduzir a média de rollbacks em $45 \%$ em relação à média da política RR.

A política SG1 "pega carona" nas notas da Geral e obtém a menor ocorrência de rollbacks das demais políticas e consegue uma redução de $57 \%$ em relação à Geral. 
A política SG2, embora tivesse permitido uma ocorrência de rollbacks um pouco maior que a SG1, teve uma surpreendente eficiência reduzindo em $73 \%$ a média da quantidade de rollbacks ocorridos quando utilizada a política Round Robin.

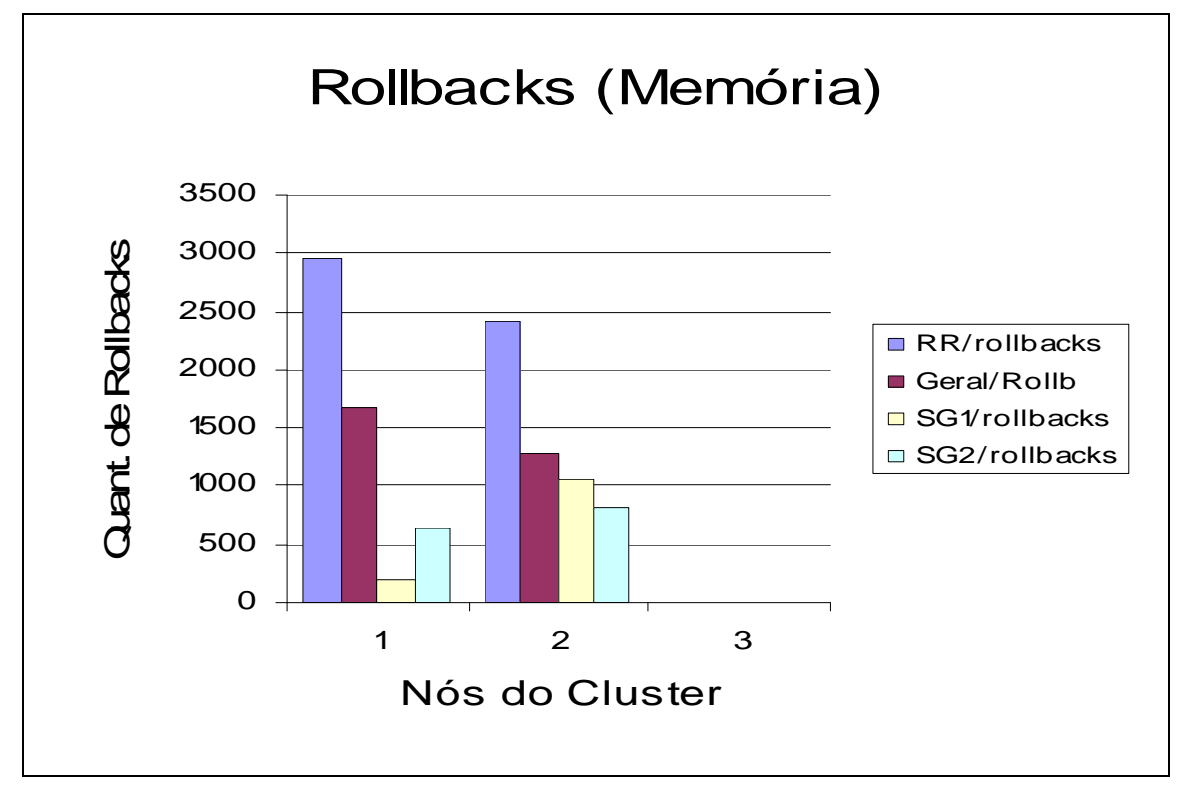

Figura 6.17 Quantidade de rollbacks ocorridos por nó no modelo memory-Bound com notas de benchmark de rede

Os tempos de execução nos três casos foram melhores que a política Round Robin, tendo-se como destaque a política SG2, que obteve a melhor média de tempo de simulação das 4 políticas avaliadas. Estes resultados são percebidos no gráfico da figura 6.18.

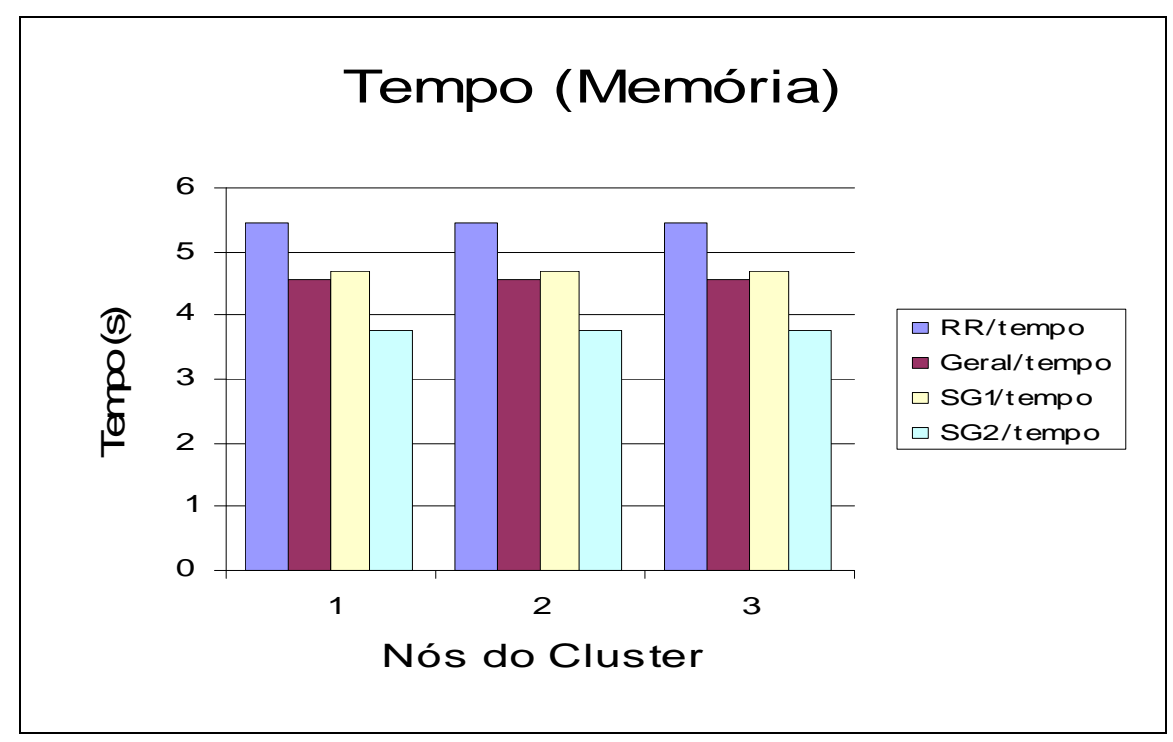

Figura 6.18 Tempos de execução em segundos por nó no modelo memory-Bound com notas de benchmark de rede 
O último modelo do segundo cruzamento, representado na tabela 6.2 por um círculo, é o modelo network-bound com notas de benchmark de CPU.

Neste modelo percebe-se uma variação grande na quantidade de rollbacks ocorridos entre os nós, conforme muda a política aplicada. Isso se deve a técnica de escalonamento que cada uma das políticas possui.

O comportamento das novas políticas SG1 e SG2 são eficientes e reduzem a quantidade de rollbacks ocorridos de acordo com as suas respectivas políticas base (figura 6.19).

A política SG1 reduziu em 21\% a média de rollbacks ocorridos na política Geral. Esta mesma redução de $21 \%$, a política SG2 atingiu em relação à média da quantidade de rollbacks ocorridos na política Round Robin. Demonstrando que ambas tiveram os melhores resultados apresentados no teste feito com este modelo (figura 6.19).

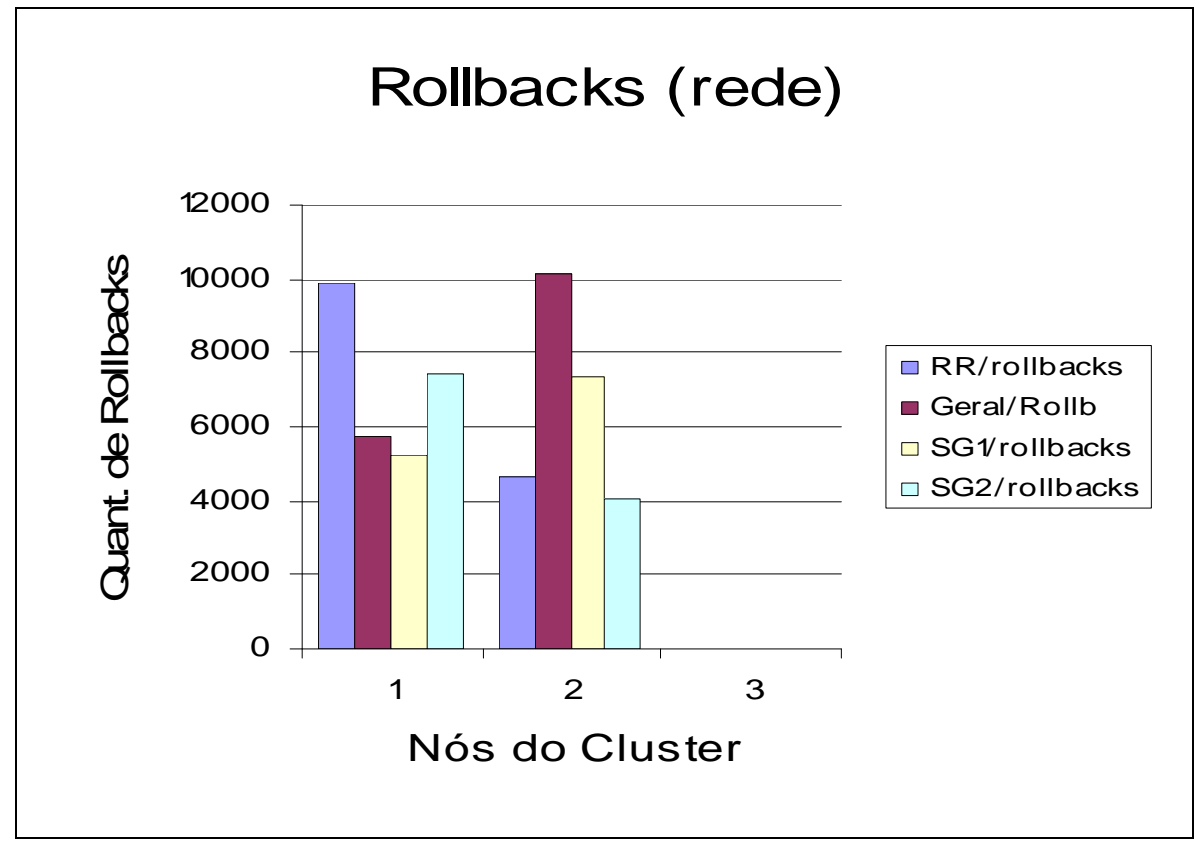

Figura 6.19 Quantidade de rollbacks ocorridos por nó no modelo Network-Bound com notas de benchmark de CPU

O tempo de simulação de todos os nós é reduzido com a utilização das políticas SG1 e SG2, comprovando assim que suas utilizações fazem um escalonamento mais eficiente dos processos causando uma redução na ocorrência de rollbacks e por conseqüência redução do tempo de simulação (figura 6.20). 


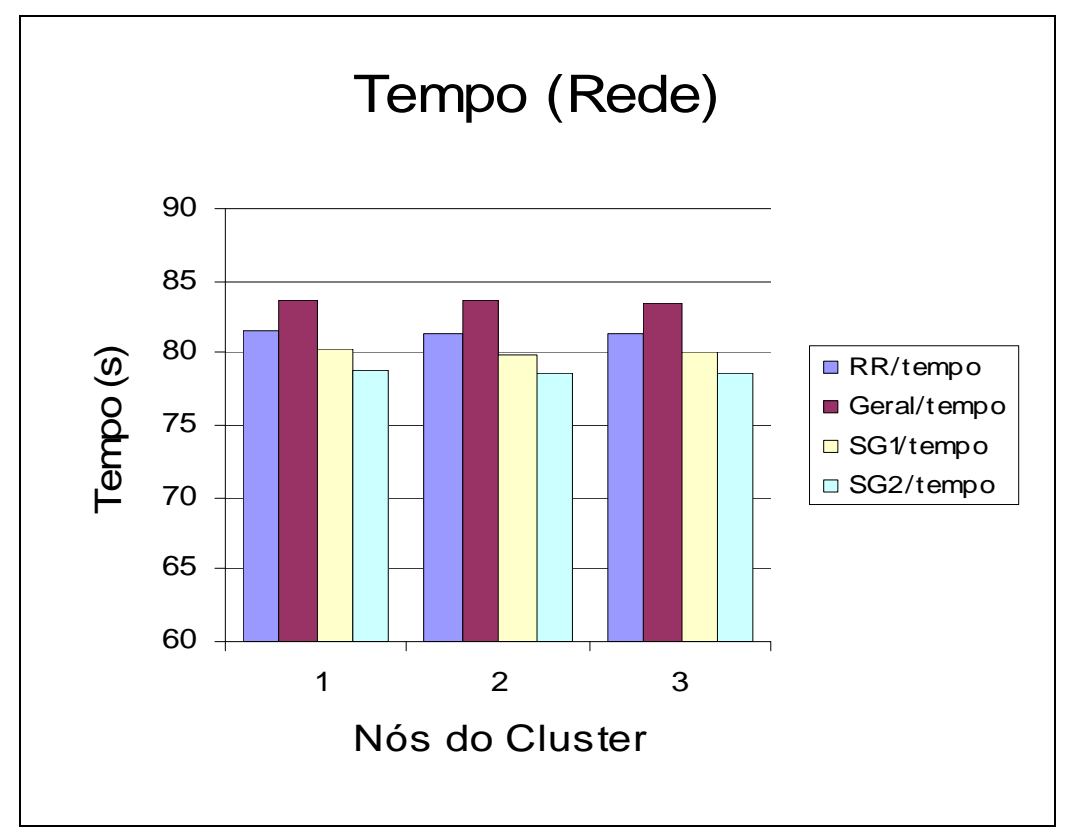

Figura 6.20 Tempos de execução em segundos por nó no modelo Network-Bound com notas de benchmark de CPU

Todos os resultados aqui apresentados mostraram-se favoráveis à utilização das políticas SG1 ou SG2 na execução de simulações distribuídas do que as políticas convencionais (Geral) e Round Robin. Reforçando a idéia de que com a redução do número de rollbacks ocorridos em uma simulação utilizando políticas de escalonamento otimistas o tempo de simulação é reduzido.

\subsection{Considerações Finais}

Todos os testes foram feitos em um ambiente dedicado com plataforma heterogênea possuindo assim características bem diversificadas. Os modelos foram definidos com 4 características cpu-bound, memory-bound, network-bound e o cruzamento de cpu-bound com network-bound.

Os parâmetros dos modelos foram definidos conforme suas características, o modelo CPU teve como característica um alto grau de processamento configurado para calcular uma multiplicação de matrizes em cada elemento de processamento a cada mensagem transmitida. O modelo rede teve um alto grau de mensagens para ser transmitido durante a simulação, já o modelo memória foi configurado com um numero maior de objetos ou elementos de processamento do que os demais modelos forçando uma alta utilização da memória. 
Os desempenhos dos modelos simulados com as quatro políticas testadas foram avaliados e assim pôde-se ter uma visão do real impacto da utilização destas políticas em uma simulação distribuída.

Inicia-se uma análise pelos modelos básicos, ou seja, modelos que utilizam notas dadas por benchmarks compatíveis com seu tipo de carga. Testes com o modelo CPU apresentam resultados positivos considerando o uso de políticas de propósito geral, percebe-se neste caso redução do numero médio de rollbacks e no tempo médio de simulação. O uso da política SG1 é a mais eficiente possuindo o menor tempo das 4 políticas avaliadas. Nota-se que nos modelos CPU a política RR é a pior escolha para quem deseja desempenho e a SG1 a melhor, entretanto sua implementação é mais trabalhosa do que a de propósito geral que também reduziu o tempo de simulação em relação ao RR, tornando uma boa opção para quem quer um equilíbrio entre desempenho e facilidade de implementação.

O modelo de memória apresenta resultados claros que mesmo a média de tempo da política SG2 ser um pouco menor que a RR, a sua complexidade de implementação torna seu uso não vantajoso. As políticas de propósito geral e SG1 não apresentam resultados satisfatórios. Para este modelo a política RR é a que proporciona o melhor custo benefício.

Os resultados referentes ao modelo de rede mostram que as políticas $\mathrm{RR}$ e de propósito geral apresentam tempos de simulação muito próximos apesar dos valores ligeiramente menores da política de propósito geral. As políticas SG1 e SG2 apresentam uma redução no tempo de execução em relação as duas outras avaliadas demonstrando que ambas podem ser utilizadas quando a prioridade for eficiência.

No modelo CPU x Rede tem-se resultados que demonstram tempos mais altos para as políticas RR e SG2. Já as políticas de propósito geral e SG1 obtiveram os menores tempos. A política SG1 mostra-se como a política que deve ser utilizada quando a necessidade de uma maior eficiência se faz necessária, entretanto a política de propósito geral é uma boa escolha quando não se tem a eficiência como objetivo principal.

Em seguida aos modelos básicos são apresentados resultados referentes aos modelos cruzados. O modelo CPU com benchmark de rede apresentou resultados que tornam a política RR a mais adequada quando a eficiência não for prioridade, as políticas específicas SG1 e 
SG2 obtiveram os menores tempos sucessivamente, entretanto sua complexidade na implementação em relação ao desempenho obtido deve ser considerado.

O modelo memória com benchmark de CPU apresenta resultados que colocam a política SG2 como a mais eficiente entre todas as políticas avaliadas, entretanto o custo benefício da política RR é mais atraente que as demais.

Os resultados do modelo rede com benchmark de memória apresenta as políticas RR e SG2 como as que usam menos tempo para execução da simulação, a SG2 obteve o menor tempo de todas as 4 políticas, entretanto a política RR é a que oferece o melhor custo benefício, pois sua implementação é fácil e seu tempo de execução é próximo do SG2.

O modelo CPU com benchmark de memória obteve resultados que apresentam as políticas RR e SG2 como as mais eficientes. A SG2 é a escolha para quem tem a prioridade de uma execução mais rápida e a RR deve ser escolhida para quem quer uma política com bom desempenho e de fácil implementação.

O modelo memória com benchmark de rede tem a política SG2 como a mais eficiente, obtendo o menor tempo de todas as demais. A política de propósito Geral com a SG1 executaram a simulação com tempos próximos, neste caso a política de propósito geral é mais vantajosa que a SG2 por ser mais fácil de implementar.

O último modelo apresentado é o de rede com benchmark de cpu. As políticas SG2 e SG1, nessa ordem, obtiveram os menores tempos de execução. Entretanto, o uso da Política RR deve ser considerado no caso da eficiência não ser o objetivo principal.

Obteve-se êxito na utilização das duas novas políticas apresentadas, pois na maioria das execuções de todos os modelos, os menores índices de ocorrência de rollbacks foram de uma dessas políticas, SG1 ou SG2. Foi confirmado neste trabalho que, como apresentado no capitulo 4 desta dissertação, a utilização das políticas convencionais de sistemas distribuídos (Geral), apresentadas no trabalho de Voorsluys (2006) e também utilizadas na avaliação exposta neste capítulo 6, tem influência na redução de rollbacks das simulações, chegando a $84 \%$ de redução em relação à política Round Robin, mostrando a viabilidade de sua utilização, principalmente quando não se possui o tempo hábil para implementação de uma política específica. 


\section{CONCLUSÃo}

\subsection{Considerações Iniciais}

Considerando que o escalonamento de processos é um fator essencial para um melhor desempenho de aplicações distribuídas, e sendo a simulação distribuída um tipo de aplicação distribuída, verifica-se a necessidade da utilização de técnicas apropriadas para o escalonamento dos programas de simulação.

Os algoritmos de escalonamento de processos de propósito geral, que tem a função de mapear processos nos processadores disponíveis, baseiam-se em informações sobre a plataforma e sobre as aplicações com o objetivo de maximizar a utilização dos recursos disponíveis.

A simulação distribuída também está sujeita às influências da plataforma e das características do modelo de simulação. Diversas técnicas podem ser encontradas na literatura da área (Carothers \& Fujimoto, 2000), que também baseiam suas decisões em informações relacionadas ao desempenho do sistema. Boukerche e Das (1997), apontam os algoritmos de uso geral inadequados para o uso na simulação distribuída, principalmente por causa dos tipos de informações nas quais as decisões são baseadas. Alguns estudos afirmam que os algoritmos convencionais não são capazes de detectar as diferenças entre as taxas de progresso dos processos lógicos da simulação. Para que isto seja possível são necessárias análises de métricas específicas.

No trabalho de Voorsluys (Voorsluys, 2006) é feita uma comparação entre a política Round Robin com a política convencional de sistemas distribuídos em geral, onde seu balanceamento de carga é feito de forma proporcional às de notas de benchmarks. Os resultados obtidos mostram que as técnicas utilizando benchmarks para escalonamento de processos de simulações distribuídas podem ser uma boa escolha, principalmente se não existe tempo hábil para implementar uma política específica ou caso não se possua conhecimento para sua implementação. 
A implementação de políticas específicas para simulação distribuída, quando focada na quantidade de rollbacks ocorridos, como nas duas novas políticas apresentadas no capitulo 5 desta dissertação, mostra-se como a melhor opção para obter um menor número de rollbacks e por conseqüência um menor tempo de simulação. A política Geral, que possui as notas de benchmark como base para escalonamento dos processos, conseguiu obter bons resultados nos testes apresentados no capitulo 6, chegando a reduzir a quantidade de rollbacks em até $84 \%$, em relação à política Round Robin. Entretanto em modelos com características memory-bound não consegue bons resultados, piorando consideravelmente o desempenho da simulação.

As políticas específicas para simulação distribuída apresentadas neste trabalho, obtiveram êxito na maioria dos casos testados, observando-se que ou a política SG1 ou a SG2 apresentam bons resultados, obtendo, na maioria das vezes, os menores índices de ocorrência de rollbacks nos modelos apresentados e por consequiência tempos reduzidos de simulação.

Portanto quando o objetivo for obter o melhor desempenho possível na simulação, a utilização de políticas específicas para simulação distribuída é a mais indicada. Entretanto, se existe a necessidade de um bom desempenho em modelos com características de rede ou CPU e não se possui o tempo necessário para implementar uma política específica, a política com propósito geral utilizando notas de benchmark, mostra-se uma boa solução. Já a política RR é recomendada nos casos em que as políticas específicas não estão disponíveis. A política RR mostra-se eficiente nos modelos de memória, sendo a melhor opção, para esse modelo, por obter tempos de simulação próximos à política específica e ser mais fácil sua implementação.

\subsection{Contribuições deste Trabalho}

As principais contribuições deste trabalho são:

Apresentar uma nova classificação para políticas específicas. No capítulo 3 é apresentada uma nova classificação de políticas específicas para simulação distribuída que utilizam protocolos otimistas. O objetivo desta classificação é organizar os tipos de políticas existentes de modo a facilitar o acesso a essas políticas. A utilização dessa classificação tornará mais eficiente as buscas das políticas e levará a uma melhor compreensão de suas característica, possibilitando escolher a política ideal para cada simulação. 
Proposta de duas novas políticas. No capítulo 5 são apresentadas duas novas políticas específicas para escalonamento de simulação distribuída. Estas políticas apresentam uma nova métrica e uma nova técnica de utilização dos dados da simulação. O objetivo principal é a análise da ocorrência de rollbacks na simulação e através destes dados obter um melhor escalonamento dos elementos de processamento conseguindo assim um melhor balanceamento da carga e consequentemente uma redução da ocorrência de rollbacks. As políticas apresentadas se mostraram mais eficientes do que as políticas convencionais para sistemas distribuídos em geral e do que a Política Round Robin mostrando-se uma boa opção para quando se têm o bom desempenho no escalonamento e o ganho de tempo nas simulações como fatores fundamentais.

Implementação das políticas específicas. As políticas apresentadas neste trabalho foram interligadas com a ferramenta Warped. Todos os processos de captação das informações geradas pelo Warped, tratamento dos dados, cálculo da métrica, o escalonamento dos processos, calculo das médias e desvios padrões estão totalmente automatizados facilitando assim sua utilização em trabalhos futuros.

\section{Avaliação de desempenho de políticas de escalonamento para simulações}

distribuídas. Na literatura são encontradas avaliações que comparam políticas específicas para simulação distribuída com a política Round Robin, ou como apresentado no capitulo 4 deste trabalho, avaliações entre políticas tradicionais para sistemas distribuídos em geral com a política Round Robin (Voorsluys, 2006). No capitulo 6 é apresentada uma avaliação de desempenho entre as duas políticas novas apresentadas neste trabalho que possuem características específicas para escalonamento de simulações distribuídas com políticas que utilizam as técnicas de escalonamento observando notas de benchmark (Geral) e ainda comparando com a política Round Robin (RR). No Cap. 6, é demonstrado que na maioria dos casos o uso de políticas específicas deve ser usado quando o objetivo principal é obter o melhor desempenho, entretanto nos modelos de memória a política RR foi eficiente e como é de fácil implementação seu uso deve ser considerado para estes modelos. A política de propósito geral mostra-se na maioria dos casos uma boa escolha quando se prioriza um bom desempenho e não se tem a possibilidade da implementação de uma política que utiliza dados específicos da simulação. Fecha-se assim uma lacuna na avaliação de políticas para simulação distribuída, pois apresenta uma comparação e uma análise completa dos dados destas três técnicas de escalonamento. 


\subsection{Propostas para Trabalhos Futuros}

Este projeto deverá ter continuidade, e algumas propostas para trabalhos futuros devem ser citadas:

- Testar as novas políticas aqui apresentadas em novos modelos de simulação além do PHOLD e em novas ferramentas de simulação diferentes do Warped;

- Testar os modelos e as políticas apresentadas em uma arquitetura homogênea;

- Automatizar sem escrita em arquivos, de forma dinâmica na memória, o cálculo da métrica de ajuste das novas políticas;

- Criar e testar um índice único com as três notas dos benchmarks com pesos diferentes para cada nó do cluster.

\subsection{Considerações Finais}

Neste trabalho é apresentada uma nova classificação de políticas de escalonamento específicas para simulação distribuída com características otimistas. As três classes propostas são: políticas em tempo de execução, políticas em tempo de mapeamento e políticas mistas.

Esta pesquisa cobre uma lacuna existente na literatura que é fazer uma comparação entre políticas tradicionais em sistemas distribuídos e Round Robin com políticas que utilizam dados específicos da simulação distribuída em execução. Através de resultados satisfatórios, pode-se considerar que as novas políticas desenvolvidas e apresentadas neste trabalho fazem um escalonamento mais justo proporcionando assim um balanceamento melhor do que as demais testadas. Pode-se chegar a essa conclusão através da análise dos resultados que mostram os rollbacks ocorridos nas simulações e pelos resultados obtidos em termos de tempo de simulação.

Com o novo balanceamento proposto, ao analisar-se os resultados da política SG1 e da SG2, obteve-se melhor resultado na maioria dos casos, pois em todos os modelos uma das duas políticas obtiveram os melhores resultados. Em apenas um caso o modelo SG1 teve pior resultado que a política geral, mas no mesmo caso a política SG2 se coloca como a melhor entre as 4 políticas avaliadas. Percebe-se assim uma eficiência nas duas políticas propostas. 


\section{Referências Bibliográficas}

(Akyildiz et al., 1992)

(Almasi, 1994)

(Araújo et al., 1999)

(Banks, 1998)

(Boukerche \& Das, 1997)

(Boukerche, 2002)

(Bryant, 1977)

(Burdorf \& Marti, 1993)

(Carothers \& Fujimoto, 2000)

(Chandy \& Misra, 1979)

(Chandy \& Misra, 1981)
AKYILDIZ, L. F.; CHEN, L.; DAS, S. R.; FUJIMOTO, R. M.; SERFOZO, R. F., Performance analysis of Time Warp with Limited Memory. In: Proceedings of the 1992 ACM Sigmetrics Conference on Measurement and Modeling Computer Systems, p. 213-224, 1992.

ALMASI, G.S. and GOTTLIEB, A.. Highly Parallel Computing, $2^{\text {a }}$ ed., The Benjamin/Cummings Publishing Company, 1994.

ARAÚJO, A.P.F., SANTANA, M.J., SANTANA, R.H.C., SOUZA, P.S.L., DPWP - A New Load Balancing Algorithm. $5^{\text {th }}$ International Conference on Information Systems Analysis and Synthesis - ISAS'99, agosto, 1999.

BANKS, J., Handbook of Simulation: Principles, Methodology, Advances, Applications, and Practice. New York: John Wiley \& Sons, Inc., 1998.

BOUKERCHE, A.; DAS, S. K. Dynamic Load Balancing Strategies for Conservative Parallel Simulations. In: Proceedings of the 11th workshop on Parallel and distributed simulation. p.20-28, 1997

BOUKERCHE, A. An Adaptive Partitioning Algorithm for Distributed Discrete Event Simulation Systems. Journal of Parallel and Distributed Computing, $\mathrm{n}^{\circ}$ 62, 1454-1475

BRYANT, R. E., Simulation of Packet Communications Architecture Computer Systems. Massachusetts Institute of Technology, 1977. (Relatório Técnico 188 - MIT-LCS).

BURDORF, C.; MARTI J. Load Balancing Strategies for Time Warp on Multiuser Workstations. The Computer Journal, v. 36, n ${ }^{\circ}$ 2, p. 168-176, 1993.

CAROTHERS, C. D.; FUJIMOTO, R. M. Efficient Execution of Time Warp Programs on Heterogeneous, NOW Platforms. IEEE Transactions on Parallel and Distributed Systems, v. 11, n 3, março, 2000.

CHANDY, K. M., MISRA, J., Distributed Simulation: A Case Study in Design and Verification of Distributed Programs. IEEE Transactions on Software Engineering. SE-5, n.5, p. 440-452, 1979.

CHANDY, K. M., MISRA, J. Asynchronous Distributed 
(Chang, 2003)

(Das \& Fujimoto, 1993)

(Deelman \& Szymanski, 1998)

(Fujimoto, 1990)

(Fujimoto, 1990b)

(Fujimoto, 2006)

(Hagenauer, 1999)

(Jefferson, 1985)

(Jones \& Das, 2000)

(Kawabata, 2002)

(Law, 1991)

(Lobato et al., 2004)
Simulation via a sequence of parallel computations. Communications of ACM, v.24, n.4, p. 11-14; 198-205, mar. 1981.

CHANG, H. S, Mathematical Methods of Operations Research. Springer-Verlag, Dezembro, 2003.

DAS, R. S.; FUJIMOTO, R. M., A performance Study of the Cancellback Protocol for Time Warp. In: Proceedings of the $7^{\text {th }}$ Workshop on Parallel and Distributed Simulation, p. 135-142, 1993.

DEELMAN, E.; SZYMANSKI, B. K. Dynamic Load Balancing in Parallel Discrete Event Simulation for Spatially Explicit Problems. In: Proceedings of the $12^{\text {th }}$ Workshop on PADS, Banff, Alberta, Canada, p. 46-53, May 1998.

FUJIMOTO, R. M., Parallel Discrete Event Simulation. Communications of the ACM, v. 33, $\mathrm{n}^{\circ} 10$, p. 31-53, 1990.

FUJIMOTO, R. M., Performance of Time Warp under Synthetic Workloads. Proceedings of the SCS Multiconference on Distributed Simulation, p.23-28,1990.

FUJIMOTO, R. M., Parallel and Distributed Simulation Systems. Proceedings of the $33^{\text {rd }}$ Winter Simulation Conference, Arlington, Virginia, p147-157, 2001.

HAGENAUER, H., Global Virtual Time Approximation for Split Queue Time Warp. 4th International ACPC Conference. In: Lecture Notes on Computer Science, $\mathrm{n}^{\circ}$ 1557, p. 540-548, 1999.

JEFFERSON, D.R., Virtual Time. IEEE Transactions on Programming Languages and Systems, p. 404-425, 1985.

JONES, K. G.; DAS, S., Parallel Execution of a Sequential Network Simulator. In: Proceeding of the 2000 Winter Simulation Conference (WSC'2000), p. 418-424, 2000.

KAWABATA, C. L. O., Projeto e implementação do mecanismo de troca de protocolos de sincronização em tempo de execução, Minidissertação de mestrado (Ciências da Computação e Matemática Computacional), ICMC/USP, maio/2002.

LAW, A. Simulation Modeling \& Analysis. New York: McGraw Hill, 1991.

LOBATO, R. S., SANTANA, M. J., SANTANA, R. H. C., ULSON, R. S., Uma hierarquia para classificação de protocolos otimistas de sincronização em simulação distribuída. CLEI - Conferência Latino Americana em Informática: Arequipa : 2004. 
(MacDougall, 1987)

(Madiseti et al., 1992)

(Martim et al., 2003)

(Misra, 1986)

(Morselli, 1995)

(Morselli, 2000)

(Netto et al, 2005)

(Prakash \& Subramarian, 1991)

(Reiher \& Jefferson, 1990)

(Sachdev et. al., 2004)

(Soares, 1992)

(Som \& Sargent, 1993)
MACDOUGALL, M. H., Simulating Computing Systems Techniques and Tools. The MIT Press, 1987.

MADISETI, V. K.; HARDAKER, D. A.; FUJIMOTO, R. M.; et al., The MIMDIX Operating Systems for Parallel Simulation. In: Proceedings of the SCS Multiconference on Parallel and Distributed Simulation, v. 24, n. 3, p. 65-74. The Society for Computer Simulation International, 1992.

MARTIN, D. E.; WILSEY, P. A.;HOEKSTRA, R. J.; KEITER, E. R.; HUTCHINSON, T. V. R.; WATERS, L. J. Redesigning the Warped Simulation Kernel for Analysis and Aplication Development. Proceedings of the $36^{\text {th }}$ Annual Simulation Symposium (ANSS'03), 2003.

MISRA, J. Distributed Discrete-event Simulation. ACM Computing Surveys, v.18, n.1, p. 39-65, 1986.

MORSELLI Jr., J. C. M., Simulação Distribuída em uma rede de Transputers utilizando o método CMB. Dissertação (mestrado), Instituto de Ciências Matemáticas e de Computação, Universidade de São Paulo (ICMC/USP), 1995.

MORSELLI Jr., C. M, Um Mecanismo para Troca de Protocolos de Sincronização de Simulação Distribuída em Tempo de Execução, Tese (Doutorado), IFSC - USP, 2000.

NETTO, M.A.S., BREDA, A., SOUZA, O.N. Scheduling Complex Computer Simulations on Heterogeneous Nondedicated Machines: A case Study in Structural Bioinformatics, IEEE International Symposium on Cluster Computing and the Grid, 2005.

PRAKASH, A.; SUBRAMARIAN, R., Optimistic Distributed Simulation. In: Proceedings of the $24^{\text {th }}$ annual Simulation Symposium, p. 123-132, 1991.

REIHER, P.L.; JEFFERSON, D. Dynamic Load Management in the Time Warp Operating System. Trans. Society for Computer Simulation, vol. 7, n ${ }^{\circ}$ 2, p. 91-120, June 1990.

SACHDEV, V.; HYBINETTE, M.; KRAEMER, E. Controlling Over-Optimist in Time-Warp Via CPU-Based Flow Control. In: Proceedings of the 2004 Winter Simulation Conference. p. 402, 2004.

SOARES, L. F. G., Modelagem e Simulação Discreta de Sistemas. Editora Campus Ltda, 1992.

SOM, T. K.; SARGENT, R. G. A New Process to Processor Assignment Criterion for Reducing Rollbacks in Optimistic Simulation. Journal of Parallel and Distributed Computing, $\mathrm{n}^{\circ} 18$, p. 509-515, 1993. 
(Som \& Sargent, 1998)

(Som \& Sargent, 2000)

(Song et al., 2002)

(Tanenbaum \& Steen, 2002)

(Voorsluys, 2006)
SOM, T. K.; SARGENT, R. G. A Probabilistic Event Scheduling Policy for Optimistic Parallel Discrete Event Simulation. In: Proceeding of the $12^{\text {th }}$ Workshop on Parallel and Distributed Simulation, p. 56-63, May 26-29, 1998.

SOM, T. K.; SARGENT, R. G. Model Structure and Load Balancing in Optimistic Parallel Discrete Event Simulation. In: Proceeding of the $14^{\text {th }}$ Workshop on Parallel and Distributed Simulation, p. 147-154, May 28-31, 2000.

SONG, H.Y.; KIM, J; CHONG, K. R. Na Analytical Model of Scheduling for Conservative Parallel Simulation. In: Euro PVM/MPI 2002, LNCS 2474, p. 191-198 - Springer-Verlag Berlin Heiderberg 2002.

TANENBAUM, A. S.; STEEN, M. van. Distributed Systems: Principles and paradigms. Upper Saddle River, NJ: Prentice Hall, 2002. 803 p.

Voorsluys, B. L., Utilização de Políticas de Escalonamento para a Execução de Simulação Distribuída, Dissertação (Mestrado), ICMC - USP, 2006. 